\title{
Primer on the Cost of Marine Fuels Compliant with IMO 2020 Rule
}

Rocío Uría-Martínez ${ }^{1}$

Paul N. Leiby ${ }^{1}$

James Corbett ${ }^{2}$

Zhaojun Wang ${ }^{2}$

${ }^{1}$ Oak Ridge National Laboratory

${ }^{2}$ University of Delaware

August 2021 


\section{DOCUMENT AVAILABILITY}

Reports produced after January 1, 1996, are generally available free via US Department of Energy (DOE) SciTech Connect.

Website www.osti.gov

Reports produced before January 1, 1996, may be purchased by members of the public from the following source:

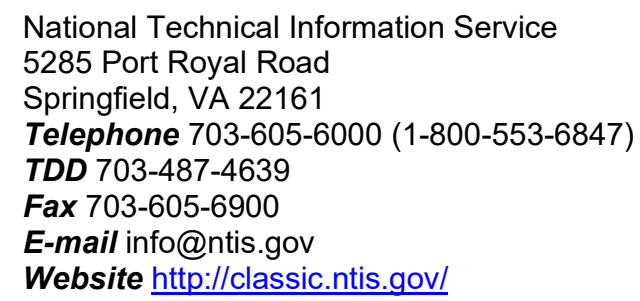

Reports are available to DOE employees, DOE contractors, Energy Technology Data Exchange representatives, and International Nuclear Information System representatives from the following source:

Office of Scientific and Technical Information

PO Box 62

Oak Ridge, TN 37831

Telephone 865-576-8401

Fax 865-576-5728

E-mail reports@osti.gov

Website https://www.osti.gov/

This report was prepared as an account of work sponsored by an agency of the United States Government. Neither the United States Government nor any agency thereof, nor any of their employees, makes any warranty, express or implied, or assumes any legal liability or responsibility for the accuracy, completeness, or usefulness of any information, apparatus, product, or process disclosed, or represents that its use would not infringe privately owned rights. Reference herein to any specific commercial product, process, or service by trade name, trademark, manufacturer, or otherwise, does not necessarily constitute or imply its endorsement, recommendation, or favoring by the United States Government or any agency thereof. The views and opinions of authors expressed herein do not necessarily state or reflect those of the United States Government or any agency thereof. 
Environmental Sciences Division

PRIMER ON THE COST OF MARINE FUEL COMPLIANT WITH IMO 2020 RULE

\author{
Rocío Uría-Martínez ${ }^{1}$ \\ Paul N. Leiby ${ }^{1}$ \\ James Corbett ${ }^{2}$ \\ Zhaojun Wang ${ }^{2}$ \\ ${ }^{1}$ Oak Ridge National Laboratory \\ ${ }^{2}$ University of Delaware
}

August 2021

Prepared by

OAK RIDGE NATIONAL LABORATORY

Oak Ridge, TN 37831-6283

managed by

UT-BATTELLE LLC

for the

US DEPARTMENT OF ENERGY

under contract DE-AC05-00OR22725 



\section{CONTENTS}

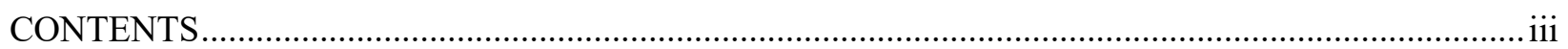

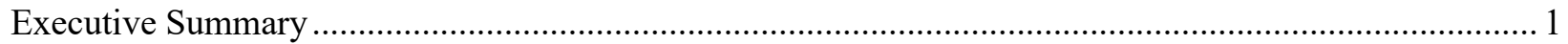

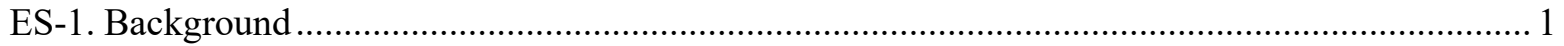

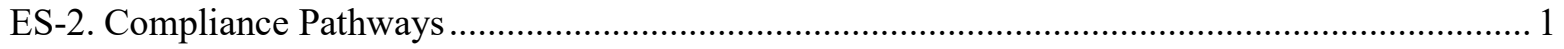

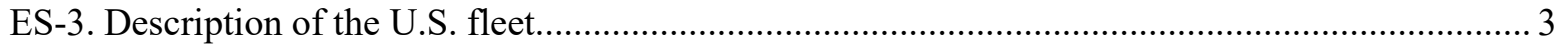

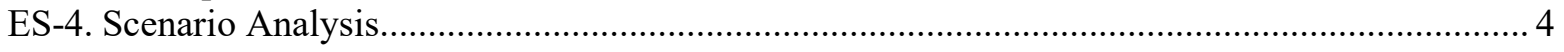

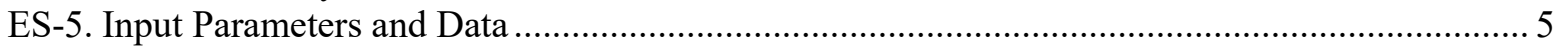

1.1.1 Vessel, Fuel, Engine and Cost Parameters............................................................. 5

1.1.2 Average Projected Prices for Marine Fuels ................................................................ 5

ES-6. Calculation of Fuel and Ship Capital Costs for IMO 2020 Compliance................................... 6

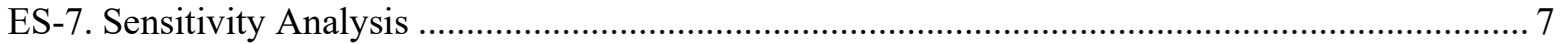

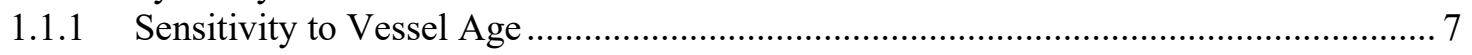

1.1.2 Sensitivity to Fuel Price ................................................................................... 9

1.1.3 Compliance Approach Costs vs Strategy for Sensitivity Case Set Results................. 10

1.1.4 Implications of a Carbon-Constrained World ...................................................... 11

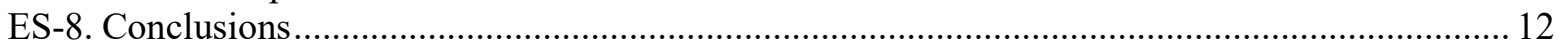

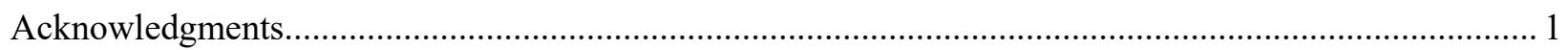

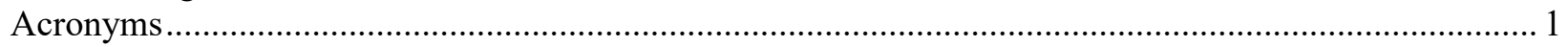

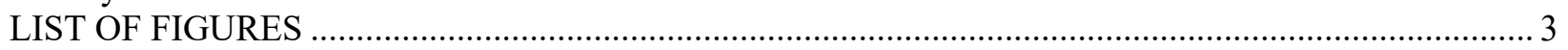

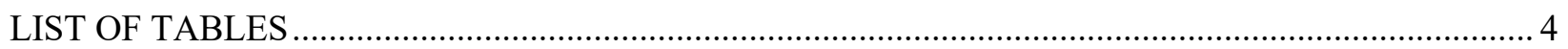

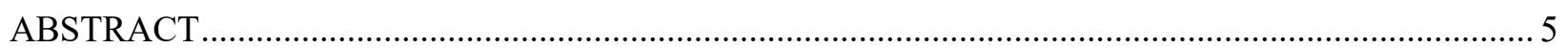

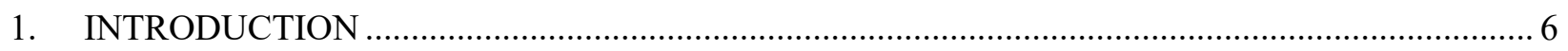

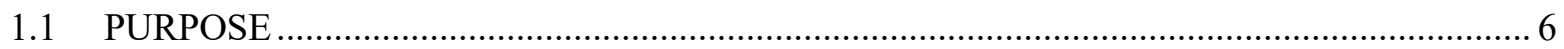

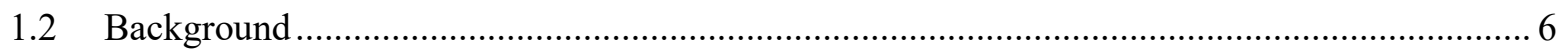

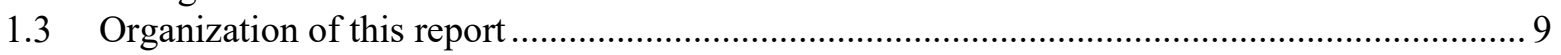

2. Marine Fuels Compliant with IMO 2020 Rule ...................................................................... 9

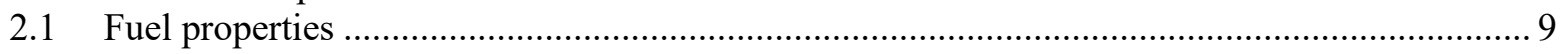

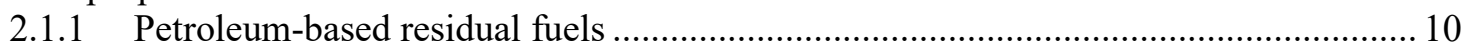

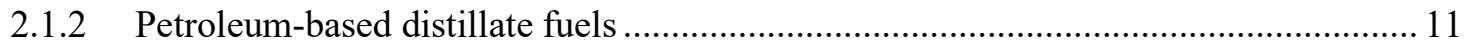

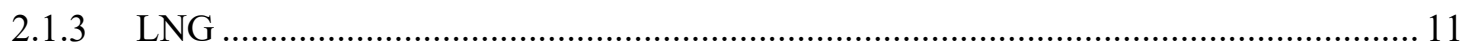

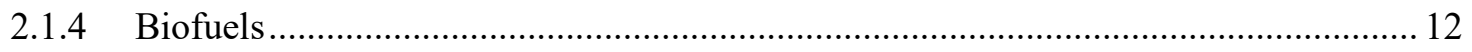

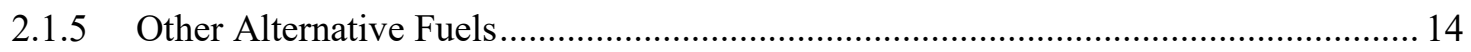

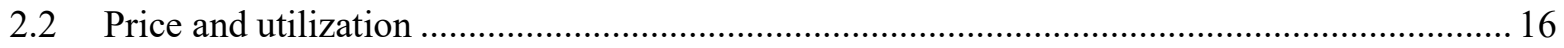

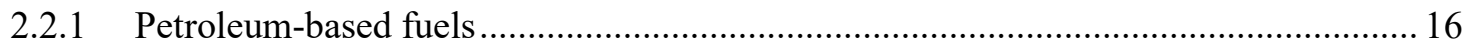

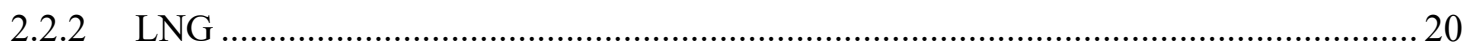

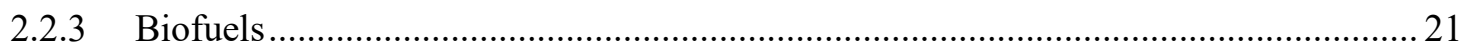

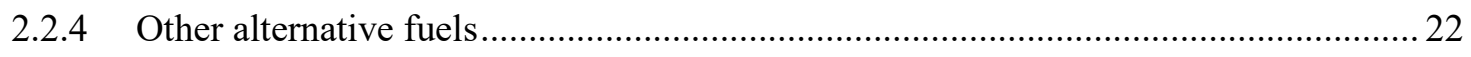

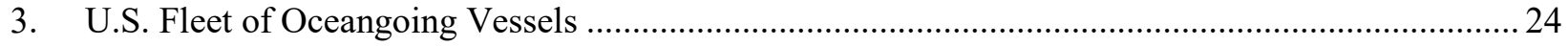

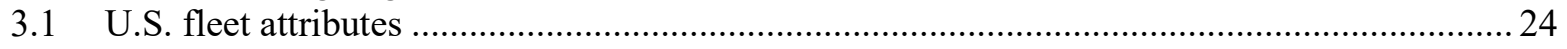

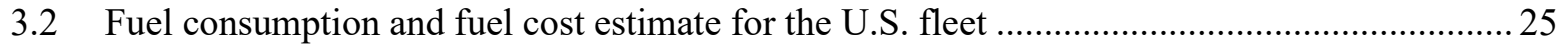

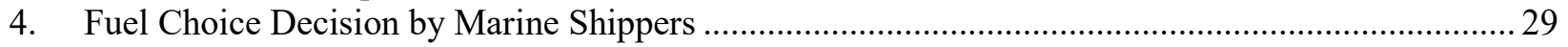

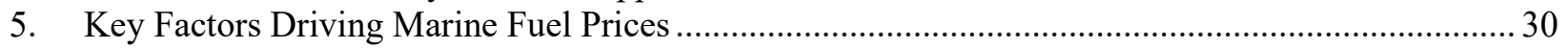

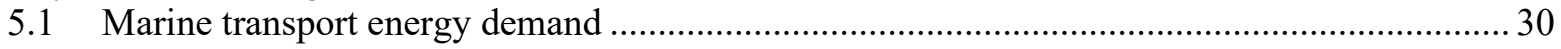

5.1.1 Trends in GDP and population (driving the demand for seaborne trade) ................... 30

5.1.2 Expanding trade agreements and free-trade zone agreements .................................. 31

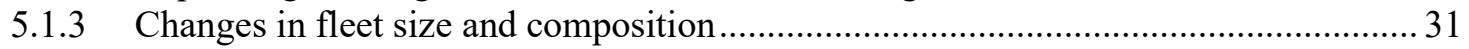


5.1.4 Mandated and market-driven increases in energy efficiency, or reductions in

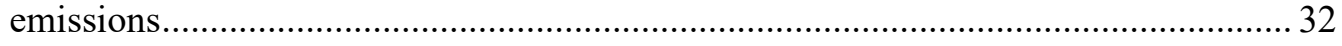

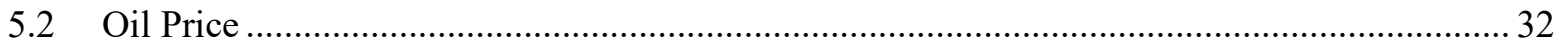

5.3 Refinery economics and the demand for other petroleum products...................................... 34

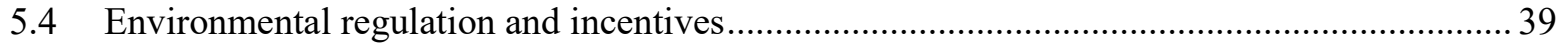

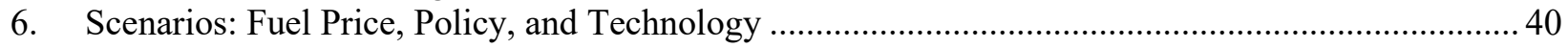

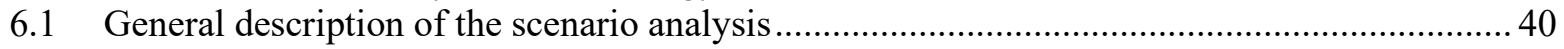

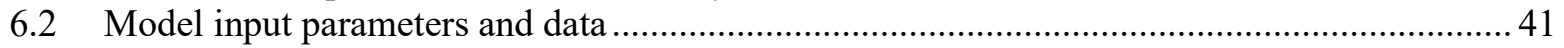

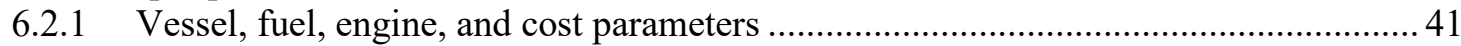

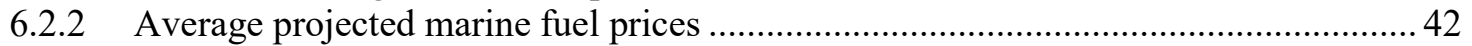

6.3 Estimated costs for base cases of each compliance approach.............................................. 43

6.4 Estimated costs and $\mathrm{CO}_{2}$ emissions for sensitivity cases ..................................................... 44

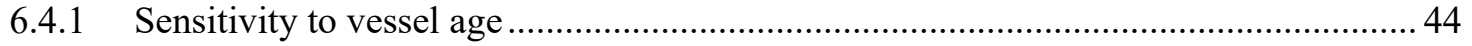

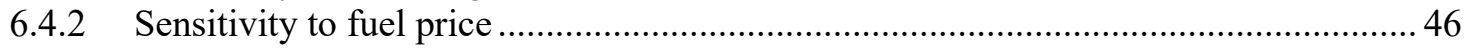

6.4.3 Compliance approach costs vs strategy for sensitivity case set results ..................... 47

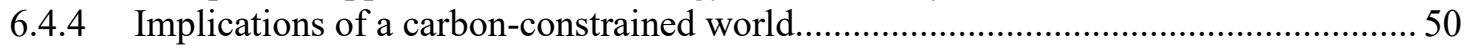

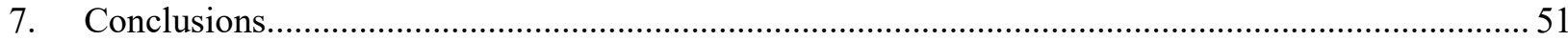

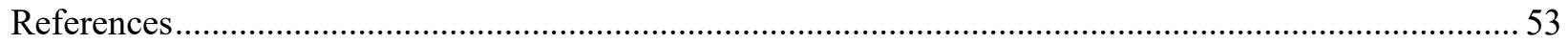

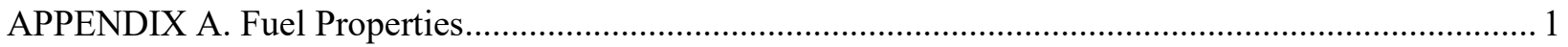

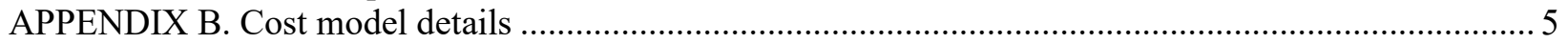




\section{EXECUTIVE SUMMARY}

\section{Primer on the cost of marine fuels compliant with the IMO 2020 rule}

\section{ES-1. BACKGROUND}

- Compliance with the IMO 2020 sulfur cap requiring ocean-going vessels to transition to fuels with a maximum sulfur content of $0.5 \%$ starting on January 1, 2020 has been near universal and marine fuel expenditures increased by less than had been projected. However, it is difficult to separate the effect of IMO 2020 from the effect of COVID19 in marine fuel prices during this period.

- $\quad$ Figure ES- 1 shows the price differential between VLSFO with $0.5 \%$ sulfur and HSFO with 3.5\% sulfur from January 2019 to December 2020. The differential peaked in the first days of 2020 at $240-320 \$ /$ ton and dropped precipitously (along with price levels) in the spring of 2020 stabilizing at $50-60 \$ /$ ton in the second half of the year. In percentage terms, the premium of VLSFO over HSFO stayed in the $25 \%-30 \%$ range in $2019-2020$.

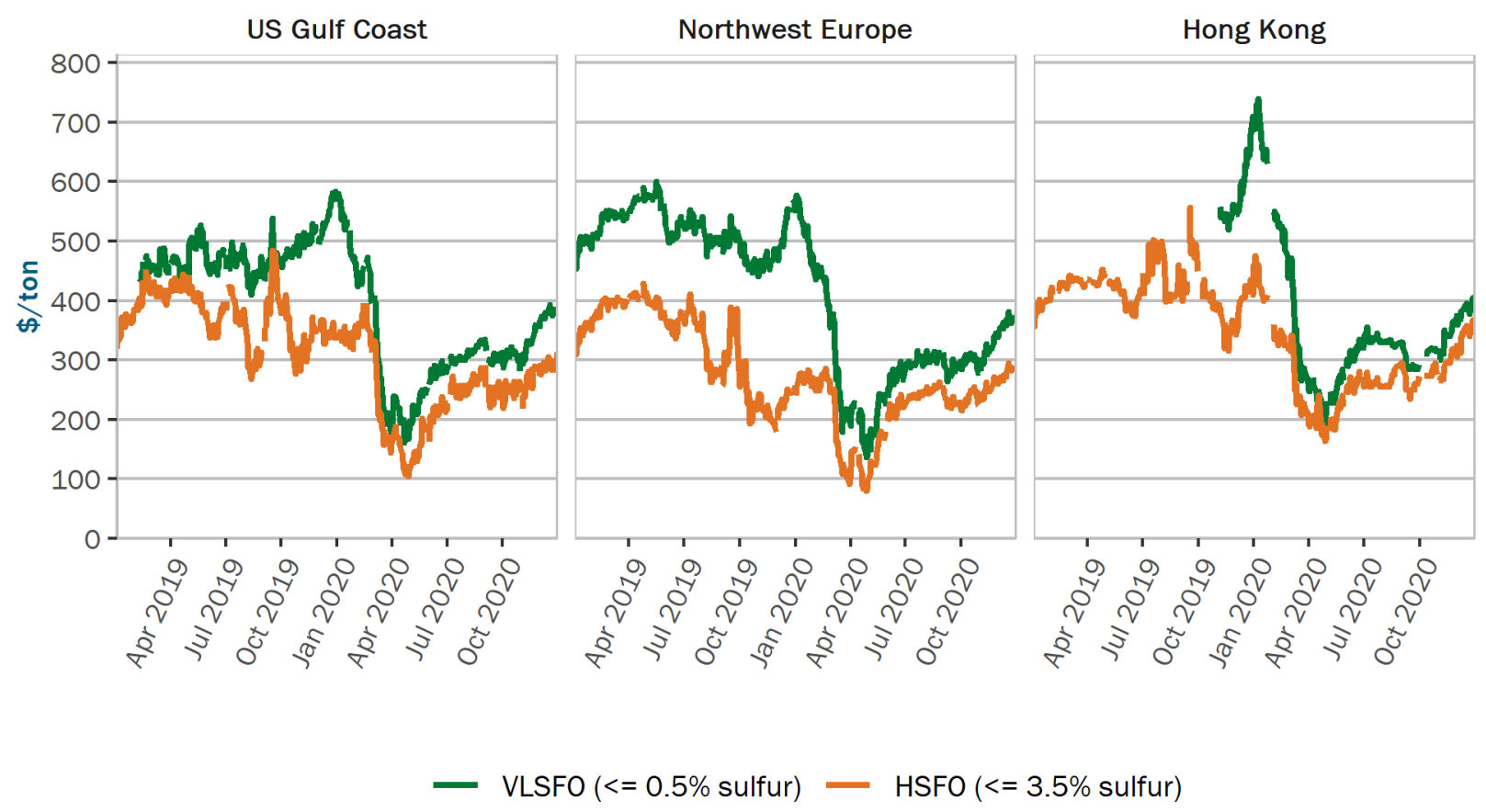

Figure ES-1. Price of heavy fuel oil and very low sulfur fuel oil in selected hubs (2019-2020)

Source: Argus

\section{ES-2. COMPLIANCE PATHWAYS}

- $\quad$ The main pathway to compliance has been petroleum fuels, mostly VLSFO but also HSFO with scrubbers. Figure ES- 2 shows the mix of petroleum-based marine fuels sold in two major bunkering 
ports (Singapore and Rotterdam) since the last quarter of 2019. VLSFO has been the most sold fuel since the beginning of 2020 in both, with HSFO in second place.

- $\quad$ The projection from many analysts that IMO 2020 would result in significant increases in consumption of higher quality, more expensive marine distillates (MGO/MDO) has not materialized.

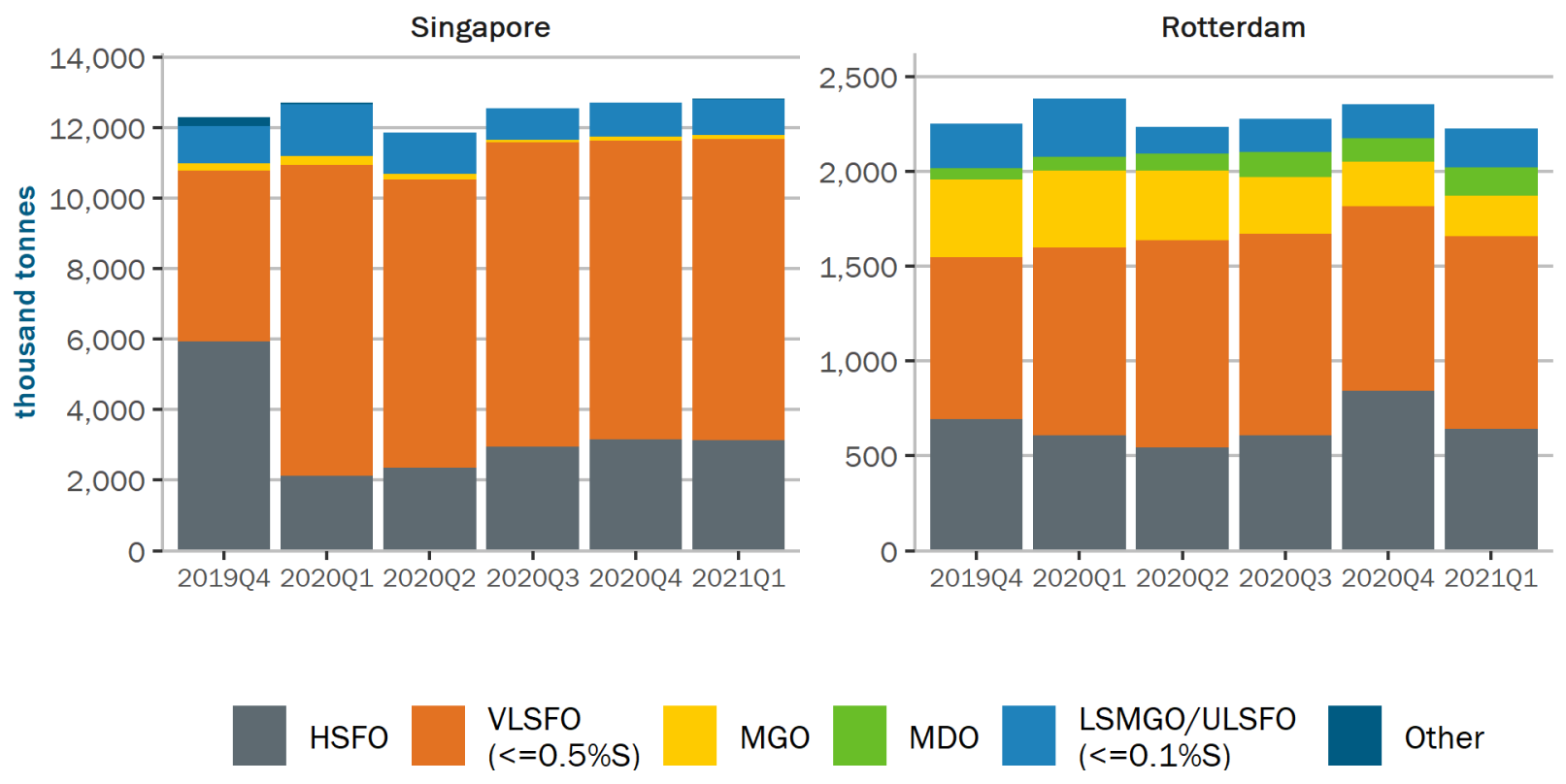

Figure ES- 2. Quarterly sales of petroleum-based bunker fuels at the ports of Singapore and Rotterdam (2019 Q42021Q1)

Source: Maritime and Port Authority of Singapore, Port of Rotterdam

- There are a range of alternative fuel options with sulfur content below the $0.5 \%$ cap, including liquefied natural gas (LNG), biofuels, methanol, and ammonia, but they are more expensive (except for LNG) than petroleum-based fuels and/or require vessel retrofits.

- LNG is the most available and cheapest of the alternative fuel options, particularly in the United States. However, it requires a retrofit investment for existing vessels with conventional marine diesel engines. Methane leakage in the well-to-tank lifecycle stage and methane slip in the tank-to-propeller stage limit the greenhouse gas (GHG) emission reductions offered by LNG.

- Twenty of the 30 U.S.-flagged vessels constructed in 2015-2019 are either compatible with LNG or "LNG-ready" (i.e., they could use LNG upon some modifications).

- Globally, there were approximately 200 LNG-fueled vessels in operation and as many newbuild orders at the end of 2019.

- Within the biofuel category, there are many combinations of feedstocks and conversion pathways to produce marine fuels, at various stages of research and development. They are typically more expensive than petroleum-based fuels, but they offer substantial reductions in GHG emissions relative to those conventional fuels. Many of them (e.g., biodiesel) do not require any retrofit investment for existing vessels; others like ethanol 
do. Biodiesel and renewable diesel are commercially available and are direct substitutes to marine distillate fuels; competition from other transportation sectors could limit availability to the marine sector. A few companies have also started offering bio-fuel oil that can be blended with petroleum-based residual fuel.

- Use of biofuel blends is growing from trial voyages into a reportable category of fuel sales in some ports (most notably, Rotterdam).

- Methanol produced from natural gas is already available in many ports, but bunkering infrastructure remains to be developed. As a liquid fuel, it is easier to store than LNG. Methanol has about half the energy content of HSFO and has been more expensive than HSFO in an energy-equivalent basis. To achieve substantial reductions in GHG lifecycle emissions relative to residual fuel oil, methanol must be produced from renewable feedstocks.

- By the end of 2019, there were 12 methanol vessels in the global fleet - most of them were chemical tankers for which methanol is both cargo and fuel; another 11 orders for new methanol-fueled vessels had been placed.

- Ammonia is the less technically mature option (for its use as marine fuel) of the ones considered in this report; yet some prominent forecasts view it as capturing a large fraction of marine fuel sales by 2050. Its advantages are its potential to be a zero-carbon fuel, as long as $\mathrm{CO}_{2}$ emissions are eliminated from production of the necessary hydrogen, and its ease of transport and storage compared to hydrogen. However, its low energy density relative to petroleum-based fuels contributes to it being more expensive than the incumbent fuels (even for the "grey" versions available today). Addressing its toxicity and emissions of NOx upon combustion requires additional capital cost to incorporate extra safety measures and exhaust after-treatment systems in the vessels.

- There are no marine engines compatible with ammonia today. However, marine engine manufacturers are developing both two-stroke and four-stroke engines for ammonia use and it is expected that the first installations could happen by 2024 .

\section{ES-3. DESCRIPTION OF THE U.S. FLEET}

- $\quad$ The U.S. fleet of ocean-going vessels comprises 184 ships with combined gross tonnage of 7.3 million tons and a median age of 15 years. Figure ES- 3 shows that the age distribution and vessel type mix vary significantly between the Jones Act segment of the fleet (i.e., the U.S.-built, owned, registered, and crewed vessels eligible for domestic waterborne freight transport) and the rest. 


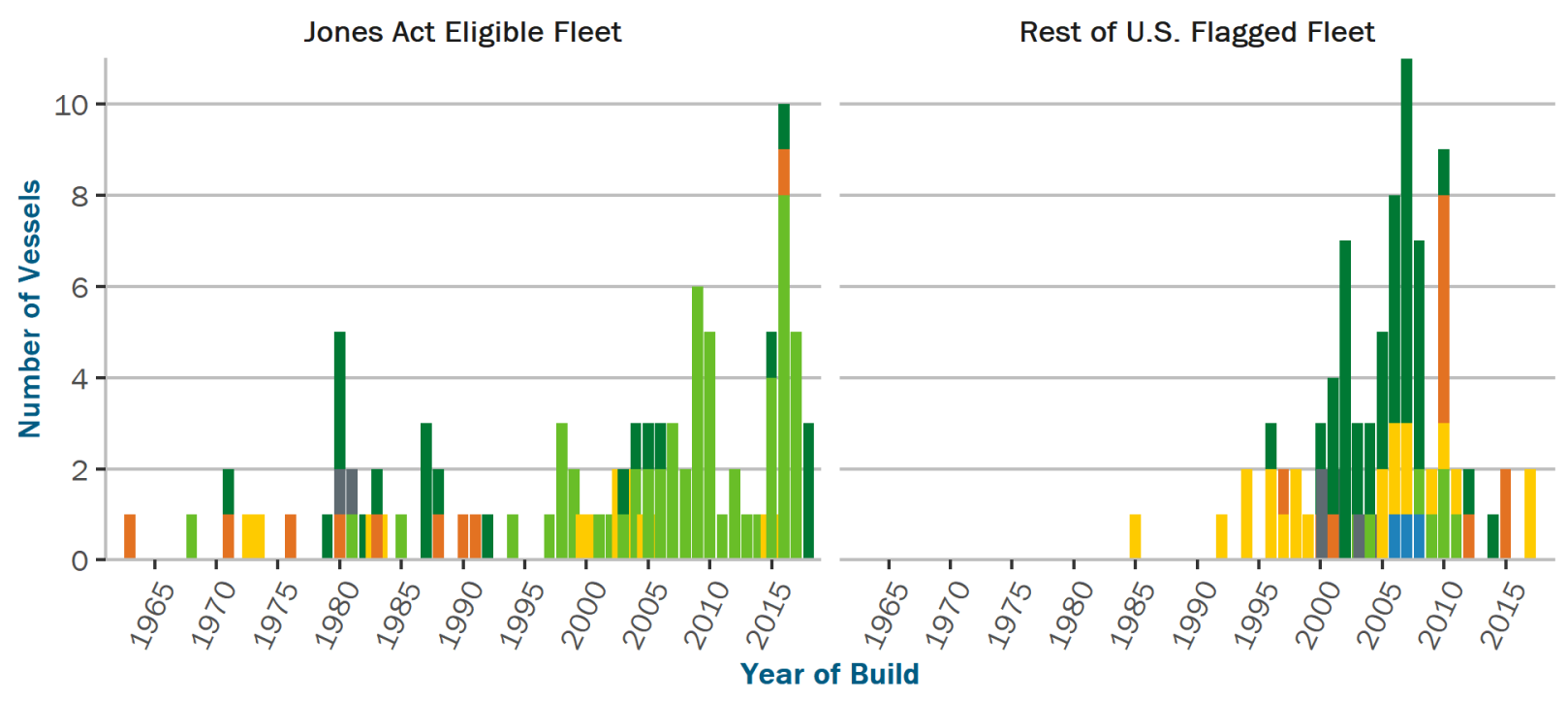

Type

Containership Dry Bulk General Cargo Ro-Ro Tanker Vehicles Carrier

Figure ES- 3. U.S.-flagged merchant fleet by year of build and ship type

Source: U.S. Department of Transportation Maritime Administration

\section{ES-4. SCENARIO ANALYSIS}

- We built a model to compare the average annual cost of eight alternative IMO compliance approaches, for the average (size and age) containership (44,000 gross tons and 19 years old) and tanker (39,000 gross tons and 14 years old) in the U.S. fleet.

- The cost model does not describe the full shipping cost; it focuses on the two components-capital cost (retrofit cost or new ship cost) and fuel cost— that vary the most across the different compliance approaches. Other ship operating costs (crew cost, maintenance, insurance etc.) are not expected to vary substantially with compliance approach.

$$
\text { Cost }=\text { annual capital charge }+ \text { annual fuel consumption } * \text { fuel price }
$$

The fuel consumption reflects any fuel-efficiency effects of the engine/ship choice and the fuel efficiency penalty of a scrubber, if chosen.

- The eight compliance approaches are combinations of engines and fuels described in terms of their average costs, emissions, and fuel efficiency:

- The three approaches compared for existing ships are VLSFO, HSFO plus scrubber, or LNG retrofit.

- $\quad$ The five approaches involving new ships use VLSFO or one of four alternative fuels: (LNG, biofuel (ethanol), methanol, ammonia). 
- The choice to replace with a new vessel depends strongly on the vessel age and the "reinvestment window", assumed to be remaining vessel operational lifetime.

- To consider GHG/decarbonization implications as part of the scenario analysis, we explore the implied cost of carbon reduction across compliance alternatives.

- We do not make explicit assumptions about GHG markets, prices, or the choice between buying credits vs investing in lower GHG technology.

\section{ES-5. INPUT PARAMETERS AND DATA}

\subsubsection{Vessel, Fuel, Engine and Cost Parameters}

Data needed for scenarios include data specific to each vessel type, engine and fuel, as well as the shared cost/economic parameters shown in Table ES- 1.

Table ES- 1. Cost Parameters Shared by All Cases

\begin{tabular}{lrrr}
\hline Parameter & Low & Base & High \\
\hline Interest rate & 0.03 & 0.04 & 0.1 \\
\hline Base vessel lifespan & 15.0 & 20.0 & 35.0 \\
\hline LNG newship cost premium & 0.2 & 0.2 & 0.2 \\
\hline Altfuel newship cost premium & 0.5 & 0.5 & 0.5 \\
\hline Newship cost multiple USvsforeign & 3.0 & 3.0 & 3.0 \\
\hline
\end{tabular}

\subsubsection{Average Projected Prices for Marine Fuels}

- $\quad$ Fuel prices are constructed from EIA's Annual Energy Outlook (AEO) 2021.

- $\quad$ The AEO contains projections for HSFO and ethanol; for the rest, the price projections are based on linear equations describing the historical relationship between the fuel of interest and a related one for which AEO offers projections.

- All prices are converted to dollars per ton of fuel oil equivalent energy to account for the different energy content of the various fuels considered.

The projected prices of conventional and alternative marine fuels, based on EIA's $A E O 2021$ projections, are summarized in Figure ES- 4. 


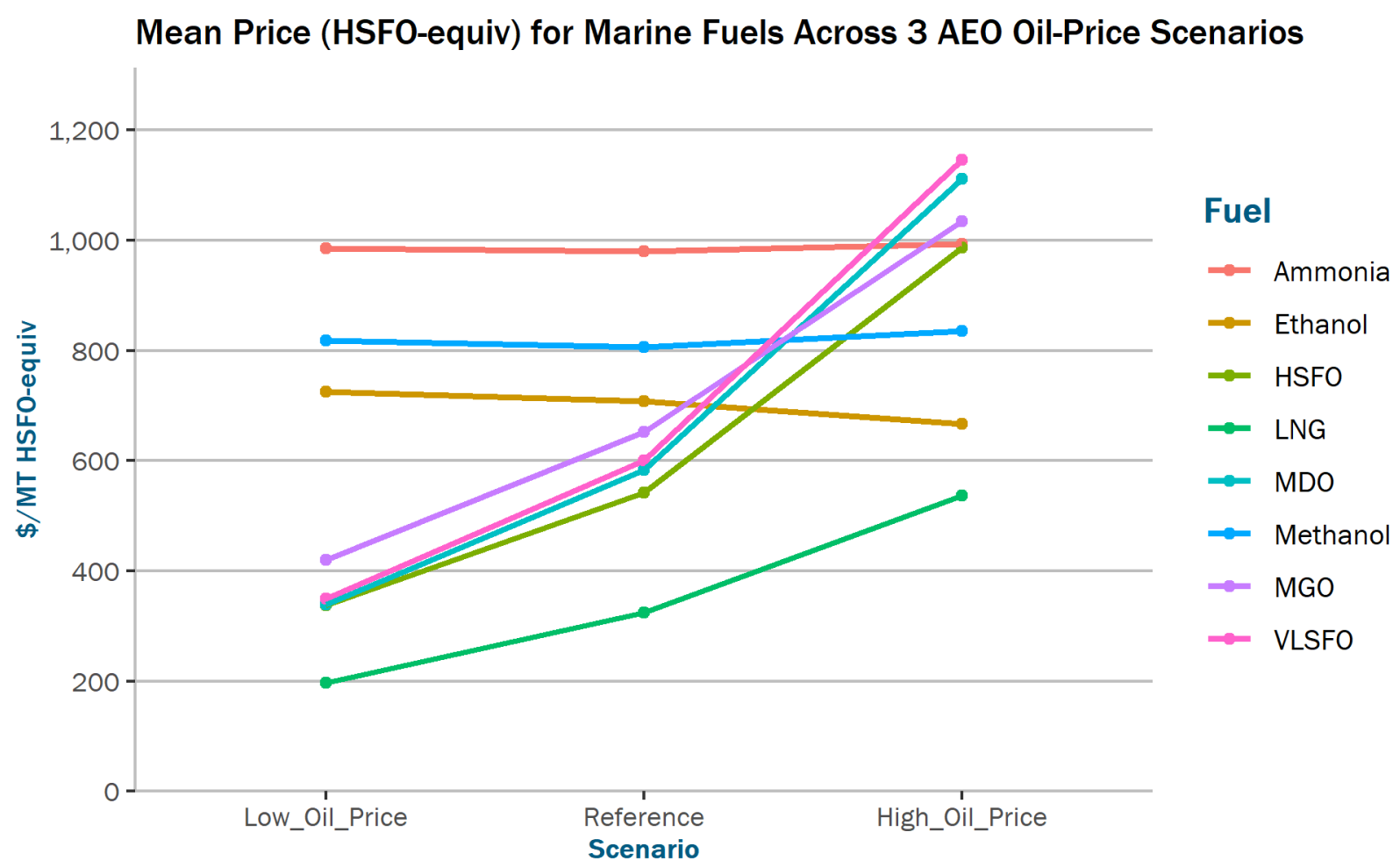

Figure ES- 4. Mean price (HSFO-equivalent) for marine fuels across three AEO oil price scenarios

- $\quad$ For each price scenario, cost calculations are based on the AEO mean price projection over the 2020-2050 period. The prices for ammonia and methanol in the AEO scenarios are for "grey" versions that use natural gas as the feedstock. Figure ES- 4 shows that some alternative fuels, like ammonia, ethanol and methanol, are less sensitive to variations in crude oil price, and so are comparatively more (or less) competitive in high (or low) oil price scenarios.

- $\quad$ A fourth price scenario (IMO_GHG_Study) is considered, based on the fuel price projections from the IMO 4th GHG study for ammonia, ethanol, LNG, and methanol (and historical prices from Argus for the petroleum-based fuels).

\section{ES-6. CALCULATION OF FUEL AND SHIP CAPITAL COSTS FOR IMO 2020 COMPLIANCE}

Given the framework for fuel and capital cost accounting described above, we compute the costs of alternative compliance approaches (in US dollars per year) and $\mathrm{CO}_{2}$ emissions.

- $\quad$ The results for the Base Case set of scenarios, with Reference AEO fuel prices in Figure ES- 5 show that the compliance approaches using new ships are, not surprisingly, far more expensive than approaches that utilize existing ships and either low-sulfur fuel oil or retrofits for scrubbers or LNG.

- An increase in fuel efficiency of $45 \%$ is assumed for all new ship alternatives.

- The results in Figure ES- 5 are for ships of average age in the U.S. fleet: 19 years for containerships and 14 years for tankers.

- The pattern of relative costs of compliant approaches is similar for containerships and tankers. One exception is that the estimated incremental cost of an LNG retrofit is lower than the use of VLSFO for tankers but not for containerships. This is due to differences in vessel configuration and the more 
limited space on container vessels for LNG storage and fuel management equipment. Furthermore, incremental annual capital charge for LNG retrofit is also lower on a typical tanker because tankers are, on average, younger than containerships in the U.S. fleet and have more years of service remaining over which to amortize the retrofit cost.

\section{Base Case Costs by Compliance Approach}

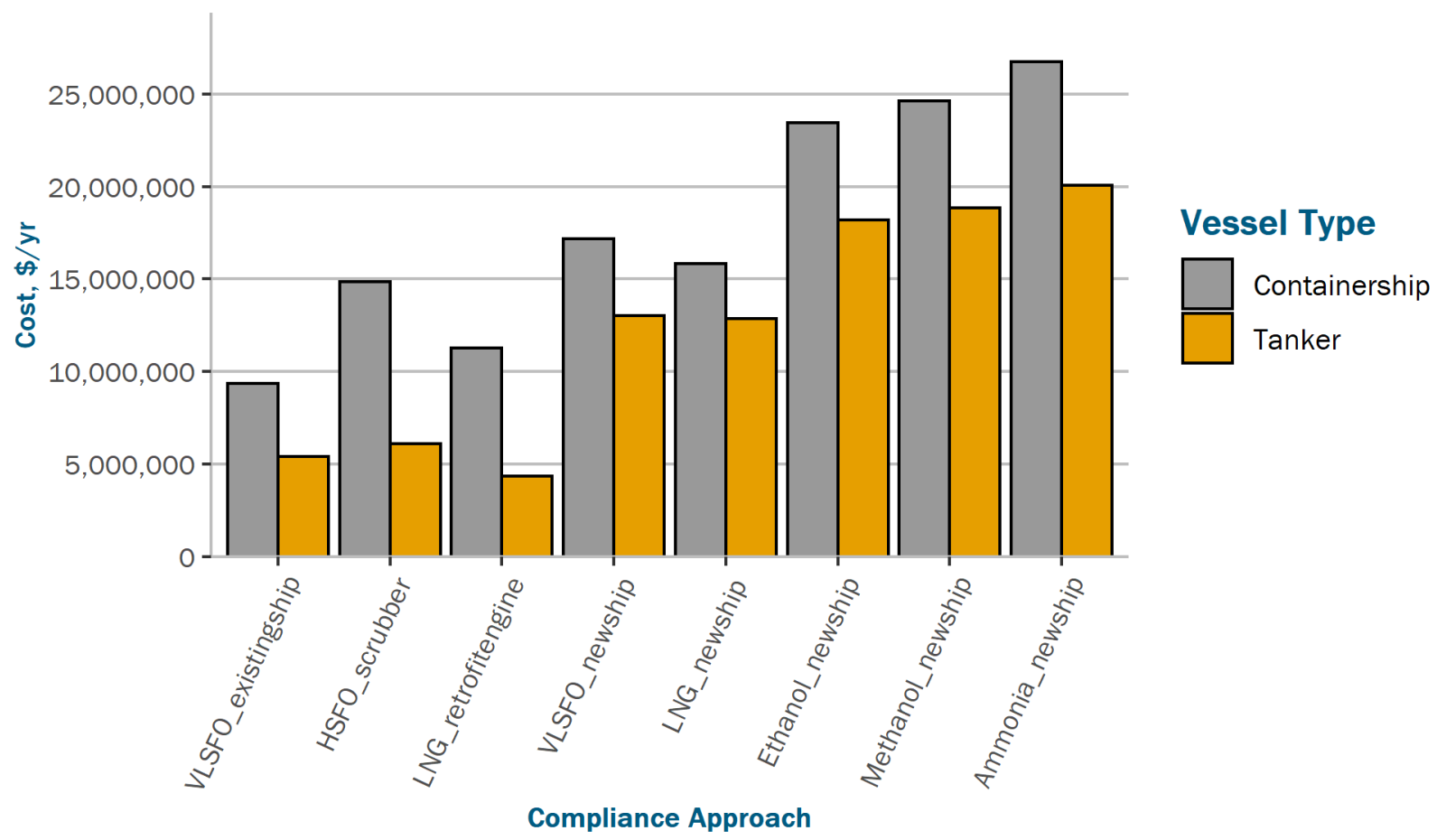

Figure ES- 5. Base Case Costs by Compliance Approach

\section{ES-7.SENSITIVITY ANALYSIS}

We consider sensitivity cases for variations of the following parameters:

- Fuel price case,

- Vessel age,

- Interest rate,

- Scrubber efficiency penalty.

\subsubsection{Sensitivity to Vessel Age}

Figure ES- 6 displays the total capital plus fuel cost of eight compliance approaches for the two ship types, for vessel ages from zero years (new) to 20 years. 


\section{Cost by Fuel/Tech Compliance Approach, Sensitivity to Age}

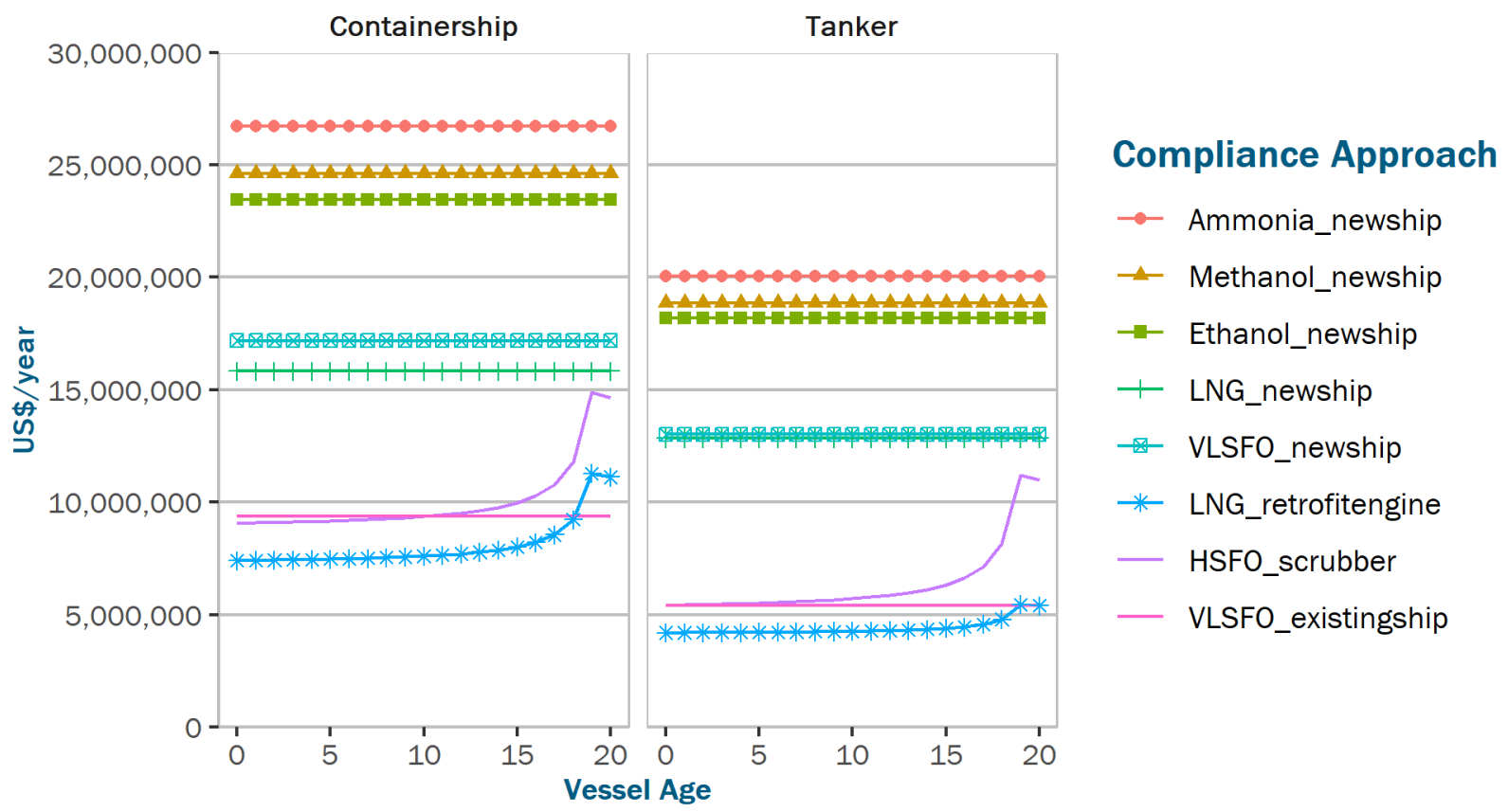

Figure ES- 6. Cost by compliance approach, sensitivity to age

- $\quad$ Figure ES- 6 shows there are 3 clearly distinct regimes or groupings of compliance approaches in terms of costs (particularly for tankers): 1) low-sulfur petroleum fuels or LNG retrofit are all part of the lowest cost regime 2) VLSFO new ship/LNG new ship are intermediate in cost, and 3) new ships with alternative fuels are the costliest.

- The principal age sensitivity arises for older vessels, here ages $\sim 14-19$, when the annualized capital cost of the retrofit options (scrubber, LNG-retrofit) rises quickly because of the limited remaining vessel life over which to amortize it.

- $\quad$ More than half (54\%) of vessels in the U.S. fleet are 14 years old or older.

- Our approach to costing out the capital investment of any option with a "newship" build makes the annual cost result invariant with the age of the existing ship.

- A critical assumption is that the scrappage cost, and the used-vessel value, is taken as approximately zero in the U.S. market of older Jones Act vessels. A second important assumption is that new vessel construction costs for a U.S. Jones Act-eligible vehicle are substantially higher than constructions costs in the global market. ${ }^{1}$

- $\quad$ As a result, for a vessel of any age from 0 to 19 years, it is more cost-effective to continue to operate used vessels as long as practical than to buy a new vessel of any kind. This is despite the assumed higher efficiency of new ships (with new engines and hull designs).

\footnotetext{
${ }^{1}$ Subsides for U.S. shipbuilding are no longer provided. Such subsidies "were passed as part of the Merchant Marine Act of 1936 and later expanded by the Merchant Marine Act of 1970 before being scrapped by the Reagan administration in 1981." (Grabow, 2021).
} 


\subsubsection{Sensitivity to Fuel Price}

- The evolution of petroleum and substitute fuel prices is a key uncertainty in this cost analysis. The range of average future fuel prices in the 4 price cases developed with EIA and IMO $4^{\text {th }}$ GHG Study/Argus assumptions translates into substantial dispersion of total costs of IMO compliant approaches. Figure ES- 7 summarizes the cost of the 8 compliance approaches for containerships and tankers, with dots showing the annual costs in each of the 4 price cases. Colored lines connect the outcomes for the same price scenario across compliance approaches.

\section{Compliance Approach Costs, various price cases}

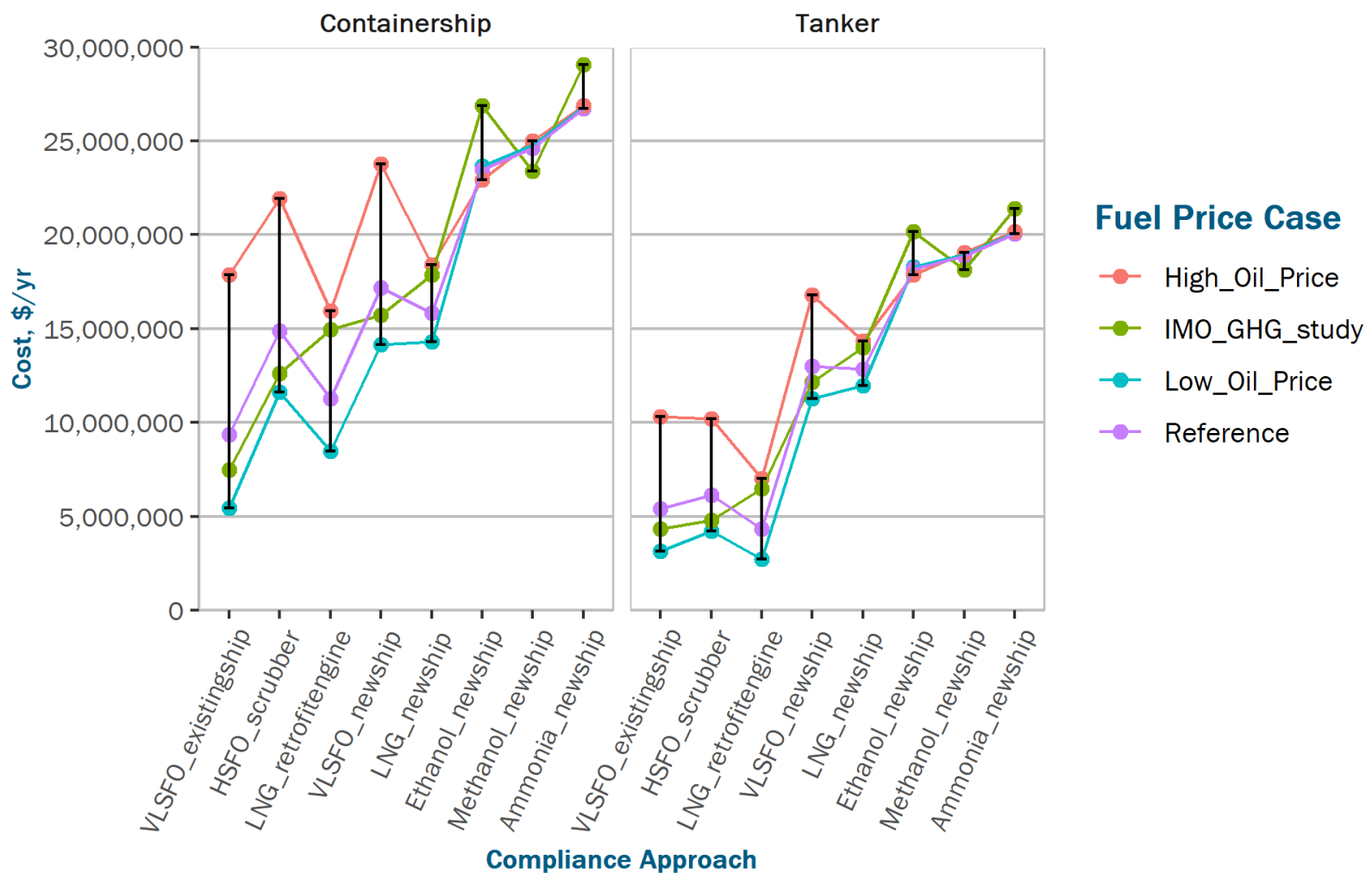

Figure ES- 7. Compliance approach costs for Base Case set with price sensitivities

- $\quad$ The previous message of 3 distinct cost regimes for compliance approaches is robust to the price sensitivity cases considered, particularly for tankers. For containerships it is not as clear cut, but there are still 2 distinct groupings: one for petroleum-based fuels and LNG, another for new alternative fuel ships with potentially lower $\mathrm{CO}_{2}$ emissions. The prices of alternative fuels (ethanol, methanol and ammonia, even if produced with fossil feedstock) move differently under different oil prices than the petroleum and LNG fuels. Thus, the costs of new alternative fuel options are in a narrower range, far less dependent on the prices of oil. New ship options are also less sensitive to fuel prices due to their assumed greater efficiency than existing ships.

- VLSFO use by existing ships is a highly competitive alternative for IMO compliance in all price scenarios except the High Oil Price one. The prospect of sustained lower petroleum prices as many regions move to electrify road transport could also create strong competition for non-petroleum marine fuels that might be used to both reduce marine sulfur and $\mathrm{CO}_{2}$ emissions. However, a return to a High Oil Price world would make the more efficient new ship options relatively less costly. 


\subsubsection{Compliance Approach Costs vs Strategy for Sensitivity Case Set Results}

\section{Containership Cost and CO2 Emissions, with Sensitivity Cases Costs CO2 Emissions}
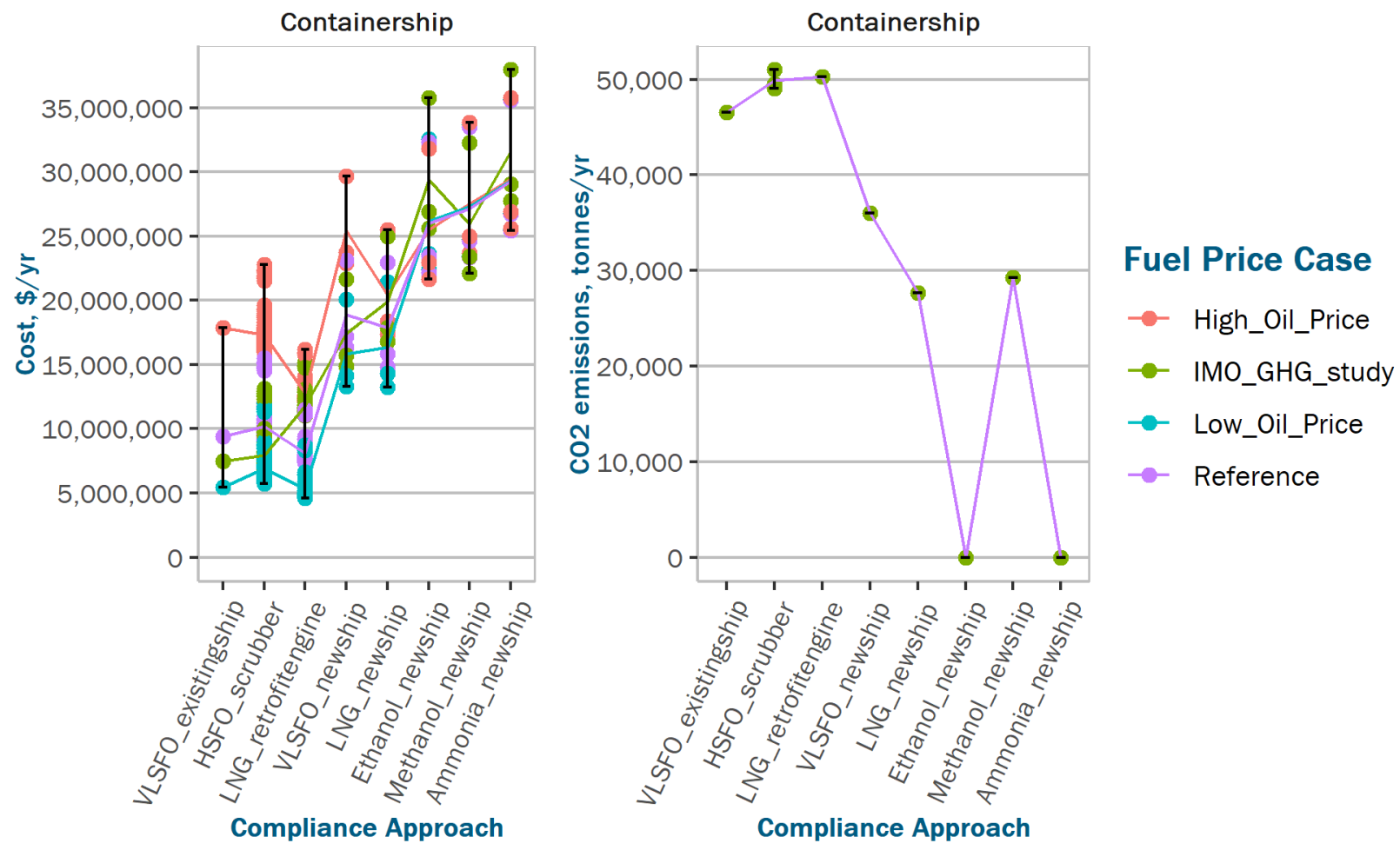

Figure ES- 8. Containership cost and $\mathrm{CO}_{2}$ emissions, various sensitivity cases

- In Figure ES- 8, the left panel shows annual costs for the 8 compliance approaches as before, but now with sensitivity cases as combinations of prices, interest rates and scrubber efficiency, each combination shown as a separate dot. Colored lines connect the mean outcomes for each price scenario across compliance approaches. ${ }^{2}$

- The right panel shows estimated tank-to-wake emissions of $\mathrm{CO}_{2}$ for each fuel, using a single value for the carbon intensity of each fuel (see Table B- 3). Uncertainty about the scrubber efficiency and fuel penalty results in a small range of $\mathrm{CO}_{2}$ emissions in the HSFO-with-scrubber compliance approach. While these are tank-to-wake emissions, they could also be lifecycle emissions, if costcompetitive net-zero GHG versions of ethanol and ammonia can be produced.

- In broad terms, the costs generally rise across the options shown in

- $\quad$ Figure ES- 8 from left to right, while the estimated $\mathrm{CO}_{2}$ emissions generally fall.

- $\quad$ Again, the prices of non-fossil fuels behave differently under different oil prices, and new ship alternative fuel options are far less dependent on the prices of oil. Furthermore, the cost of new alternative fuel and other new ship options, both alternative and conventionally fueled, are less dependent on ship age, since the old ship is assumed scrapped. But new ships are a more capitalintensive approach and do show sensitivity to the cost of capital (the interest rate).

\footnotetext{
${ }^{2}$ For tankers, the equivalent figure is presented in Chapter 6.
} 


\subsubsection{Implications of a Carbon-Constrained World}

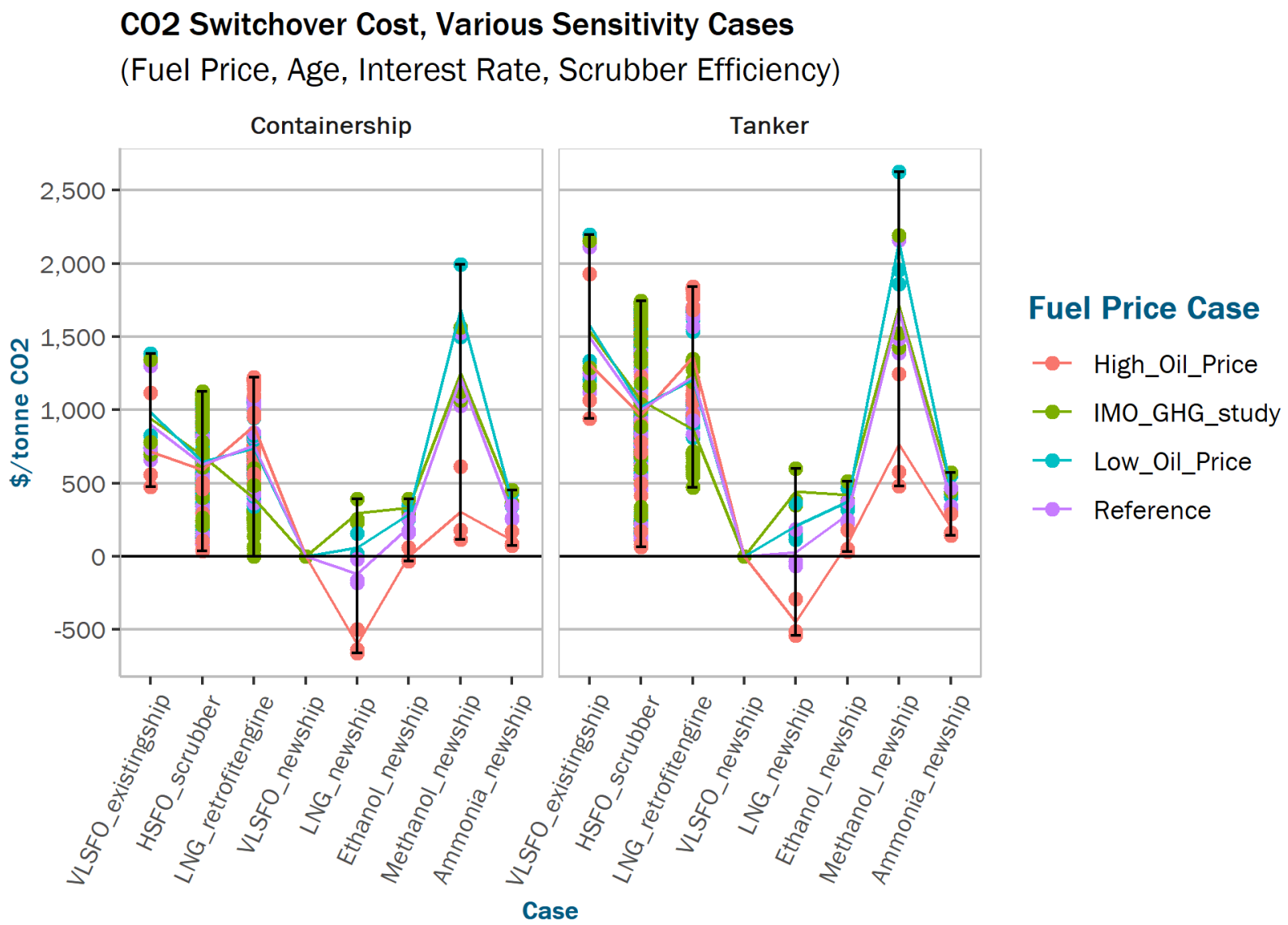

Figure ES- 9. $\mathrm{CO}_{2}$ switchover cost, various sensitivity cases

- $\quad$ Figure ES- 9 reports the $\mathrm{CO}_{2}$ switchover cost for the 8 compliance approaches using a new ship fueled by VLSFO as the reference point. Some basis of comparison is necessary, and VLSFO new ship was chosen as the reference because it was an intermediate approach both in terms of cost and $\mathrm{CO}_{2}$ emissions. As the reference option, the switchover cost for VLSFO new ship is reported as zero across all sensitivity cases.

- Note that we only look at $\mathrm{CO}_{2}$ emissions (rather than $\mathrm{CO}_{2}$-equivalent) and only for the tank-to-wake stage of the fuel lifecycle; methane slip is not accounted for.

- Given a non-zero carbon cost, approaches to the right of VLSFO new ship, which have higher cost but lower $\mathrm{CO}_{2}$ emissions, become relatively more advantageous due to the carbon price. In contrast, points to the left (lower cost, higher emissions) would get penalized by a carbon price.

- Note that carbon price tilts the costs around the new VLSFO ship option raising cost of existing petroleum ships and lowering relative cost of new-non-petroleum ships. Absent a $\mathrm{CO}_{2}$ cost, a new VLSFO ship is in the middle in terms of cost and $\mathrm{CO}_{2}$ emissions given its more efficient use of petroleum relative to that of existing ships.

- $\quad$ The figure shows that a positive $\mathrm{CO}_{2}$ cost could make cost-effective the switch from an existing ship using petroleum or LNG to a new, more efficient ship using VLSFO. A (typically large) positive 
$\mathrm{CO}_{2}$ cost could also incentivize the switch from a new VLSFO ship to a new alternative fuel (ethanol, methanol or ammonia) ship, provided those fuels achieve lower $\mathrm{CO}_{2}$ emissions.

- In many cases, particularly those involving a new alternative fuel ship, the $\mathrm{CO}_{2}$ cost would have to be rather high before such an investment would be justified based on net economics alone. However, this switchover cost is lower for scenarios with higher oil prices, and lower if capital costs or alternative fuel costs can be reduced.

\section{ES-8. CONCLUSIONS}

- Contrary to some initial concerns, IMO 2020 compliance with low-sulfur petroleum-based fuels neither has turned out to be nor is expected to be (based on AEO 2021 price forecasts) very expensive.

- $\quad$ LNG retrofit is cheaper than use of VLSFO or HSFO plus scrubbers in some of the price scenarios; although choosing LNG can make sense from a commercial/cost optimization standpoint as well as to reduce local air pollutants, it offers limited improvement in $\mathrm{CO}_{2}$ emissions and has additional challenges related with methane slip, which makes it a risky fuel in the context of potentially more ambitious GHG reduction targets by IMO.

- Capital cost for retrofits of existing ships is less economic for those ships which are older, i.e., much of the U.S. fleet.

- $\quad$ Relative to the existing fleet, fueled almost entirely with petroleum-based fuels, a more diversified fuel mix likely results in lower overall price risk.

- This result is driven by the fact that the correlation between petroleum fuels and alternative fuels is lower than the correlation across petroleum fuels (e.g., residual fuels and distillate fuels). Reductions in price risk due to diversification of the fuel portfolio are possible at the fleet level and at the vessel level (with dual-fuel engines).

- While $\mathrm{CO}_{2} / \mathrm{GHG}$ emissions are not directly a consideration for IMO 2020 compliance, there is a prospect of a more carbon-constrained global energy market. The fuel and vessel options for IMO 2020 compliance vary significantly in their carbon intensity, particularly on a tank-to-wake basis. The potential need for ships to reduce their carbon intensity can be a supplementary consideration for U.S. shippers evaluating the longer-term implications of their IMO compliance approaches and investments.

- However, the comparatively high cost of new ship investment, based on U.S. construction costs, implies that a high effective cost for $\mathrm{CO}_{2}$ would be needed to motivate the switchover from existing ships to new, more efficient ships, or new alternative fuel ships.

- There remains substantial uncertainty about this switchover cost of $\mathrm{CO}_{2}$ in part because the costs of producing low- or zero-lifecycle $\mathrm{CO}_{2}$ fuels for marine use in significant volumes (such as green ammonia or biofuel) are not yet established.

- A prospect of sustained lower petroleum prices as many regions move to electrify road transport could also create strong competition for non-petroleum marine fuels that might be used to both reduce marine sulfur and $\mathrm{CO}_{2}$ emissions. 


\section{ACKNOWLEDGMENTS}

The work described in this document was sponsored by the U.S. Department of Transportation Maritime Administration (DOT MARAD). The authors gratefully acknowledge the support and guidance of Tom Thompson at DOT MARAD.

\section{ACRONYMS}

$\begin{array}{ll}\text { AEO } & \text { Annual Energy Outlook } \\ \text { BIMCO } & \text { Baltic and International Maritime Council } \\ \text { BTL } & \text { Biomass to Liquid } \\ \text { CO }_{2} & \text { carbon dioxide } \\ \text { cst } & \text { centistokes, a measure of fuel kinematic viscosity } \\ \text { DWT } & \text { deadweight tons } \\ \text { ECA } & \text { emission control area } \\ \text { EEDI } & \text { Energy Efficiency Design Index } \\ \text { EIA } & \text { Energy Information Administration } \\ \text { ETS } & \text { Emissions Trading System } \\ \text { EU } & \text { European Union } \\ \text { FTA } & \text { free-trade agreement } \\ \text { GDP } & \text { Gross Domestic Product } \\ \text { gge } & \text { gallon of gasoline equivalent } \\ \text { GHG } & \text { greenhouse gas } \\ \text { GHG4 } & \text { IMO 4 }{ }^{\text {th }} \text { GHG Study } \\ \text { GT } & \text { gross ton } \\ \text { HFO } & \text { heavy fuel oil } \\ \text { HSFO } & \text { high-sulfur fuel oil } \\ \text { IBIA } & \text { International Bunker Industry Association } \\ \text { IEA } & \text { International Energy Agency } \\ \text { IFO } & \text { intermediate fuel oil } \\ \text { IMO } & \text { International Maritime Organization } \\ \text { ISO } & \text { International Organization for Standardization } \\ \text { IPIECA } & \text { International Petroleum Industry Environmental Conservation Association } \\ \text { LNG } & \text { liquefied natural gas } \\ \text { MAC } & \text { marginal abatement cost } \\ \text { MDO } & \text { marine diesel oil } \\ \text { MEPC } & \text { Marine Environment Protection Committee } \\ \text { MGO } & \text { marine gasoil } \\ \text { MMbbl } & \text { millions of barrels } \\ \text { NOx } & \text { nitrogen oxides } \\ \text { NWE } & \text { Northwest Europe } \\ \text { PAJ } & \text { Petroleum Association of Japan } \\ \text { SEEMP } & \text { Ship Energy Efficiency Management Plan } \\ \text { SOX } & \text { sulfur oxide } \\ \text { SVO } & \text { straight vegetable oil } \\ \text { TEU } & \text { twenty-foot equivalent unit } \\ & \end{array}$


UNCTAD United Nations Conference on Trade and Development USGC U.S. Gulf Coast

VGO vacuum gasoil

VLSFO very low sulfur fuel oil

WTI West Texas Intermediate (crude oil) 


\section{LIST OF FIGURES}

Figure ES- 1. Price of heavy fuel oil and very low sulfur fuel oil in selected hubs (2019-2020) ............... 1

Figure ES- 2. Quarterly sales of petroleum-based bunker fuels at the ports of Singapore and

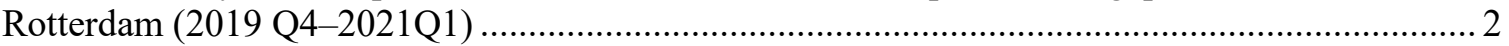

Figure ES- 3. U.S.-flagged merchant fleet by year of build and ship type ............................................. 4

Figure ES- 4. Mean price (HSFO-equivalent) for marine fuels across three AEO oil price

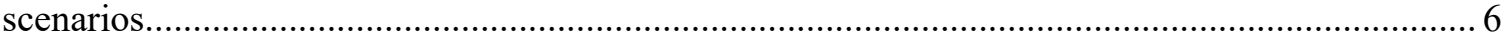

Figure ES- 5. Base Case Costs by Compliance Approach................................................................... 7

Figure ES- 6. Cost by compliance approach, sensitivity to age ............................................................... 8

Figure ES- 7. Compliance approach costs for Base Case set with price sensitivities ................................ 9

Figure ES- 8. Containership cost and $\mathrm{CO}_{2}$ emissions, various sensitivity cases ................................... 10

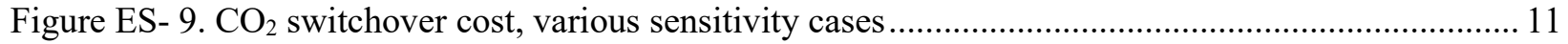

Figure 1. Price of heavy sulfur fuel oil and very low sulfur fuel oil in selected regions (2019-

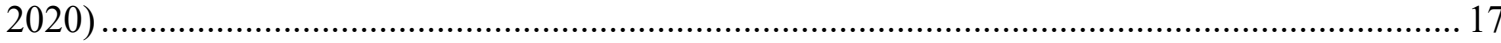

Figure 2. Price of selected petroleum-based marine fuels in Northwest Europe ..................................... 18

Figure 3. Quarterly sales of petroleum-based marine fuels at the Ports of Singapore and

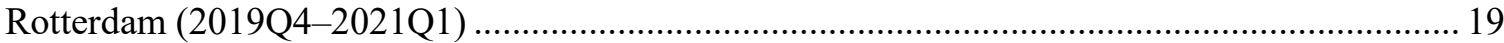

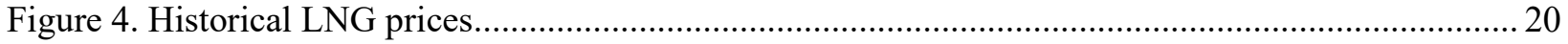

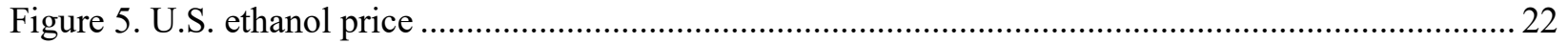

Figure 6. Historical prices of methanol and ammonia in the United States............................................ 23

Figure 7. U.S.-flagged oceangoing merchant vessels by year of build and ship type............................. 24

Figure 8. U.S.-flagged oceangoing merchant vessels by ship type and deadweight tonnage .................... 25

Figure 9. Estimated U.S. oceangoing merchant fleet fuel costs......................................................... 27

Figure 10. U.S. fleet count, fuel consumption, and annual fuel costs by vessel type ..............................2 28

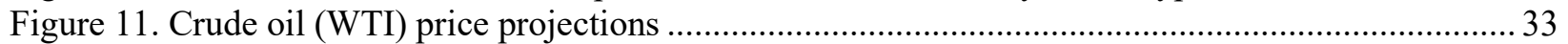

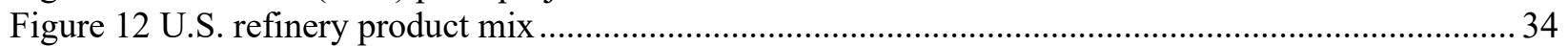

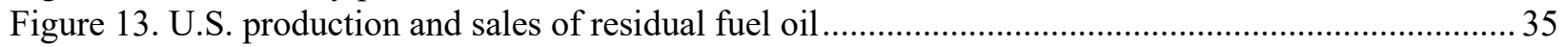

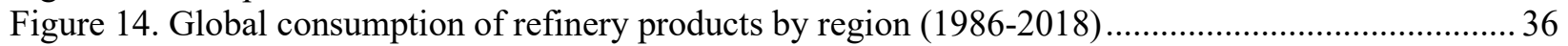

Figure 15. Prices of gasoline, VGO, and VLSFO in Northwest Europe (2019-2020) ............................ 37

Figure 16. Distillate product prices in New York Harbor (2019-2020) …............................................. 38

Figure 17. Mean price for marine fuels across three AEO oil price scenarios. ...................................... 42

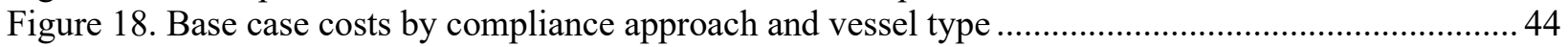

Figure 19. Cost by fuel/technology compliance approach, sensitivity to vessel age .............................. 45

Figure 20. Compliance approach costs by fuel price case and vessel type.............................................. 46

Figure 21. Compliance approach cost and $\mathrm{CO}_{2}$ emissions for containership, with sensitivity cases ......... 48

Figure 22. Compliance approach cost and $\mathrm{CO}_{2}$ emissions for tanker, with sensitivity cases .................... 49

Figure 23. $\mathrm{CO}_{2}$ switchover cost by compliance approach and vessel type (across all sensitivity cases) 


\section{LIST OF TABLES}

Table ES- 1. Cost Parameters Shared by All Cases ............................................................................. 5

Table 1. Energy consumption (international shipping, domestic shipping, and fishing) by fuel type (million tons).

Table 2. Energy consumption (international shipping, domestic shipping, and fishing) by fuel type (percentage).

Table 3. Future Fuel Costs in 2030 and 2050 from IMO GHG4 Study (unit: \$/ton).............................. 16

Table 4. Estimated Fuel Consumption of the U.S. Oceangoing Merchant Fleet (2019 prices) .................. 26

Table 5. Estimated Fuel Costs of the U.S. Oceangoing Merchant Fleet (2019 prices)..............................26

Table 6. Estimated Fuel Consumption of the U.S. Oceangoing Merchant Fleet by Vessel Type ..............27

Table 7. Estimated Fuel Cost of the U.S. Oceangoing Merchant Fleet by Vessel Type............................28

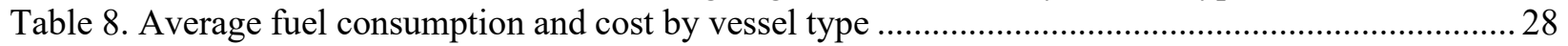

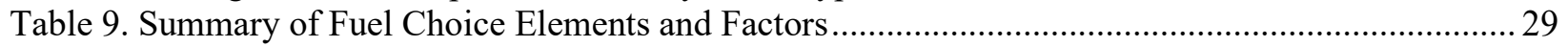

Table 10. Primary Fuel and Technology Compliance Path Options Evaluated........................................ 41

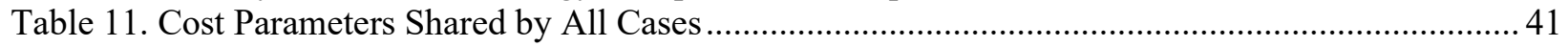

Table 12. Mean prices from AEO (and IMO GHG4 study/Argus)...................................................... 43

Table A- 1. Correspondence between petroleum-based fuels discussed in the report and ISO

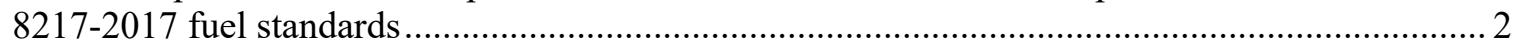

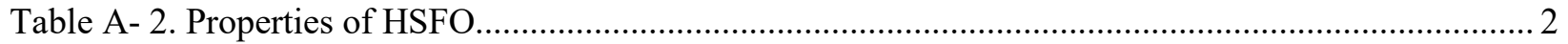

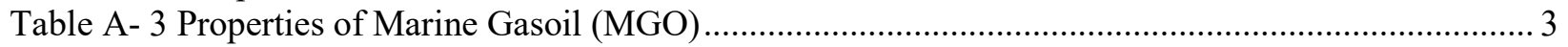

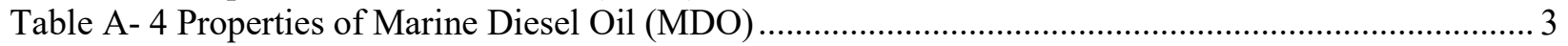

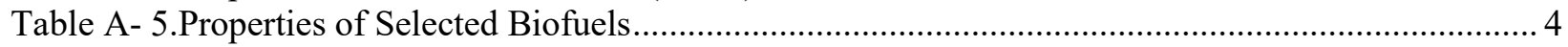

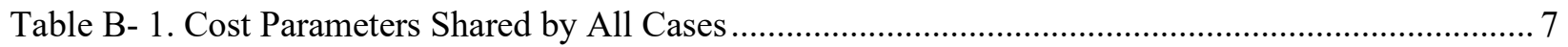

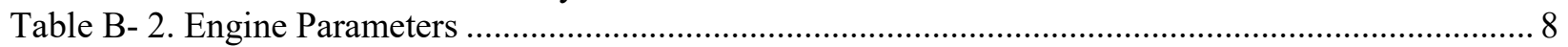

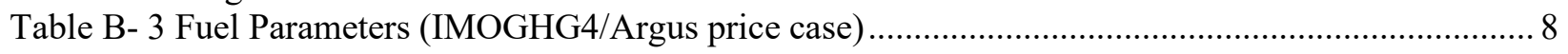

Table B- 4. Vessel Parameters (Base case) .................................................................................. 8

Table B- 5. Marine Fuel Prices (\$/MT) Based on Relationships to Other Prices ...................................... 9 


\begin{abstract}
This report aims to provide information for owners and operators of U.S. ocean-going marine cargo vessels on the cost of different approaches to compliance with the IMO mandate to reduce the sulfur content of marine fuels (outside emission control areas) to no more than $0.5 \%$. The IMO 2020 rule came into effect on January 1, 2020. The report discusses a suite of options for compliance including low-sulfur petroleum-based fuels and alternative fuels. Since fuel prices are a primary factor in determining the cost of the various alternatives, the document also includes a discussion of the main drivers of marine fuel prices. The cost analysis compares the average annual costs (capital and fuel) out to 2050 of each compliance approach under alternative scenarios regarding fuel prices, policy, and technology innovation. The cost calculations apply to representative U.S. fleet vessels for containership and tanker types. Even though the analysis focuses on average cost of approaches to comply with IMO 2020, the comparison of approaches also acknowledges other benefits or risks including fuel price risk and the contribution of the approach to addressing other potential environmental performance objectives or regulations.
\end{abstract}




\section{INTRODUCTION}

\subsection{PURPOSE}

The purpose of this report is to provide information for owners and operators of U.S. ocean-going marine cargo vessels on the cost and non-cost considerations of various IMO 2020-compliant fuel options for different vessel types and ages under multiple scenarios regarding key drivers of marine fuel prices and other economic parameters.

Fuel price is a salient consideration for shipowners because fuel cost typically represents about $30 \%$ of annual total shipping costs and $\sim 75 \%$ of voyage costs (Stoft, 2009; Wang et al., 2021). ${ }^{3}$ Technical, environmental, and social considerations are also important. Given the timeframe discussed in this report (2020-2050), long-lived capital investments in the shipping fleet and for bunkering infrastructure will also be influenced by IMO's GHG emission reduction strategy. The initial IMO strategy targets a reduction of carbon dioxide emissions per unit of transport work (carbon intensity), as an average across international shipping, of at least $40 \%$ by 2030 and $70 \%$ by 2050 as well as a reduction in total annual GHG emissions by at least 50\%, compared with 2008 levels (Resolution MEPC.304(72)).

\subsection{BACKGROUND}

The global sulfur limit of marine fuel oil became $0.5 \%$ on January $1^{\text {st }}, 2020$ (MARPOL Annex VI regulation 14). Also, several states have set more stringent domestic regulation. For example, IMO ratified emission control areas (ECAs) in the Baltic Sea, the North Sea, and North America; China has also established a domestic ECA. Compliance options include using low-sulfur petroleum-based fuels, installing an exhaust gas cleaning system (typically known as a scrubber), or switching to alternative fuels.

Many studies were conducted regarding the potential impact of the IMO 2020 sulfur regulation after the IMO confirmed its implementation in 2016. One aspect covered by these studies was the anticipated change in marine fuel mix post-IMO 2020. For instance, the International Transport Forum estimated a global marine fuel consumption of 3.9 million barrels (MMbbl) per day in 2020 of which $30 \%$ would be residual fuel oil and $70 \%$ would be marine gasoil, representing a demand shift of $2 \mathrm{MMbb1} /$ day from residual fuel oil into gasoil (International Transport Forum, 2016). Argus, a data and market intelligence provider, projected that the switch would be largely from high-sulfur fuel oil (HSFO) to marine gasoil (MGO) at least in the first few months of 2020 due to concerns about the stability and compatibility of the other main option, very low sulfur fuel oil (VLSFO) blends. ${ }^{4}$ Argus posited that it could take up to five years to reach a stable new level of HSFO consumption in the marine shipping sector with the level of the price spread between high and low-sulfur fuels determining the additional scrubber installations and refinery investments in residue destruction and desulphurization. ${ }^{5}$ For the United States, the U.S. Energy Information Administration (EIA) projected in its Annual Energy Outlook 2019 (AEO 2019) that the share of HSFO in the ocean-going bunker fuel markets would drop from 58\% in 2019 to $3 \%$ in 2020 , and

\footnotetext{
${ }^{3}$ The fuel cost shares in Stopford (2009) are for a 10-year-old Capesize bulk carrier under Liberian flag at 2005 prices. Total shipping costs include capital costs. Voyage costs are the variable costs incurred in a particular voyage. More recent estimates of the fuel cost share in total shipping costs developed for containerships in Wang et al. (2021) were in the same range. Nonetheless, fuel share of costs can vary significantly from ship to ship and over time depending on fuel price levels, vessel age, and vessel operations.

${ }^{4}$ https://www.argusmedia.com/en/blog/2019/august/14/imo-2020-navigating-the-transition-period

5 https://www.argusmedia.com/en/blog/2019/october/9/imo-2020-series-after-the-storm
} 
then rebound to $24 \%$ in 2022 as more vessels installed scrubbers. The share of low-sulfur residual fuel oil consumed in the U.S. bunker fuel market would increase from $38 \%$ in 2020 to $43 \%$ in 2025 and the marine distillate fuels would increase from $36 \%$ in 2019 to $57 \%$ in 2020 , and then decline to $29 \%$ by 2025 (EIA, 2019a).

Two major studies focused on the question of low-sulfur fuel availability and reached opposite conclusions. To decide on the implementation date of the $0.5 \%$ sulfur limit, the IMO hired consultants led by CE Delft for a fuel availability study. The study estimated the demand for marine fuels in 2020 and assessed whether the global refinery sector would be able to produce sufficient low-sulfur fuels by 2020 while meeting all other refined product demands. They concluded that demand could be met (CE Delft et al., 2016). However, the EnSys/Navigistics study, submitted to the IMO Marine Environment Protection Committee (MEPC) 70 by the International Petroleum Industry Environmental Conservation Association (IPIECA), the Baltic and International Maritime Council (BIMCO), Petroleum Association of Japan (PAJ), Fuels Europe/Concawe, and Canadian Fuels, claimed that refining capacity would not be sufficient (MEPC 70/5/5). One important difference between the two studies is their assumptions about the mix of low-sulfur fuels to be demanded. The EnSys/Navigistics study projected a higher share of distillate marine fuels than the CE Delft study which assumed a larger role for blended fuels (i.e., VSLFO).

Several estimates of the cost burden to ship operators due to compliance measures with IMO 2020 were also offered by analysts and shippers in the run up to 2020. The Coalition for Responsible Transportation reported an estimated $\$ 50$ to $\$ 60$ billion annual cost of IMO 2020 compliance across the entire shipping industry. Container lines projected that their annual fuel costs could increase by $\$ 12$ billion. Hapag Lloyd announced it expected its annual fuel bill to increase by $\$ 1$ billion per year based on an assumption of a $\$ 250 /$ ton spread between low-sulfur fuel and HSFO. Maersk stated that their annual fuel bill may increase by $\$ 2$ billion which would be approximately a $60 \%$ increase.

IMO 2020 was expected to have price impacts beyond bunker fuel markets. The International Energy Agency (IEA) estimated a 20\%-30\% increase in diesel prices as the demand for low sulfur marine fuels increased in early 2020. The Fuels Institute conducted a literature review of the impacts of IMO 2020 and found the estimates of price impacts to gasoline and diesel ranged from 25 to 75 cents per gallon, while most reports agreed that the impact would be short-lived lasting 2-3 years (Fuels Institute, 2019).

Many of these anticipated dislocations in marine fuel and other markets did not materialize as IMO 2020 came into force because shippers were able to obtain substantial quantities of VLSFO at lower cost than marine gasoil or other alternatives. This was due to a combination of effective planning by shippers, improved flexibility by refiners in producing low-sulfur blends, and the overlaying petroleum demand reductions and dislocations due to the COVID pandemic. On average, the VLSFO price was $25 \%-40 \%$ higher (equivalent to a $\$ 70 /$ ton-\$90/ton price differential) than the price of HSFO in major bunkering ports in 2020 (see Figure ES- 1). However, the low-sulfur fuels that have been adopted in 2020 to comply with the new sulfur limit increasingly appear as not sustainable options for the medium and long term. Low-carbon fuels for the shipping industry will be needed to achieve the IMO GHG reduction objectives. CE Delft (2021) examined the carbon dioxide $\left(\mathrm{CO}_{2}\right)$ emissions of the two major approaches being used for compliance with the IMO 2020 rule: scrubber and low-sulfur petroleum fuels. The study concluded that well-to-wake $\mathrm{CO}_{2}$ emissions increase by $1.5 \%-3 \%$ with the scrubber strategy and by at least $1 \%$ with the use of low-sulfur fuels. In the case of scrubbers, the additional emissions are related to the increased fuel use to operate them, emissions during the scrubber manufacturing process, and emissions from the ocean caused by the discharge of acidic water. With low-sulfur petroleum fuels, the increased emissions stem from the additional refinery operations required for their production.

The marine shipping industry is in the process of testing multiple alternative low-carbon fuels and there are competing views about the marine fuel mix by 2050. For instance, DNV (2019) puts forth a projected 
2050 marine fuel mix where the largest share (39\%) corresponds to carbon-neutral fuels, followed by $34 \%$ petroleum-based fuels, $23 \%$ liquefied natural gas (LNG), and $5 \%$ electricity. This mix would meet the IMO GHG reduction target of 50\% lower $\mathrm{CO}_{2}$ emissions (relative to 2008) in 2050. (IEA, 2021) foresees the shipping industry will not achieve the more ambitious objective of net zero emissions by 2050 due to the lack of available low-carbon fuel options in the market today and the long operational life of vessels. Under "the most technically feasible, cost-effective, and socially acceptable" pathway to net zero emissions identified in IEA's modeling, $80 \%$ of marine fuels are still petroleum-based by 2030 and the mix is completed with bioenergy, ammonia, and small market shares of gas and hydrogen. By 2050 , ammonia would become the most consumed marine fuel (about 45\%), followed by bioenergy (20\%), with the rest equally divided between oil and hydrogen.

The 2050 marine fuel mixes in the DNV and IEA reports differ greatly from the actual fuel mix of the global fleet in 2018, described in detail in the Fourth IMO GHG Study (IMO GHG4). Table 1 summarizes the global marine fuel volumes consumed across international shipping, domestic shipping, and fishing fleets for 2012-2018, based on the bottom-up voyage-based estimation method. The IMO studies group all residual fuels into the general label of HFO and all distillates into the general label of MDO. HFO use decreased by $3.5 \%$ from 2012 to 2018 whilst MDO and LNG use increased ( $41 \%$ and $23.4 \%$ respectively) over the same period. Methanol is a new entrant fuel in the inventory with no use recorded until 2015 and growing to 160,000 tons by $2018 .{ }^{6}$

The international shipping segment accounts for $95 \%$ of LNG consumed for marine transportation, $84 \%$ of HFO consumption, $81 \%$ of methanol consumption and $37 \%$ of MDO consumption. ${ }^{7}$ In 2018 , less than $2 \%$ of global fuel oil sales had sulfur content below $0.5 \%$ (IMO, 2019d), which clarifies that the use of ULSFO for ECA compliance is small. ${ }^{8}$

Table 1. Energy consumption (international shipping, domestic shipping, and fishing) by fuel type (million tons)

\begin{tabular}{|c|c|c|c|c|c|c|c|}
\hline Fuel type & 2012 & 2013 & 2014 & 2015 & 2016 & 2017 & 2018 \\
\hline HFO & 230.99 & 224.7 & 222.57 & 208.48 & 218.73 & 226.74 & 223.05 \\
\hline LNG & 8.94 & 9.17 & 9.01 & 8.23 & 8.54 & 9.96 & 11.44 \\
\hline MDO & 67.91 & 72.28 & 76.78 & 99.51 & 100.34 & 102.93 & 102.99 \\
\hline Methanol & 0 & 0 & 0 & 0.02 & 0.13 & 0.16 & 0.16 \\
\hline $\begin{array}{l}\text { Total bottom-up } \\
\text { estimate }\end{array}$ & 308.80 & 307.21 & 309.57 & 318.20 & 329.63 & 341.58 & 339.27 \\
\hline
\end{tabular}

Table 2 displays fuel mix shares. It shows that the percentages of energy consumption of different fuel types were stable from 2015 to 2018 . HFO accounted for $66 \%$ and MDO accounted for $30 \%$ of marine fuel use during that period.

Table 2. Energy consumption (international shipping, domestic shipping, and fishing) by fuel type (percentage)

\begin{tabular}{|c|c|c|c|c|c|c|c|}
\hline Fuel type & 2012 & 2013 & 2014 & 2015 & 2016 & 2017 & 2018 \\
\hline HFO & $75 \%$ & $73 \%$ & $72 \%$ & $66 \%$ & $66 \%$ & $66 \%$ & $66 \%$ \\
\hline LNG & $3 \%$ & $3 \%$ & $3 \%$ & $3 \%$ & $3 \%$ & $3 \%$ & $3 \%$ \\
\hline MDO & $22 \%$ & $24 \%$ & $25 \%$ & $31 \%$ & $30 \%$ & $30 \%$ & $30 \%$ \\
\hline Methanol & $0.000 \%$ & $0.000 \%$ & $0.000 \%$ & $0.006 \%$ & $0.039 \%$ & $0.047 \%$ & $0.047 \%$ \\
\hline $\begin{array}{l}\text { Total bottom-up } \\
\text { estimate }\end{array}$ & $100 \%$ & $100 \%$ & $100 \%$ & $100 \%$ & $100 \%$ & $100 \%$ & $100 \%$ \\
\hline
\end{tabular}

\footnotetext{
${ }^{6}$ See Table 9 fuel type allocation in the IMO GHG4 study.

${ }^{7}$ See Table 34 of IMO GHG4 study.

${ }^{8}$ See Page 87 of the IMO GHG4 study.
} 
The IMO GHG4 study compares the bottom-up energy consumption estimates shown in Table 1 with topdown estimates reported by IEA. ${ }^{9}$ Marine fuel use estimates from the bottom-up approach are greater than those from the top-down method, but top-down values are within the range of the error bars of the bottom-up approach results.

If no new policies are adopted, GHG emissions are projected to increase from about $90 \%$ of 2008 emissions in 2018 to $90 \%-130 \%$ of 2008 emissions by 2050 for a range of plausible long-term economic and energy scenarios. Though the IMO GHG reduction initial strategy will be adjusted, the short- and medium-term reduction measures include fuel efficiency improvements through speed reduction and energy-saving technologies. Medium- and long-term strategy measures will rely on fuel substitution with lower-carbon alternative fuels. These potential GHG reduction measures may impact fuel selections of the world and U.S. fleets, and could interact with fuel and technology responses to the IMO 2020 rule.

\subsection{ORGANIZATION OF THIS REPORT}

Chapter 2 describes marine fuels that can be used to comply with the IMO 2020 rule. Section 2.1 summarizes relevant properties of each of the fuels. Section 2.2 presents available pricing information for the set of fuels currently used and price projections from published technoeconomic analyses for alternative, low-carbon selected fuels. Chapter 3 presents U.S. fleet characteristics and a baseline estimate of fleet fuel consumption based on vessel characteristics and aligned with fuel mix estimates from the IMO GHG4 study. These sections provide the basis for analyzing a shift to IMO 2020 compliant and possibly lower-carbon fuels. Chapter 4 discusses the factors (price and non-price) entering shippers' fuel decisions. Chapter 5 examines key factors that may drive future marine fuel prices. Chapter 6 presents marine fuel cost scenarios built around alternative futures for oil price and environmental policy. Conclusions are presented in Chapter 7.

\section{MARINE FUELS COMPLIANT WITH IMO 2020 RULE}

This section summarizes the fuel properties of a range of fuels that can be used to comply with the IMO 2020 rule. Apart from the petroleum-based fuels used by most of the world fleet today (HSFO plus scrubbers, VLSFO, MGO and MDO), the analysis includes LNG, multiple biofuels, methanol, and ammonia.

\subsection{FUEL PROPERTIES}

\section{Marine Fuel Categories and the ISO 8217 Standard}

For hydrocarbons from petroleum, synthetic, or renewable resources and their blends, the ISO 8217 standard (2017 edition) specifies the requirements for fuels used in marine diesel engines and boilers (prior to onboard treatment). Key fuel properties include cold flow performance, stability, viscosity, acid number, flashpoint, ignition quality, and catalyst fines. The fuel is classified as a distillate or a residual fuel depending on whether it was produced through distillation or accrued as a residue in the oil refinery. Residual fuels are divided into six fuel types depending on their kinematic viscosity-RMA, RMB, RMD, RME, RMG, and RMK. Large kinematic viscosity values such as $700 \mathrm{~mm}^{2} / \mathrm{s}$ describe very viscous residue fuels. The lower the kinematic viscosity value, the thinner the fuel. As a rule of thumb, the lower

\footnotetext{
${ }^{9}$ The bottom-up method derives estimates of energy consumption from data sources describing shipping activity. The primary source of vessel activity data used is the Automatic Identification System (AIS). The top-down approach is based on statistical data derived from fuel delivery reports.
} 
the viscosity, the higher the quality of the marine fuel. Residual fuels are used in large, medium to slowspeed marine engines. Vessels usually use intermediate fuel oil (IFO) 380 with the ISO 8217 designation RMG 380 or RMK 380 if not in an ECA. Marine distillate fuels are divided into seven types: DMX, DMA, DFA, DMZ, DFZ, DMB, and DFB. ${ }^{10}$ Marine diesel oil (MDO) is categorized as a distillate (DMB), allowed to have traces of residual fuel, and marine gasoil (MGO) is categorized as DMA. Table A-1 in Appendix A matches fuel categories in this report to ISO 8217-2017 fuel standards.

\subsubsection{Petroleum-based residual fuels}

\subsubsection{High Sulfur Fuel Oil (HSFO) plus Scrubbers}

Table A- 2 in Appendix A summarizes the properties of HSFO. HSFO plus sulfur scrubbers may be an economically attractive option to comply with the IMO 2020 sulfur rule if the discount in HSFO price relative to VLSFO is sufficiently large to compensate for the costs of installation and operation of the scrubber. The challenges include the high cost of scrubber installation, disposal of the sulfur-rich wash water, and a shortage of onshore facilities to handle it. Additionally, scrubbers may not represent a viable long-term option to comply with other environmental regulations. The Swedish Environmental Research Institute conducted a comprehensive study which shows that discharge water from scrubbers will have serious consequences for the marine ecosystem (MEPC 75/INF.10). For these reasons, in our IMO 2020 compliance scenarios in Section 6 we do not consider HSFO with scrubber as a candidate option for future new vessels but consider HSFO with scrubber retrofit as a compliance option for existing vessels.

\subsubsection{Very Low Sulfur Fuel Oil (VLSFO)}

VLSFO must meet the ISO 8217:2017 specifications to be commercialized. More specifically, the default assumption is that VLSFO is a residual fuel that meets RMG 380 specifications. ${ }^{11}$ However, within fuels compliant with the ISO 8217 specifications and having no more than $0.5 \%$ sulfur, some of the fuel properties can span wide ranges (e.g., viscosity). Price reporting agencies are addressing the variations in viscosity in different ways in their price assessment methodologies. S\&P Global Platts added a requirement of a minimum viscosity of $30 \mathrm{cst}$ at 50 degrees Celsius to the specifications of Marine Fuel $0.5 \%$ bunker considered for its daily price index. Price assessments of VLSFO by Argus are for a viscosity of 380 cst in most ports, with the rest either being $180 \mathrm{cst}$ or of unspecified viscosity in the few ports where this attribute varies most widely.

The IMO 2020 sulfur cap has driven the transition to VLSFO. Refineries can use a variety of recipes to produce this blended fuel. As a result, there have been significant variances in the composition of VLSFOs in its first year of widespread utilization. The differences in composition make proper fuel handling practices essential to avoid mixing batches that could be incompatible anywhere along the fuel lines and storage tanks. In the first quarter of 2020, some ports (Antwerp, Busan) had more than 10\% of VLSFO samples off-spec ISO 8217 with respect to a variety of parameters (catalytic fines, pour point, acid number), but the percentage of off-spec samples declined rapidly after the first few months. ${ }^{12}$ The most common problems are marginal exceedance of sulfur and high total sediment potential which have resulted in increased sludge formation in purifiers and filters but have not led to major breakdowns or

\footnotetext{
${ }^{10}$ Dieselnet: https://dieselnet.com/standards/us/fuel.php

${ }^{11}$ https://ibia.net/2021/03/18/vlsfo-fact-vs-fiction/

12 Data from samples analyzed through Bureau Veritas VeriFuel program.
} 
engine damage in most cases. ${ }^{13}$ On the other hand, one positive attribute of VLSFO is that it has slightly higher energy content than HSFO.

The supply of VLSFO at ports proved larger than expected beforehand. The 70 reports on non-availability in the IMO GISIS system from January to July of 2020 are much less than what was expected. Most of these 70 non-availability reports are about HFO and MGO supply failure: 50 report HFO non-availability, 16 report MGO non-availability, and 1 is about MDO non-availability (MEPC 75/5/Add.1).

Though VLSFOs meet the IMO 2020 mandated 0.5\% global sulfur limit, there are some issues regarding VLSFO fuel quality and environmental effects. Several proposals, claiming it to result in very significant increases in black carbon emissions from ships due to high content of aromatics, called on IMO to stop the use of blended VLSFO, especially in or near the Arctic (PPR 7/8, MEPC 75/5/5, MEPC 75/5/4). The International Chamber of Shipping argued that the aromatic content and estimated cetane number of VLSFOs were issues that needed to be considered (MEPC 75/5/6). IPIECA and the International Bunker Industry Association (IBIA) contended that the study of PPR 7/8 was based on flawed assumptions about VLSFO blends and argued that initial data contrarily suggested that VLSFOs are more paraffinic than HSFO (MEPC 75/5/7).

\subsubsection{Petroleum-based distillate fuels}

Marine gasoil (MGO) and marine diesel oil (MDO) have very similar ISO 8217 specifications (see details in Table A- 3 and Table A- 4 of Appendix A). The only differences are that 1) MDO specification allows a wider range of viscosities, slightly higher density, slightly higher pour point, and higher sulfur content than MGO, and 2) there is a constraint on carbon residue for MGO but not for MDO. In both cases, the IMO 2020 sulfur rule is a more stringent constraint on sulfur content than what is allowed in the ISO 8217 specification.

\subsubsection{LNG}

LNG is natural gas-a complex mixture of hydrocarbons and non-hydrocarbons with methane as its primary ( $70 \%-99 \%$ by volume) constituent-that has been cooled to a liquid state. The liquefied gas has a volume 600 times lower than in its gaseous state enabling long-distance transportation routes that are not viable by pipeline. LNG has a boiling point of $-161^{\circ} \mathrm{C}$, liquid density of $426 \mathrm{~kg} / \mathrm{m}^{3}$, gas density at $25^{\circ} \mathrm{C}$ of $0.656 \mathrm{~kg} / \mathrm{m}^{3}$, and specific gravity at $15^{\circ} \mathrm{C}$ of 0.554 . Its flammability limits (in air by volume) range from $5 \%$ to $15 \%$ and its auto ignition temperature is $595^{\circ} \mathrm{C}$ (Girdhar, 2018). The heating value of LNG is about $49 \mathrm{MJ} / \mathrm{kg}$ (Lundgren and Wachsmann, 2014), 20\% higher than HSFO.

An increasing number of newly built ships are powered either by natural gas exclusively or by a combination of conventional diesel and natural gas. Advantages of LNG include lower operating cost, a reduction of sulfur and particulate matter emissions to levels that meet current standards in ECAs, and an increase in power system efficiency (Livanos et al., 2014). Challenges include high investment costs, need for additional handling safety measures, methane slip, and storage issues (boil-off releases of methane, degradation or change in gaseous mix over time). Due to heat entering the LNG tank, a fraction of the stored LNG evaporates in the form of boil-off gas. Since the more volatile fractions of LNG boil off first, the composition and quality of stored LNG changes over time ("LNG ageing"). Boil-off gas must be proactively managed to maintain tank pressure within a safe range (Dobrota et al., 2013). In volume

\footnotetext{
${ }^{13}$ http://www.gard.no/web/updates/content/30350874/imo-2020-a-review-of-the-transition-to-vlsfos
} 
terms, LNG tanks need to be $80 \%$ bigger than those for HSFO. This space requirement imposes an opportunity cost, particularly for containerships.

Lack of bunkering infrastructure is one of the major barriers to LNG adoption, though natural gas infrastructure is growing. As of December 2020, 124 ports provide LNG re-fueling infrastructure, increasing from 114 from the beginning of the year, and the number may be 170 at the end of $2022 .{ }^{14}$ As for bunkering operations, DNV (2014) identifies and evaluates four potential alternatives: truck to ship, shore to ship, ship to ship, and portable tank transfer.

The lifecycle GHG emissions of LNG as bunker fuel can vary significantly depending on engine type and fuel lifecycle (natural gas transportation mode and traveled distance, liquefaction technology). While using LNG as marine fuel results in lower $\mathrm{CO}_{2}$ emissions than using marine distillates, emissions of methane-a greenhouse gas with higher global warming potential than $\mathrm{CO}_{2}$ over a 100 -year period-are higher for LNG. Achieving a reduction in well-to-wake net GHG emissions with LNG versus marine distillates requires minimizing methane leakage in the upstream stages (well to tank) and minimizing methane slip in the downstream stages (tank to wake) (Thomson et al., 2015). The methane slip problem practically disappears for modern two-stroke engines (about $0.01 \%$ leakage in low-speed two-stroke highpressure engines vs. $6.9 \%$ in medium-speed 4 -stroke low pressure engines), but the complex fuel gas supply system they require may increase engine costs by about $40 \%$ compared to medium-speed fourstroke engines (Sharafian et al., 2019).

\subsubsection{Biofuels}

Biofuels have very low sulfur content and many of them can be used in marine diesel engines without requiring modification, which makes them an attractive option for compliance with the IMO 2020 sulfur cap. Additionally, they offer potential synergistic benefits when blended with petroleum fuels by improving overall lubricity, and potentially lowering ash and emission profiles (Tan and Tao, 2019). Biofuels have higher energy density than other alternative fuels and offer the potential for large reductions in greenhouse gas emissions. However, the extent of the reduction varies widely across combinations of feedstocks and conversion pathways. Feedstocks that do not compete with land for agricultural purposes are preferable from a sustainability perspective. These include agricultural and forestry residues, municipal solid waste, and energy crops that can be grown on marginal land such as switchgrass.

Next, we discuss in more detail six liquid biofuels of interest: biodiesel, renewable diesel, BTL, bio-oil, bio-crude, and lignin ethanol oil.

Biodiesel is a fuel comprised of mono-alkyl esters of long chain fatty acids derived from vegetable oils or animal fats via transesterification, designated B100 as in the biodiesel standard ASTM D 6751, and the EN 14214 standard in Europe referring to FAME (Fatty Acid Methyl Esters) (Knothe, 2010). Biodiesel can be applied in diesel engines as B100 or in blend fuels without engine modification. With the latest revision of the ISO 8217 standard in 2017, blends of up to 7\% FAME by volume are allowed in specific marine distillate grades as DF (Distillate FAME) grades (Tyrovola et al., 2017).

Biodiesel has proven to increase lubrication, reduce engine wear and extend engine life cycle (Mohd Noor et al., 2018). Its flashpoint is higher than that of petroleum diesel, making biodiesel less flammable, safer to handle, and easier to store. However, biodiesel also presents several challenges for its use as marine fuel. Biodiesel price is higher than that of petroleum diesel and, depending on the biomass feedstock used

${ }^{14} \mathrm{https}: / /$ safety4sea.com/wp-content/uploads/2021/02/LNG_2021_A_view from the bridge FINAL.pdf 
to produce it, can fall into the food-versus-fuel debate. Biodiesel has $12 \%$ less energy content than petroleum diesel and emits more nitrogen oxide $\left(\mathrm{NO}_{\mathrm{x}}\right)$ during combustion (Atabani et al., 2012). High viscosity and density sometimes create problems to the fuel injection system (Tesfa et al., 2010). Higher cloud and pour point may cause solidification in cold weather and cause clogged filter and fuel lines that lead to engine system damage. Oxidation and degradation may happen over time and form deposits in piping and engines. Bacteria and mold may grow if condensed water accumulates in the biodiesel fuel. Biodiesel can deteriorate natural rubber materials such as hoses and seals. Some of these challenges can be addressed through current and future research.

Renewable diesel is produced by applying a hydrotreating process known as fatty acids-to-hydrocarbon hydrotreatment to vegetable oil. ${ }^{15}$ The production process is usually more expensive than FAME biodiesel. Because it is hydrogenated, renewable diesel does not contain oxygen, and therefore users will not encounter the challenges biodiesel presents relating to storage and performance in freezing temperatures. It also burns cleaner than biodiesel. Renewable diesel meets conventional diesel fuel requirements, such as ASTM D975 specification for petroleum in the United States and EN 590 in Europe except for some low limits of density (Lindfors, 2010). Because it has the same chemical structure as petroleum diesel, renewable diesel can leverage existing infrastructure for delivery and storage and be used in conventional diesel engines with no blending required. Renewable diesel is in production at commercial scale. The U.S. renewable diesel production capacity surpassed 1 million gallons a day in 2020, with most of it (along with some imports), being used to meet the requirements of the California Low Carbon Fuel Standard. Beyond the hydrotreated fats, oils, and greases that make most of the renewable diesel used today, it can also be produced through catalytic upgrading from other feedstocks like algae and wood extractives (Hsieh \& Felby, 2017).

Biodiesel and renewable diesel result from applying additional processing steps - transesterification or hydrotreating, respectively - to the vegetable oil extracted from the crops. Straight vegetable oils (SVOs) without any further processing steps can also be used as marine fuel. They can replace MDO or HSFO in low speed engines due to similar properties, but they are not recommended for long-term use as they may cause carbon deposits and engine damage (Hsieh and Felby, 2017).

BTL (biomass to liquid fuels) is a multi-step process to convert biomass into synthetic hydrocarbon fuels via gasification. BTL processes involve the high temperature gasification of biomass for the production of syngas and the subsequent chemical synthesis of liquid green diesel through the FischerTropsch process (Douvartzides et al., 2019). BTL should meet the specifications contained in EN 15940 for paraffinic diesel fuels and EN 16709 (Engman et al., 2016). BTL-diesel's cetane number can reach up to 75 , much higher than conventional diesel. Creating a clean and stable enough bio-syngas through gasification at commercial scales remains a bottleneck. The required investment for commercial scale biomass gasification Fischer-Tropsch plants is high in relation to that for other biofuel technologies. Tan \& Tao (2019) present a technoeconomic analysis of a gasification and Fischer-Tropsch process using biomass or co-feeding biomass with coal or natural gas. The minimum fuel selling price per gallon of gasoline equivalent (gge), using $\mathrm{n}^{\text {th }}$ plant financing and operation assumptions, is $\$ 3.79 /$ gge for the coalbiomass co-feed, $\$ 2.99 /$ gge using only biomass, and $\$ 2.37 /$ gge for the case in which biomass is co-fed with natural gas.

Fast pyrolysis bio-oil, also known as fast pyrolysis oil, is produced through thermal decomposition of biomass (Douvartzides et al., 2019). It consists of an emulsion with $20 \%-30 \%$ water. The high oxygen content leads to low $\mathrm{pH}$ values, which makes the fuel acidic and corrosive, with low heating values and high viscosities (Chong and Bridgwater, 2017), making it difficult to use it as drop-in transportation fuel. For the marine sector, testing is being conducted for blends of bio-oil and other biofuels or petroleum

\footnotetext{
${ }^{15}$ It is also known as hydrotreated vegetable oil (HVO) in some of the literature.
} 
fuels. Galindo et al. (2020) test blends of bio-oil, ethanol, and MGO. They find that a 10:60:30 blend of those three components is closest in its properties to MGO out of all the blends considered, but the large fraction of ethanol results in a lower flashpoint than needed for a marine fuel. Kass et al. (2021) present promising results from tests of blends of bio-oil and VLSFO, with bio-oil lowering the viscosity of VLSFO, offering excellent combustion properties, and displaying good compatibility with infrastructure metals. Pyrolysis oil production is still in the early stages of development and being used for small-scale power and heat generation.

Biocrude is produced through hydrothermal liquefaction of biomass at moderate temperature and high pressure. Unlike the pyrolysis process, hydrothermal liquefaction can use wet feedstocks (e.g., algae, wet waste). Another advantage of bio-crude over bio-oil is its higher energy content (Hsieh \& Felby, 2017). Blending VLSFO with bio-crude lowers its viscosity and maintains good combustion properties, but additives will likely be required to improve the stability of the blend (Kass et al., 2021).

Lignin ethanol oil has been identified as another promising biofuel for marine applications. It results from a solvolysis process that uses sulfur-free lignin as feedstock and ethanol as organic solvent (Nielsen et al., 2017). ${ }^{16}$ The resulting bio-oil could be blended with other marine fuels or used as drop-in (Hsieh \& Felby, 2017). A group of shippers and their customers is working on development of this fuel which has been validated at laboratory scale but requires tests on vessel engines as the next step toward commercialization. ${ }^{17}$

Ethanol is commercially available and widely used in light-duty vehicle road transport. Future multi-fuel marine engines could potentially use ethanol, but it is not compatible with existing marine diesel engines. For that reason, ethanol has greater promise as a marine fuel in blends, such as lignin ethanol oil.

In summary, there are many bio-based options under active evaluation for marine fuels. Most of them require additional research and development investment to drive down their costs toward competitiveness with petroleum-based fuels. Apart from the ones discussed in this section, biogas and bio-based methanol can also be used to replace fossil-based LNG and methanol for additional reductions in GHG emissions. Some of the considerations to narrow down the list of candidate biofuels for specific shippers today include whether or not they are already commercially available and whether they are drop-in fuels or suitable for blending with either residual marine fuels or distillates. Zhou et al (2020) explain that today there are more biofuel alternatives for MGO/MDO (e.g., biodiesel, renewable diesel) than for marine residual fuels because bio-based diesel substitutes are already being used for road transportation. These bio-based distillate fuels could also replace marine residual fuels, but they are higher quality than needed for vessels that have been previously operated on HSFO and, therefore, also more expensive.

\subsubsection{Other Alternative Fuels}

Other alternative fuels for marine use include hydrogen, methanol, ammonia, and electricity (batterypowered). Hydrogen as a marine fuel has zero emissions during combustion and has gravimetric energy density (energy per unit mass) three times that of HSFO (Kim et al., 2020). Though hydrogen can be used in gas turbines and internal combustion engines, the efficiency is low. It is more suitable for use in a fuel cell due to its electrochemical kinetics (Perčić et al., 2020). A key barrier to the use of hydrogen as marine

\footnotetext{
${ }^{16}$ Lignin is the main byproduct from second-generation ethanol production and has typically been combusted for heat and power at the refinery which is a very low-value use. Lignin valorization is an area of great interest to improve the economics of advanced biorefineries.

${ }^{17}$ https://www.maersk.com/news/articles/2019/10/29/maersk-join-forces-with-industry-peers-and-customers-todevelop-leo
} 
fuel is its very low volumetric energy density (energy per unit volume) and resulting special, typically high-pressure, storage requirements. Other challenges include its high flammability, very high production costs, and lack of bunkering infrastructure (Van Biert et al., 2016, Kim et al., 2020). Still, it is a pathway supporting deep decarbonization, and there are three newbuild orders using hydrogen according to Clarksons Research (Offshore Energy).

Methanol is an ideal fuel for use in spark ignition engines, on its own or blended with gasoline, particularly due to its high octane numbers (Dierickx et al., 2018). Its high auto-ignition temperature (470 ${ }^{\circ} \mathrm{C}$ ) and low cetane number ( 3), make it ill-suited for compression ignition (Yao et al., 2017). However, there are multiple strategies to retrofit marine diesel engines for methanol use: changing compression ignition to spark ignition, using combustion improvers, or installing a pilot fuel injection system (Ming and Chen, 2021).

Drawbacks of methanol include a lower heating value of $19.9 \mathrm{MJ} / \mathrm{Kg}$, about half of petroleum-based fuels. Thus, for an equivalent energy content, the space needed for storing methanol in a tank will be approximately twice that of traditional diesel fuels (Lundgren and Wachsmann, 2014). Safety concerns also exist to use methanol in a marine environment since it is flammable with a low flashpoint and it is considered toxic (Lundgren and Wachsmann, 2014).

Methanol as a marine fuel offers large reductions in well-to-propeller emissions of NOx, SOx, and particulate matter relative to residual fuel oil. However, well-to-propeller $\mathrm{CO}_{2}$ methanol emissions are only significantly lower than those of residual fuel oil and LNG if the methanol is produced with renewable feedstocks such as forest residue or landfill gas (Corbett and Winebrake, 2018).

Ammonia as a marine fuel is a less technically mature option than either LNG or methanol, but it is viewed as a promising candidate for zero-carbon fuel in the marine sector. An ammonia-powered ship would emit no $\mathrm{CO}_{2}$ and lifecycle emissions can be close to zero if ammonia is produced using renewable hydrogen (or if the emissions from conventional hydrogen production processes are captured and stored). Even though hydrogen could be itself a marine fuel, the additional step in a Haber-Bosch process to turn it into ammonia is advantageous enough to make it a more appealing alternative. Ammonia has higher energy density than hydrogen, it is easier to transport, and can be stored at lower pressure and higher temperature than liquefied hydrogen (Kim et al., 2020).

Ammonia marine engines are not available today. However, MAN is developing a two-stroke engine and Wartsila a four-stroke engine to use this fuel. The first installations of these new engine models could take place by $2024 .{ }^{18}$ As in the case of methanol, global infrastructure for distribution of ammonia is already available and many ports have ammonia terminals. Nonetheless, bunkering infrastructure availability would require additional capital investment.

Even with green ammonia and suitable engines, drawbacks to the use of ammonia as marine fuel include its toxicity (can be lethal for exposures at high concentrations), its low volumetric energy density which results in requirements for larger storage tanks, corrosion issues for some materials, and the need for a pilot fuel to help ignition. Additionally, ammonia vessels with combustion engines would have emissions of $\mathrm{NO}_{\mathrm{x}}$ upon combustion which are harmful for human health and the environment. These emissions can be mitigated with after-treatment systems or using fuel cells instead of combustion engines; both solutions entail higher capital costs.

The advantages of electricity from batteries include zero tank-to-wake emissions, higher efficiency than a diesel generator, lower noise and vibration, and low operating cost (if electricity prices are low).

\footnotetext{
${ }^{18}$ https://cen.acs.org/business/petrochemicals/ammonia-fuel-future/99/i8
} 
However, the gravimetric energy density (energy per unit of mass) is 150 times lower than diesel and the volumetric density is 100 times lower than diesel (Kim et al., 2020). There are 141 vessels in the global fleet with battery hybrid and 109 new orders (Offshore Energy).

\subsection{PRICE AND UTILIZATION}

Table 3 shows the estimated future fuel costs in 2030 and 2050 reported in the IMO GHG4 study for a range of existing and potential marine fuels. We summarize these projected prices in Table 3 for comparison with actual pricing data presented in the rest of this section.

Table 3. Future Fuel Costs in 2030 and 2050 from IMO GHG4 Study (unit: \$/ton)

\begin{tabular}{lll}
\hline Fuels & $\mathbf{2 0 3 0}$ & $\mathbf{2 0 5 0}$ \\
\hline HFO & 375 & 375 \\
\hline LNG & 590 & 590 \\
\hline Hydrogen & 3,300 & 3,300 \\
\hline Ammonia & 660 & 660 \\
\hline Methanol & 400 & 400 \\
\hline Ethanol & 670 & 670 \\
\hline Synthetic LNG & & 4,500 \\
\hline Biomass LNG & & 2,250 \\
\hline Synthetic methanol & & 1,500 \\
\hline Biomass methanol & & 800 \\
\hline Synthetic ethanol & & 2,600 \\
\hline Biomass ethanol & & 1,300 \\
\hline
\end{tabular}

Source: IMO 4th GHG Study

\subsubsection{Petroleum-based fuels}

Figure 1 shows the observed prices for HSFO with 3.5\% sulfur content and VLSFO with $0.5 \%$ sulfur content from April 2019 to November 2020 in three ports/regions: Hong Kong, Northwest Europe (NWE), and U.S. Gulf Coast (USGC). 


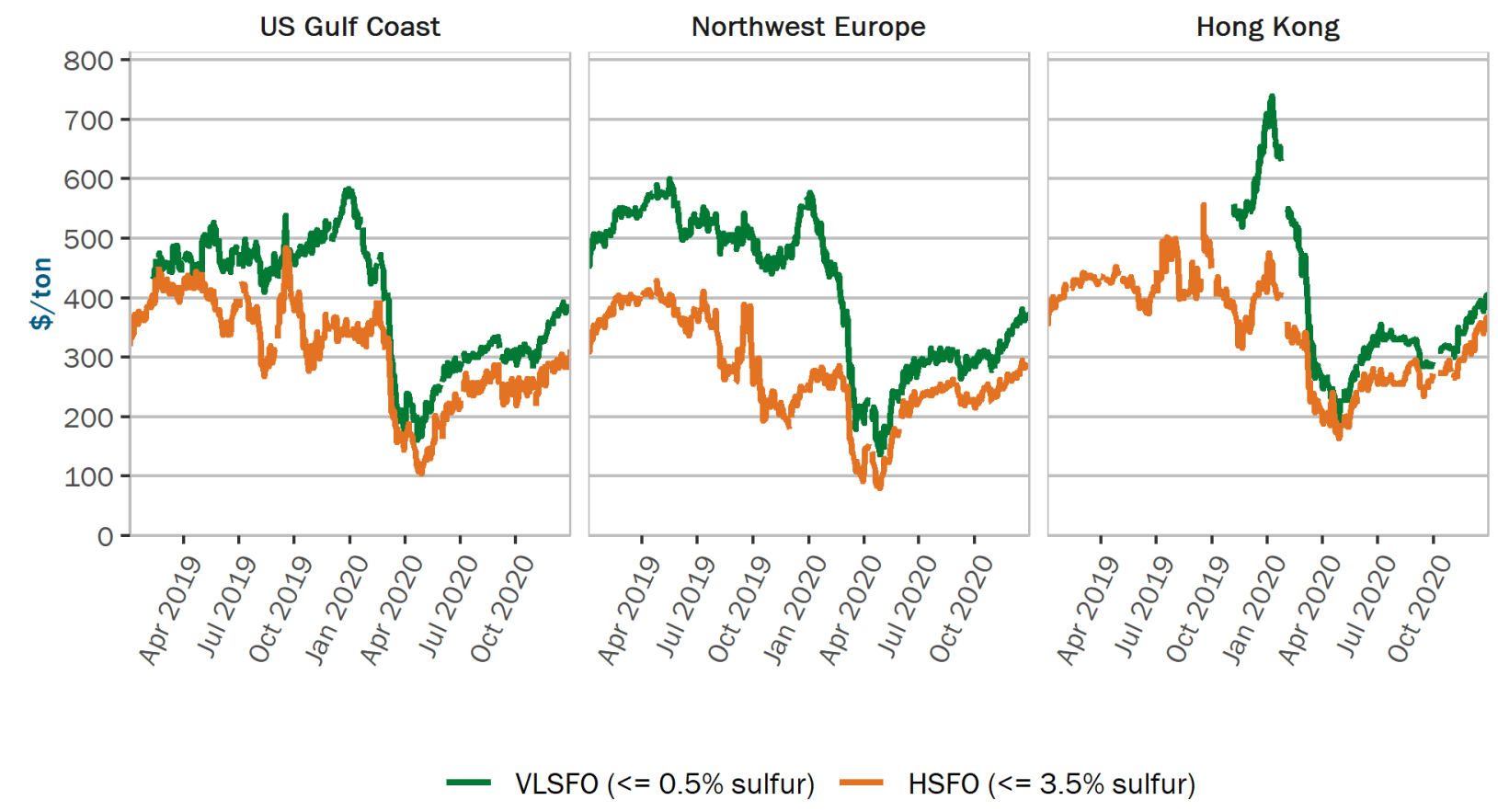

Figure 1. Price of heavy sulfur fuel oil and very low sulfur fuel oil in selected regions (2019-2020)

Source: Argus

Notes: All fuels have the same viscosity (380 cst). USGC prices are fob (VLSFO 0.5\%) or fob ex-wharf (HSFO 3.5\%), NWE prices are barge prices, Hong Kong prices are delivered on board.

The average HSFO price in 2019 was $\$ 330 /$ ton in NWE, \$375/ton in the USGC, and \$418/ton in Hong Kong. Prices for the low sulfur fuel started being reported at different points of 2019 in these ports. During the first three quarters of 2019, the VLSFO to HSFO differential averaged \$76/ton in the USGC and \$164/ton in NWE. In the last quarter of 2019, as the transition from HSFO to VLSFO gradually unfolded and amid concerns about unavailability of VLSFO, the average differential increased to $\$ 168 /$ ton in the USGC and \$255/ton in NWE. In November-December, the average differential stood at \$200/ton in Hong Kong.

In both USGC and NWE, the VLSFO to HSFO differential peaked on January 3 of 2020 at \$241/ton and $\$ 323 /$ ton, respectively; for Hong Kong the peak differential was $\$ 300 /$ ton on December 30 of 2019. In all three regions, the differential declined over the first quarter of 2020 averaging at $\$ 104 /$ ton in USGC, $\$ 171$ ton in NWE, and \$159.68/ton in Hong Kong. From April through the end of November 2020, as petroleum product demand and prices plummeted due to the COVID pandemic, the differential stabilized at even lower levels: \$60/ton in USGC, $\$ 61 /$ ton in NWE, and \$48/ton in Hong Kong. These values are much lower than had been expected making the HSFO plus scrubber option for compliance with the IMO 2020 rule less attractive and resulting in some delays and cancellations of scrubber orders. By March 2020 , DNV estimates the number of scrubbers installed was approximately $4,000 .{ }^{19}$

\footnotetext{
${ }^{19}$ https://www.manifoldtimes.com/news/dnv-gl-estimates-4000-vessels-to-be-equipped-with-scrubbers/
} 
Petroleum-based marine fuel prices generally move together across regions and fuels and are linked to developments in the crude oil markets. For instance, the correlation between the HSFO prices in Figure 1 was $81 \%$ for the NWE-Hong Kong pair, $89 \%$ for the USGC-NWE pair, and $91 \%$ for the USGC-Hong Kong pair. Strong spatial price co-movement is a key attribute of the crude oil market that leads to the idea of a "one great pool" globally for crude oil. This linkage of price movements is also present in crude oil products. Li and Yip (2019) measure volatility spillovers, that is the transmission of price fluctuations from one region or fuel to another, in marine fuel markets. They use monthly IFO 380 price data for 12 markets (Singapore, Hong Kong, Japan, and South Korea in Asia; Rotterdam, Gibraltar, Genoa, and Fujairah in Europe; Houston, Philadelphia, Panama and Los Angeles in America) from January 2008 to May 2017. They find that the total volatility spillover index is approximately $70 \%$ in the three regions. This means that $\sim 70 \%$ of total price volatility in each region spills over from market shocks and news originated in other ports in the region, with the degree of transmission declining as geographical distance increases. Singapore, Rotterdam, and Houston transmit more volatility than they receive which makes them the central hubs in their respective regions. The total volatility spillover index among these three central hubs is $65 \%$ with Singapore being the only net transmitter of volatility among the three.

Figure 2 shows the price series of a larger set of marine fuels in Northwest Europe. Besides HSFO with $3.5 \%$ sulfur and VLSFO ( $<0.5 \%$ sulfur $)$, it includes the prices of a more viscous HSFO and the marine gasoil with $0.1 \%$ sulfur that is needed for navigation through the ECA in that region.

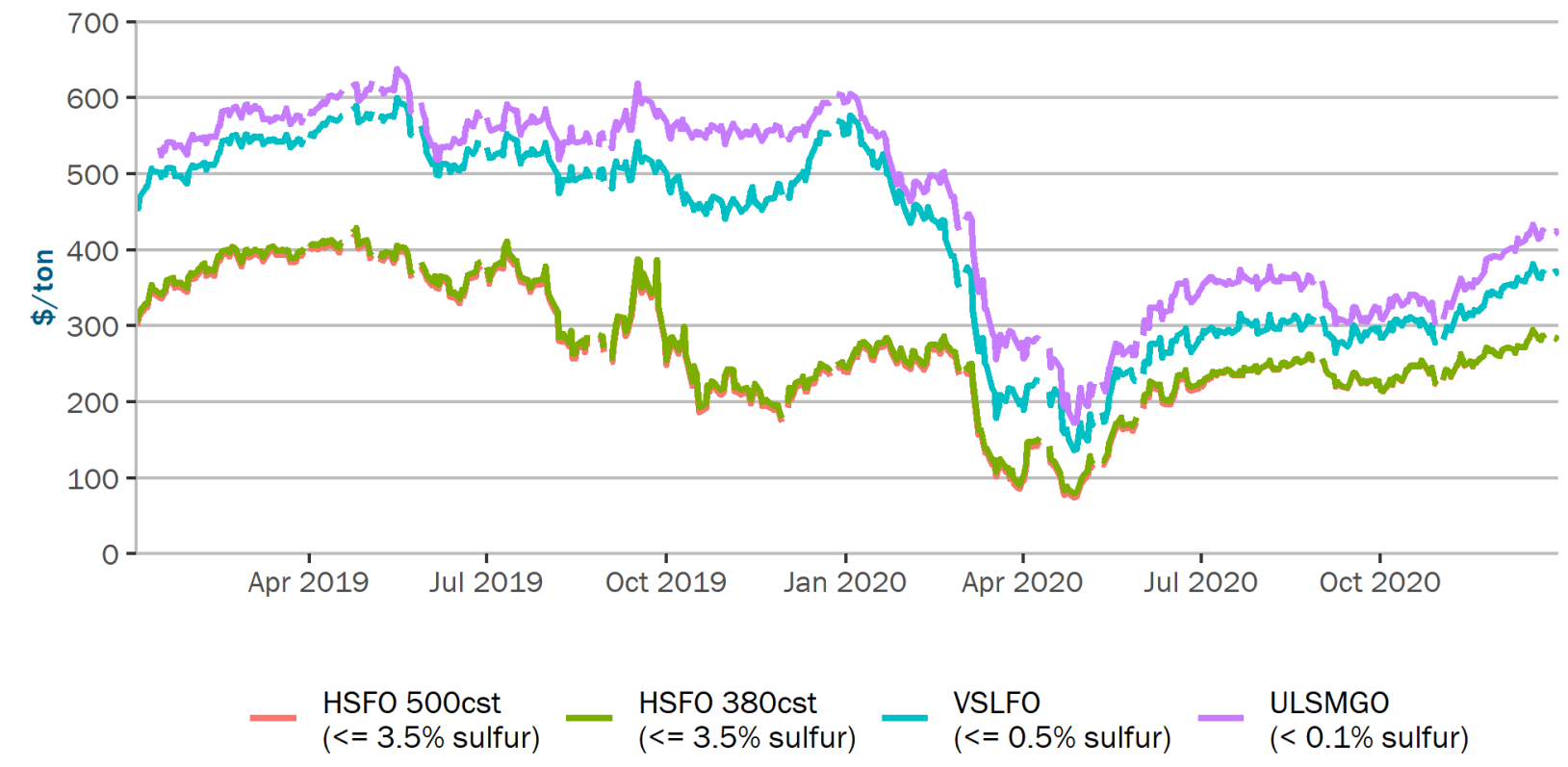

Figure 2. Price of selected petroleum-based marine fuels in Northwest Europe

Source: Argus

Figure 2 shows that the difference in viscosity (500 cst versus $380 \mathrm{cst}$ ) for the two HSFOs results in a small difference in price (\$276/ton for the 380 cst HSFO versus \$271/ton for the 500 cst HSFO) with an average premium of approximately $\$ 5 /$ ton for the lower viscosity HSFO.

Despite the IMO 2020 rule and the substantial drop in global petroleum prices from, the premium of marine gasoil over VLSFO in this region has remained stable through 2019-2020. It averaged \$50/ton in 2019 and \$47/ton in January-November 2020. 
Figure 3 provides information about the petroleum-based marine fuel sale mix in two major bunkering ports (Singapore and Rotterdam) before and after implementation of the IMO 2020 sulfur rule.
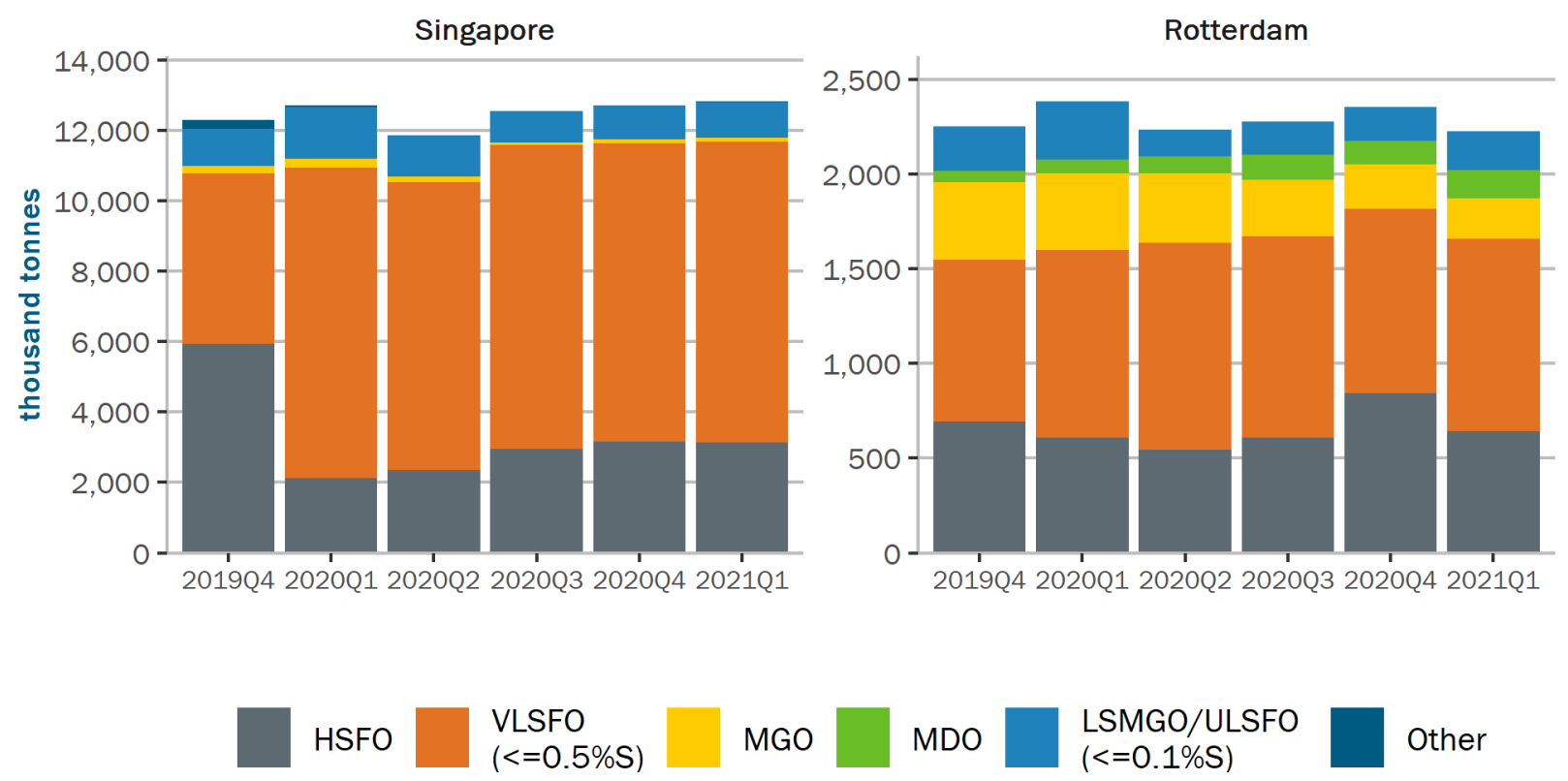

Figure 3. Quarterly sales of petroleum-based marine fuels at the Ports of Singapore and Rotterdam (2019Q42021Q1)

Source: Maritime and Port Authority of Singapore, Port of Rotterdam

At the Port of Singapore, which ranks first in the world by bunker fuel sales, HSFO had accounted for at least $90 \%$ of total sales in 2010-2018 but that percentage fell to $78 \%$ in 2019 as the transition toward marine fuels with lower sulfur content got under way in the last quarter of the year. Since the first quarter of 2020, more than two thirds of Singapore bunker fuel sales have been VLSFO, with a small uptick in HSFO sales starting in the third quarter of 2020. To date, the IMO 2020 rule has not resulted in an increase of sales of MGO in Singapore. MGO sales experienced a slight increase in the first quarter of 2020 but declined after that and accounted for just $1 \%$ of total sales since then. Sales of fuels with $0.1 \%$ sulfur content stabilized at around 1 million tons per quarter after a brief increase at the beginning of 2020.

The transition to lower sulfur fuel started somewhat earlier in Rotterdam where VLSFO already captured the major share of sales in the last quarter of 2019 (38\%). VLSFO has continued to account for the higher share of bunker fuel sales in Rotterdam since then. The share of VLSFO peaked in the second quarter of 2020 at $49 \%$. In the second half of 2020, sales of HSFO and MDO rebounded slightly. The share of MGO has steadily declined through 2020 but remains significantly higher in Rotterdam than in Singapore (10\% versus $1 \%$ in the first quarter of 2021).

Although VLSFO is the most sold fuel in both ports since the start of 2020, it is worth noting that HSFO is the second, with more volume sold in both ports than MGO/MDO. Figure 3 shows that both Singapore and Rotterdam experienced a small bump in total bunker fuel sales at the very beginning of 2020 . This might reflect shippers' increased reliance on the major bunkering hubs right after the IMO 2020 rule came into effect due to concerns about unavailability of low sulfur fuels at smaller ports. As of 2021, reports 
have emerged that HSFO sales are concentrating in major hubs as it becomes uneconomical for smaller ports to offer it. ${ }^{20}$

\subsubsection{LNG}

As of November 2020, there are 202 LNG fueled vessels in operation and 227 LNG newbuild orders (15 million gross tons) (Clarksons, 2020). This is a 67\% increase from 121 and 135 vessels in operation and ordered respectively as of May $1^{\text {st }}, 2018$ (Le Fevre, 2018). According to Clarksons, the current LNGfueled fleet is led by tankers ( 34 in operation and 72 newbuild orders). The numbers are 50 and 24 for ferries, 11 and 30 for containers, 32 and 19 for offshore, and 7 and 28 for cruise ships (Offshore Energy). The LNG fleet represents approximately $0.05 \%$ of the 2020 world merchant fleet (vessels above 1,000 gross tons). ${ }^{21}$ LNG vessel orders account for $10 \%-20 \%$ of the order book. ${ }^{22}$

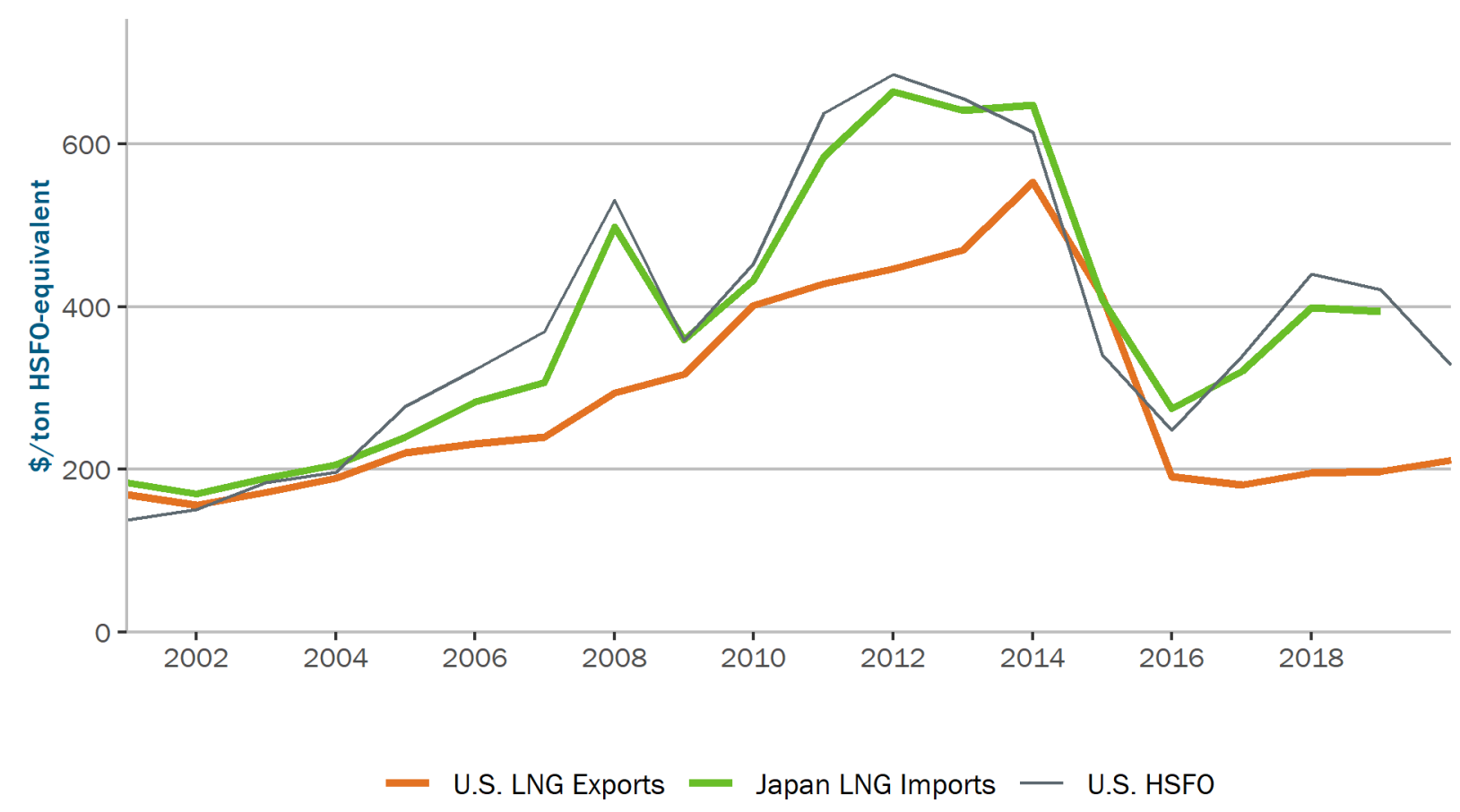

Figure 4. Historical LNG prices

Source: EIA, BP Statistical Review

Figure 4 shows two LNG price series, in comparison with the price of HSFO, all on an energy-equivalent basis. Japan's LNG import prices have been above U.S. LNG export prices for the past two decades and the difference has become wider for most of the 2010s as development of gas shale formations led to lowprice, abundant natural gas production in the United States.

LNG has approximately 20\% higher energy content than HSFO. Japan LNG import prices (in \$/ton HSFO equivalent) were approximately equal to U.S. HSFO prices during this period. Figure 4 also shows

\footnotetext{
${ }^{20}$ https://www.spglobal.com/platts/en/market-insights/blogs/oil/060121-shipping-high-sulfur-fuel-oil-emissionstargets-imo-2020-decarbonization

${ }^{21} \mathrm{http}$ ://infomaritime.eu/index.php/2021/07/15/top-15-shipowning-countries/

22 https://sea-lng.org/why-lng/global-fleet/
} 
a very strong correlation (0.98) between the U.S. HSFO price and the Japan LNG price. This near-perfect correlation is consistent with LNG price being indexed to a crude oil price (typically Brent or Japanese Crude Cocktail) which has been the standard method for setting the long-term contract prices of LNG imports in Asia (Agerton, 2017).

U.S. LNG export prices, accounting for the higher energy content of LNG, were lower than U.S. HSFO prices in 17 of the 20 years shown in the plot. For 2016-2020, the price of U.S. LNG has been consistently lower and more stable than the price of HSFO. U.S. LNG export prices are less correlated with U.S. HSFO prices than Japan LNG import prices. But the correlation is still strongly positive $(0.82$ for annual prices, 0.71 using monthly prices).

\subsubsection{Biofuels}

Clarksons Research reports 23 vessels using biofuel as well as seven newbuild orders (Offshore Energy). In recent years, there have been multiple trials of vessels using blends or $100 \%$ bio fuel oil produced from waste or residue feedstocks. For 2019, the Port of Rotterdam reported that $2 \%$ of sales of fuel oil and $0.5 \%$ of distillates were biofuel bunker blends with biofuel fractions being typically in the $20 \%-30 \%$ range. ${ }^{23}$

Of the biofuels described in Section 2.1, ethanol, biodiesel, and renewable diesel are the three being produced at commercial scale and traded. All three are being used in the transportation sector, mostly for road transport although aviation is also increasingly demand bio-based sustainable aviation fuels. Figure 5 shows the price of wholesale corn ethanol in the U.S. Gulf Coast from 2014 to January 2021 compared to the HSFO price.

${ }^{23} \mathrm{https}$ :/www.portofrotterdam.com/en/news-and-press-releases/2019-demand-in-rotterdam-bunker-port-moresustainable 


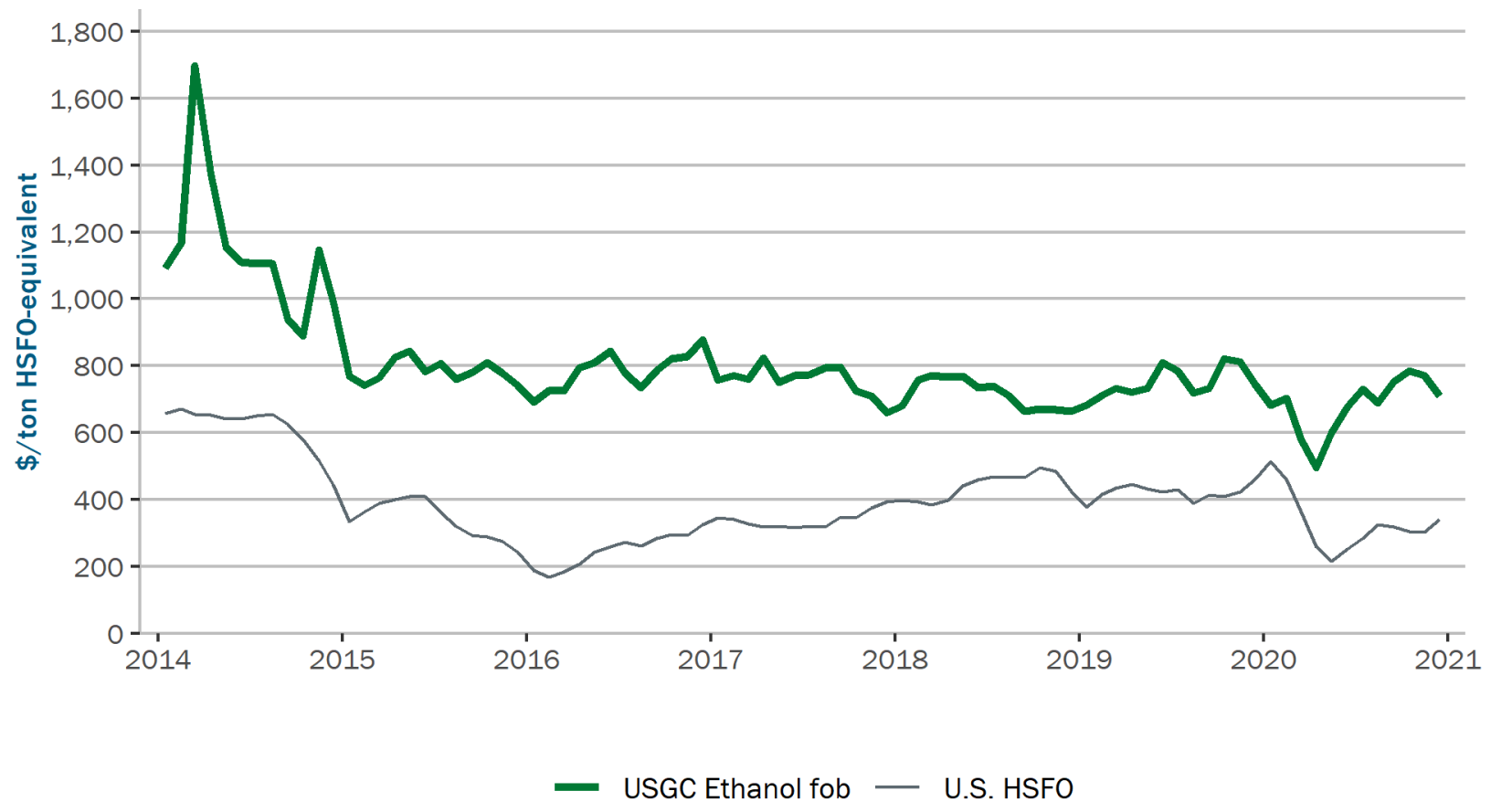

Figure 5. U.S. ethanol price

Source: Argus, EIA

A ton of ethanol has approximately $67 \%$ of the energy content of a ton of HSFO. On average, ethanol was twice as expensive as HSFO in dollars per ton of HSFO equivalent through the period shown in Figure 5. The coefficient of variation was higher for HSFO than ethanol ( 0.31 versus 0.21$)$ meaning that the ethanol price was overall more stable during this period despite the initial pronounced spike in 2014. The correlation between the monthly prices of ethanol and HSFO during the past seven years was 0.65 .

\subsubsection{Other alternative fuels}

By the end of 2019, there were 12 vessels and 11 new orders using methanol according to Clarksons Research (Offshore Energy). Most of the 12 vessels using methanol as fuel were chemical tankers using part of their cargo as fuel (Ming and Chen, 2021).

According to the Methanol Institute, methanol is already available at more than 100 ports worldwide because it is widely traded for industrial applications and for use as a fuel additive in some countries. In April 2021, the world's first barge-to-ship methanol bunkering operation took place at the Port of Rotterdam, an alternative to bunkering operations via cargo shore pipelines. ${ }^{24}$ The IMO adopted interim guidelines on safety standards for methanol vessels in December 2020 and the International Organization for Standardization (ISO) is in the process of developing a methanol marine fuel grade specification. These activities help pave the way to wider adoption of methanol in the marine shipping sector.

\footnotetext{
${ }^{24}$ https://www.bunkerspot.com/global/53179-global-world-s-first-barge-to-ship-methanol-bunkering-at-port-ofrotterdam
} 
For methanol and ammonia, the available (monthly) price data series only covered 2018-2020 for methanol and 2019-2020 for ammonia. The annual average contract price of methanol, as reported by the Methanol Institute, was $\$ 388 /$ ton and the annual average price of ammonia for fertilizer applications in the U.S. Midwest was $\$ 566 /$ ton. The annual average price of HSFO in the United States fell in between those two values at $\$ 421 /$ ton. Figure 6 shows the monthly evolution of the three series accounting for differences in their energy content.

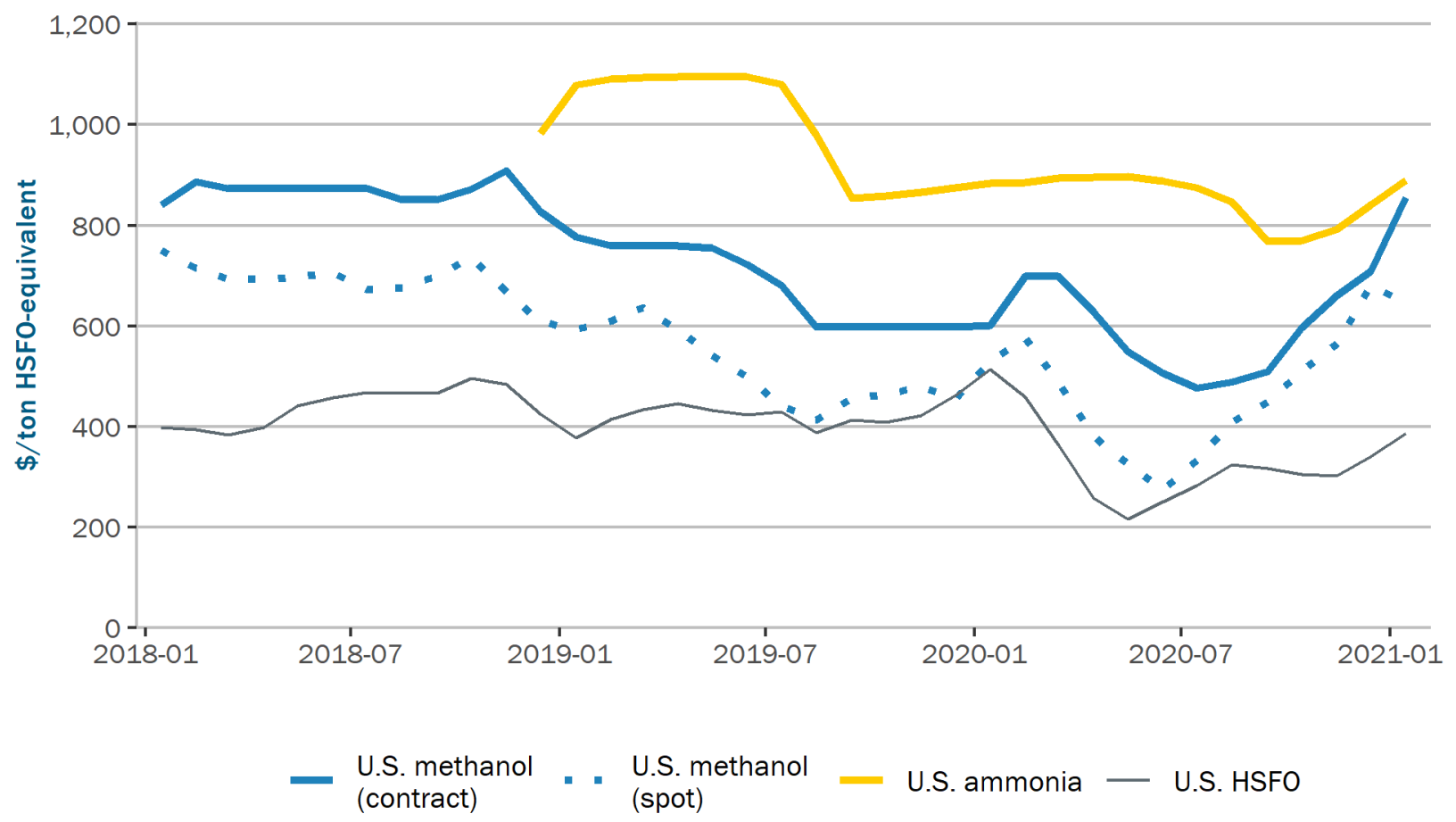

Figure 6. Historical prices of methanol and ammonia in the United States

Source: Methanol Institute, U.S. Department of Agriculture, EIA

Both methanol and ammonia have approximately $56 \%$ of the energy content of HSFO. Once the differences in energy content are accounted for, HSFO has been cheaper than either methanol or ammonia during the whole period shown, often by a significant margin.

For methanol, Figure 6 includes series for contract and spot prices to highlight their sizable difference. On average, the contract price was 30\% higher than the spot price during this period. Ammonia was more expensive than HSFO and methanol in 2019 and 2020. However, it should be noted that this ammonia price is for its application, in powder form, as fertilizer and might differ from its price as marine fuel.

Both methanol and ammonia are mostly used in industrial applications and display relatively low correlations with the HSFO price: 0.6 for methanol and 0.44 for ammonia. The prices shown in Figure 6 are for "grey" versions of the fuels produced from fossil fuel feedstocks and without carbon capture and storage. Those conventional pathways (coal gasification in the Asia Pacific and natural gas steam reforming in the rest of the world) account for most of the methanol and ammonia produced today (IEA, 2018). For methanol, Ming (2021) reports that worldwide production capacity ( 110 million tons) is distributed across 90 large fossil-based methanol plants and only nine plants with combined capacity of less than one million tons use renewable feedstocks. 


\section{U.S. FLEET OF OCEANGOING VESSELS}

\subsection{U.S. FLEET ATTRIBUTES}

As of June 2020, the U.S.-flagged merchant fleet of oceangoing vessels registered in the U.S. Department of Transportation Maritime Administration dataset (1,000 gross tons and above) comprised 184 ships with combined gross tonnage of 7.3 million tons. Jones Act-eligible vessels account for $53 \%$ of the U.S. fleet and $48 \%$ of gross tonnage. ${ }^{25}$ Figure 7 shows that the current fleet has been built between 1963 and 2019. The median year of build is 2006 . On average, tankers, vehicles vessels, Ro-Ros, and containerships are newer than general cargo vessels and dry bulk vessels.

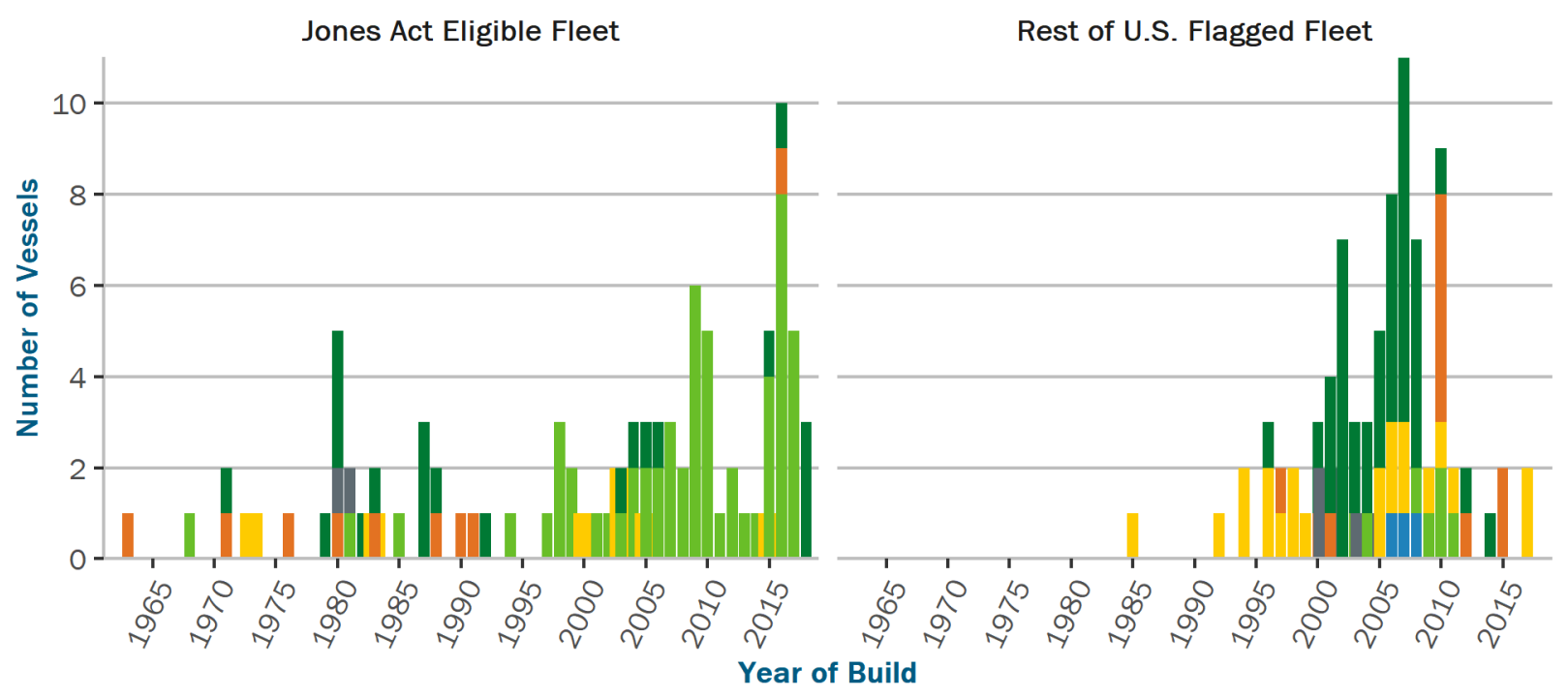

Type

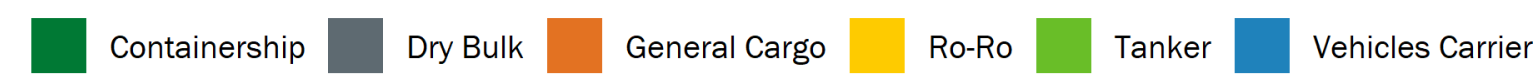

Figure 7. U.S.-flagged oceangoing merchant vessels by year of build and ship type

Source: U.S. Department of Transportation Maritime Administration

Figure 8 shows the type and size distribution of the U.S. fleet. Most U.S.-flagged vessels are containerships and tankers (64 each), and next are Ro-Ro and General Cargo vessels (28 and 20 respectively). There are only five dry bulk vessels and three vehicle carriers. Tankers, containerships, and dry bulk vessels have the largest sizes with average deadweight tonnages of 65,000, 49,000, and 45,000 DWT, respectively. The average tonnage of vehicles carriers and Ro-Ros are 27,000 and 21,000 DWT, and the average tonnage of general cargo ships is 9,000 DWT.

${ }^{25}$ Section 27 of the Merchant Marine Act of 1920 (Jones Act) requires domestic waterborne freight transport to be conducted on vessels that are U.S.-built, owned, registered, and crewed. 


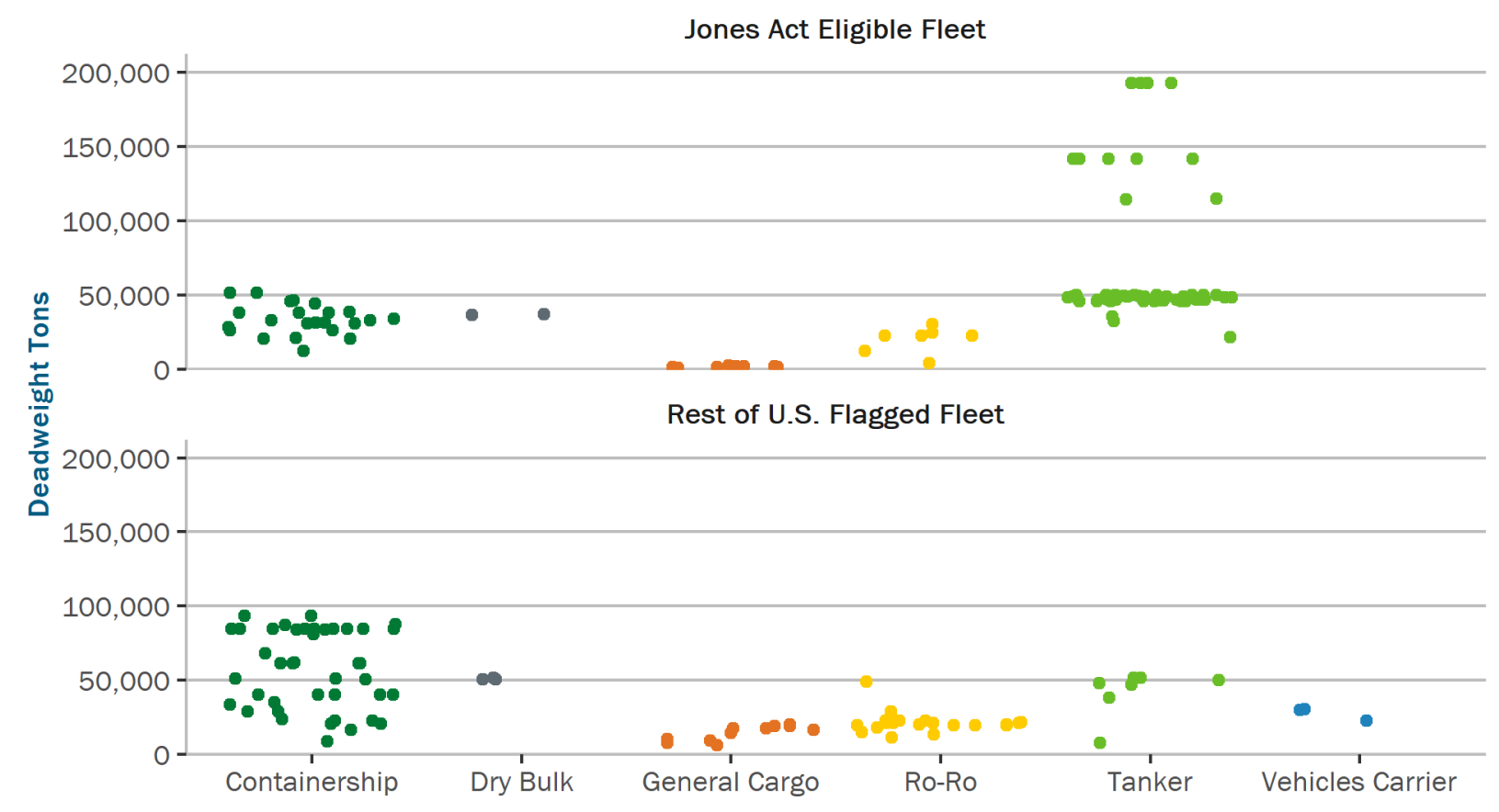

Figure 8. U.S.-flagged oceangoing merchant vessels by ship type and deadweight tonnage

Source: U.S. Department of Transportation Maritime Administration

Figure 7 and Figure 8 show significant differences in vessel type, age, and size for the Jones Act-eligible segment of the fleet. All but one of the vessels that are older than 30 years are Jones Act-eligible. Tankers are the predominant vessel type among the Jones Act fleet ( $58 \%$ of the total), but they represent less than $10 \%$ of the rest of the U.S. fleet. In contrast, containerships account for $48 \%$ of the U.S. vessels not eligible for domestic waterborne freight but only $23 \%$ of the Jones Act fleet. The average deadweight tonnage of containerships, dry bulk, general cargo, and Ro-Ro U.S. vessels is smaller for those eligible for domestic freight.

No public information is available on the engine type of every vessel in the fleet, or which fuel they use. Desk research revealed that, out of the 30 U.S.-flagged vessels built in 2015-2019, six have dual-fuel engines that can use LNG and an additional 14 have engines that are LNG-ready. All 20 of these vessels that use or could use LNG upon limited modifications are Jones Act vessels. The choice of LNG for these vessels is mainly driven by compliance with the North American ECA standards for sulfur oxide $\left(\mathrm{SO}_{\mathrm{x}}\right)$, $\mathrm{NO}_{x}$, and particulate matter emissions. Low U.S. natural gas prices also contribute to making the use or the option to use LNG attractive for these shipowners.

\subsection{FUEL CONSUMPTION AND FUEL COST ESTIMATE FOR THE U.S. FLEET}

Table 4 shows the fuel consumption estimate for the U.S. fleet in 2020, differentiating the Jones Acteligible ships from the rest. The fuel consumption for each vessel was estimated using the average fuel consumption per year assumed in the IMO GHG4 emissions inventory, for the appropriate size category bin based on deadweight tonnage data. All vessels are assumed to use residual fuels or distillate fuels, since the percentage of the fleet using alternative fuels is still very small. Based on the GHG4 study, the 
assumed percentages of residual and distillate fuels are $68 \%$ and $32 \%$, respectively. Note that the IMO study groups all residuals into the general label HFO and all distillates into the general label MDO.

The estimated fuel consumption for the U.S. fleet in 2020 is 1.26 million tons of HFO and 0.59 million tons of marine distillates. The Jones Act segment of the fleet accounts for $53 \%$ of U.S. vessels and $43 \%$ of fuel consumption. This difference results from the Jones Act vessels being smaller as well as by differences in vessel type and operation. The U.S. fleet in 2020 accounts for approximately $0.5 \%$ of the world's fleet fuel consumption as estimated by the GHG4 study (339.27 million tons, estimated for the year of 2018).

Table 4. Estimated Fuel Consumption of the U.S. Oceangoing Merchant Fleet (2019 prices)

\begin{tabular}{|c|c|c|c|c|c|c|c|c|c|}
\hline & Count & $\begin{array}{c}\text { Average } \\
\text { Main } \\
\text { Engine } \\
\text { Power }^{1} \\
\text { (kW) }\end{array}$ & $\begin{array}{l}\text { Average } \\
\text { Design } \\
\text { Speed }^{1} \\
\text { (kts) }\end{array}$ & $\begin{array}{c}\text { Average } \\
\text { Main } \\
\text { Engine } \\
\text { Fuel }^{2} \\
\text { (kt/y) }\end{array}$ & $\begin{array}{c}\text { Average } \\
\text { Auxiliary } \\
\text { Engine } \\
\text { Fuel }^{2} \\
\text { (kt/y) }\end{array}$ & $\begin{array}{l}\text { Average } \\
\text { Boiler } \\
\text { Fuel }^{2} \\
\text { (kt/y) }\end{array}$ & $\begin{array}{c}\text { Total } \\
\text { Residual fuel }^{\text {oil (ton) }}{ }^{3} \\
(68 \%)\end{array}$ & $\begin{array}{c}\text { Total } \\
\text { Distillate } \\
\text { fuel oil } \\
(\text { ton })^{3} \\
(32 \%)\end{array}$ & $\begin{array}{l}\text { Total fuel } \\
\text { oil (ton) }\end{array}$ \\
\hline $\begin{array}{l}\text { Total } \\
\text { Ships }\end{array}$ & 184 & 24,191 & 17.6 & 6.2 & 1.2 & 1.4 & $1,255,212$ & 590,688 & $1,845,900$ \\
\hline $\begin{array}{l}\text { Jones } \\
\text { Act } \\
\text { Eligible }\end{array}$ & 98 & 12,257 & 15.6 & 7.8 & 1.5 & 1.2 & 540,192 & 254,208 & 794,400 \\
\hline $\begin{array}{l}\text { Non- } \\
\text { Jones } \\
\text { Act } \\
\text { Eligible }\end{array}$ & 86 & 37,791 & 19.5 & 4.5 & 0.9 & 1.7 & 715,020 & 336,480 & $1,051,500$ \\
\hline \multicolumn{10}{|c|}{$\begin{array}{l}1 \text { The main engine power and design speed of each vessel are from Table } 35 \text { in the IMO GHG4 Report, according to the DWT } \\
\text { and type of each vessel. } \\
{ }^{2} \text { The main engine fuel, auxiliary engine fuel, and boiler fuel consumption for every vessel are from Table } 35 \text { in the IMO GHG4 } \\
\text { Report, according to the vessel's DWT and type. } \\
{ }^{3} \text { We assume } 68 \% \text { of the main engine, auxiliary engine, and boiler fuel consumptions are residual fuels, and } 32 \% \text { of them are } \\
\text { distillate fuels, according to the data from the IMO GHG4 Report. The total residuals consumption is the sum of all Jones Act- } \\
\text { eligible vessels or all Non-Jones Act-eligible vessels. They are not calculated with columns } 3 \text { to } 7 \text {, which are summary data for } \\
\text { illustration. } \\
{ }^{4} \text { The sum of Columns } 8 \text { and } 9 \text {. }\end{array}$} \\
\hline
\end{tabular}

Table 5 shows the estimated total fuel cost segmented by Jones Act eligibility. At the average prices of $\$ 400 /$ ton and $\$ 560 /$ ton for residual and distillate fuels, the total fuel cost for the U.S. fleet in 2020 is $\$ 833$ million of which 43\% is for Jones Act-eligible vessels. Fuel prices for residual and distillate fuel oil are from Argus, a fuel market data provider. A national average price was constructed as volume-weighted average of the prices for HSFO (for residual fuels) and MGO (for distillate fuels) in three U.S. locations: U.S. Gulf Coast, New York Harbor, and Los Angeles. The volume weights are based on EIA bunker fuel sales data for each of the regions. In 2019, VLSFO was already available in these large ports but not utilized much yet, so we simply use the price of residual fuel oil 3.5\% (HSFO) and MGO.

Table 5. Estimated Fuel Costs of the U.S. Oceangoing Merchant Fleet (2019 prices)

\begin{tabular}{lccc}
\hline Fuel price & $\begin{array}{c}\text { Residual Fuel Oil Cost } \\
(@ \mathbf{\$ 4 0 0 / t o n )}\end{array}$ & $\begin{array}{c}\text { Distillate Fuel Oil Cost } \\
(@ \mathbf{\$ 5 6 0 / t o n})\end{array}$ & Total Fuel Cost \\
\hline Total Ships & $\$ 502,084,800$ & $\$ 330,785,280$ & $\$ 832,870,080$ \\
\hline Jones Act Eligible & $\$ 216,076,800$ & $\$ 142,356,480$ & $\$ 358,433,280$ \\
\hline Non-Jones Act Eligible & $\$ 286,008,000$ & $\$ 188,428,800$ & $\$ 474,436,800$ \\
\hline
\end{tabular}


The fuel costs in Table 5 are based on 2019 prices as 2020 might not be a representative year in terms of price levels because of the weakness in petroleum product prices due to COVID. However, it is informative to compare the US-flagged fleet fuel costs considering price uncertainty (Figure 9), using the $10 \%$ and $90 \%$ percentile of prices from November 2019 to September 2020 as indicative of the substantial fuel price risk potentially faced by shippers.

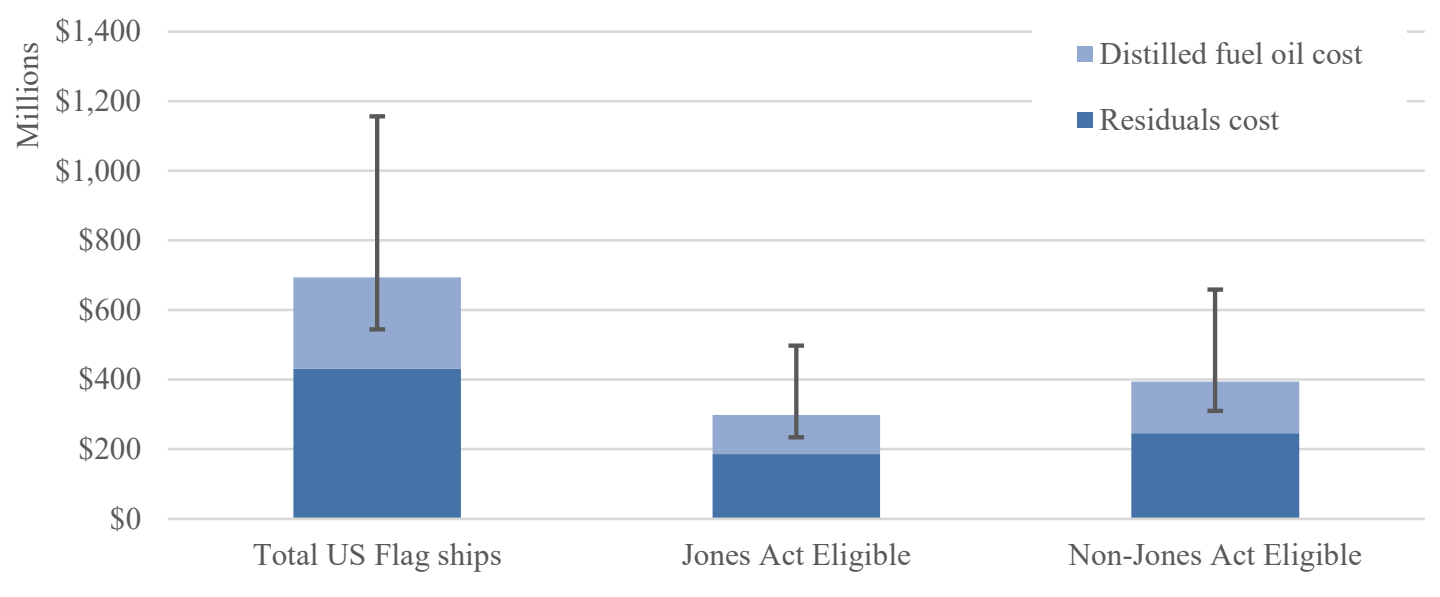

Figure 9. Estimated U.S. oceangoing merchant fleet fuel costs

Note: Fuel costs are estimated with median fuel costs from November 2019 to September 2020 and error bars are estimated with $10 \%$ and $90 \%$ percentile of prices during the same time frame.

Table 6 and Table 7 show the estimated U.S. fleet fuel consumption and cost by vessel type. The fleet of containerships consumes the most fuel, followed by tankers and Ro-Ro vessels. This ranking is partly determined by the number of vessels in each category. Table 8 presents average fuel consumption and fuel cost (see also Figure 10) per vessel for each vessel type. Differences in fuel consumption across vessel types result from differences in size, engine technology, and operational patterns. Containerships consume the most fuel, followed by Ro-Ro vessels, and vehicle carriers.

Table 6. Estimated Fuel Consumption of the U.S. Oceangoing Merchant Fleet by Vessel Type

\begin{tabular}{lrrr}
\hline Vessel type & $\begin{array}{r}\text { Residual Fuel Oil } \\
\text { (tons) }\end{array}$ & $\begin{array}{r}\text { Distillate Fuel Oil } \\
\text { (tons) }\end{array}$ & $\begin{array}{r}\text { Total Fuel } \\
\text { (tons) }\end{array}$ \\
\hline Containership & 590,920 & 278,080 & 869,000 \\
\hline Dry Bulk & 14,620 & 6,880 & 21,500 \\
\hline General Cargo & 29,988 & 14,112 & 44,100 \\
\hline Ro-Ro & 245,412 & 115,488 & 360,900 \\
\hline Tanker & 350,812 & 165,088 & 515,900 \\
\hline Vehicles Carrier & 23,460 & 11,040 & 34,500 \\
\hline Grand Total & $\mathbf{1 , 2 5 5 , 2 1 2}$ & $\mathbf{5 9 0 , 6 8 8}$ & $\mathbf{1 , 8 4 5 , 9 0 0}$ \\
\hline
\end{tabular}


Table 7. Estimated Fuel Cost of the U.S. Oceangoing Merchant Fleet by Vessel Type

\begin{tabular}{|c|c|c|c|}
\hline Vessel type & $\begin{array}{r}\text { Residual Fuel Oil cost } \\
\text { (@ } \$ 400 / \text { ton })\end{array}$ & $\begin{array}{r}\text { Distillate Fuel Oil Cost } \\
\text { (@ \$560/ton) }\end{array}$ & Total Fuel Cost \\
\hline Containership & $\$ 236,368,000$ & $\$ 155,724,800$ & $\$ 392,092,800$ \\
\hline Dry Bulk & $\$ 5,848,000$ & $\$ 3,852,800$ & $\$ 9,700,800$ \\
\hline General Cargo & $\$ 11,995,200$ & $\$ 7,902,720$ & $\$ 19,897,920$ \\
\hline Ro-Ro & $\$ 98,164,800$ & $\$ 64,673,280$ & $\$ 162,838,080$ \\
\hline Tanker & $\$ 140,324,800$ & $\$ 92,449,280$ & $\$ 232,774,080$ \\
\hline Vehicles Carrier & $\$ 9,384,000$ & $\$ 6,182,400$ & $\$ 15,566,400$ \\
\hline Grand Total & $\$ 502,084,800$ & $\$ 330,785,280$ & $\$ 832,870,080$ \\
\hline
\end{tabular}

Table 8. Average fuel consumption and cost by vessel type

\begin{tabular}{lrrr}
\hline Vessel Type & Vessel Count & $\begin{array}{r}\text { Average Fuel Consumption } \\
\text { per Vessel (tons) }\end{array}$ & $\begin{array}{r}\text { Average Fuel Cost per } \\
\text { Vessel }\end{array}$ \\
\hline Containership & 64 & 13,578 & $\$ 6,126,500$ \\
\hline Dry Bulk & 5 & 4,300 & $\$ 1,940,200$ \\
\hline General Cargo & 20 & 2,205 & $\$ 994,900$ \\
\hline Ro-Ro & 28 & 12,889 & $\$ 5,815,600$ \\
\hline Tanker & 64 & 8,061 & $\$ 3,637,100$ \\
\hline Vehicles Carrier & 3 & 11,500 & $\$ 5,188,800$ \\
\hline Grand Total & $\mathbf{1 8 4}$ & $\mathbf{1 0 , 0 3 2}$ & $\mathbf{\$ 4 , 5 2 6 , 5 0 0}$ \\
\hline
\end{tabular}

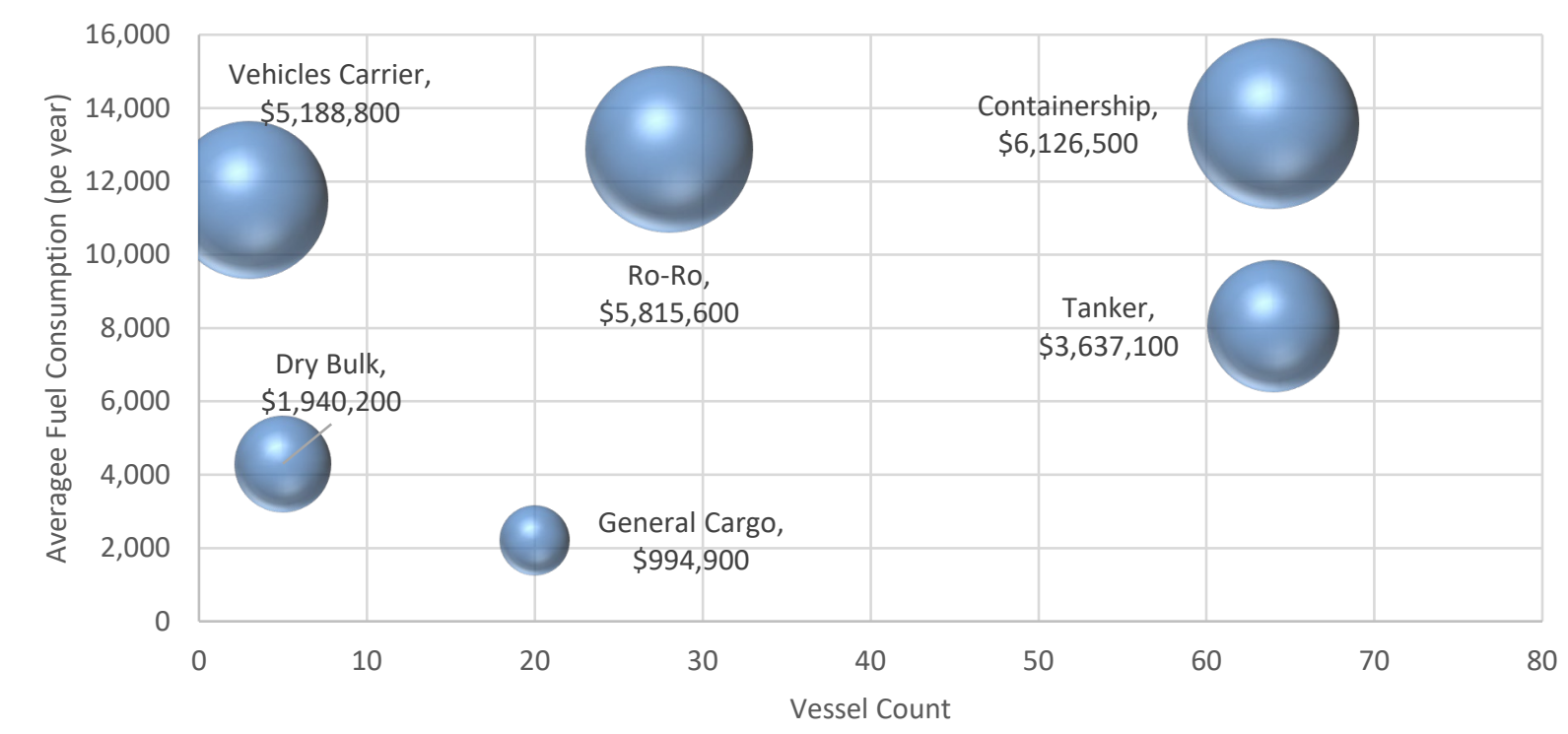

Figure 10. U.S. fleet count, fuel consumption, and annual fuel costs by vessel type

Note: Bubble size shows the average annual fuel costs per vessel. 


\section{FUEL CHOICE DECISION BY MARINE SHIPPERS}

For existing vessels, the fuel choice set for fleet operators is limited by the capability of the vessel to accommodate a fuel, i.e., ability to receive the fuel during bunkering, store it onboard, deliver it to the engine/prime mover, combust or release the fuel energy in the engine/prime mover, and manage any fuel return, waste products, and exhaust. Other fuel choice determinants include fuel price, fuel-specific technology investment/installation costs, and operating costs including specialized labor, maintenance costs, and payload implications if any. These fuel choice elements are summarized in Table 9.

Table 9. Summary of Fuel Choice Elements and Factors

\begin{tabular}{lll}
\hline Fuel Choice Elements & Enabling factors & Determining factors \\
\hline Energy carrier (fuel) & Bunkering (receiving fuel), & Fuel price \\
& Storage, & \\
& Handling requirements & \\
\hline Technology (engine/prime mover, and & Engine-fuel match & Installation/retrofit costs \\
ancillary machines) & Pretreatment/posttreatment & Maintenance costs \\
\hline Operations (vessel service, route, crew) & $\begin{array}{l}\text { Specialized fuel } \\
\text { training/certification }\end{array}$ & $\begin{array}{l}\text { Revenue payload } \\
\text { implications }\end{array}$ \\
& Voyage match with energy range & \\
\hline
\end{tabular}

As described in Chapter 1 and Chapter 2, most fleet operators have chosen strategies involving petroleum-based fuels to meet the IMO 2020 sulfur limits. That is because these fuels meet all the enabling factors and score favorably along the determining factors listed in Table 9. Natural gas and other gaseous fuels require different handling and storage and must be matched with engine technology that often involves liquid fuel for initiating combustion. Some biofuels are near drop-in replacement for petroleum while others require modifications to the fuel and engine systems. Other alternative fuels, e.g., ammonia, hydrogen, electricity, and nuclear, will require new ship designs to effectively integrate energy carrier, engine technology, and operating service.

The choice of approach to comply with the IMO 2020 sulfur cap (low-sulfur petroleum-based fuels, scrubbers, and LNG) in specific countries has been the focus of several published analyses. For instance, Cuong and Hung evaluate the options for Vietnamese shipowners to comply with the 2020 sulfur cap considering political, legal, economic, environmental, technological, and sociological aspects. They conclude that a compliant blended fuel (e.g., VLSFO) is the priority solution for the existing Vietnamese commercial fleet, most of which is old, while LNG appears as an attractive solution for new ships (Cuong and Hung, 2020).

The ranking of compliance strategies changes with vessel age and type. Li et al. examine three abatement options to comply with the 2020 sulfur cap: switching to low-sulfur fuels, installing scrubbers, and running on LNG (Li et al., 2020). Applying a multinomial logistic regression model to data from the Clarkson World Fleet Register database, they find that scrubbers and LNG are more attractive for new vessels and older vessels' operators prefer low-sulfur petroleum fuels. The choices also differ across vessel types. Scrubbers, LNG, and low-sulfur petroleum fuels are respectively the most preferred choices among the following three groups: tankers, containers, and roll-on/roll-off carriers; gas ships; and offshore ships and ferries. Li et al. 2020 find that vessel size does not have a statistically significant effect on compliance strategy.

Solakivi et al. (2019) conduct empirical analysis of the approaches for compliance with the sulfur content limits in the Baltic ECA, implemented in 2015, chosen by vessels calling port in Finland (Solakivi et al., 2019). Using a logistic regression model, they find that majority of ships calling at Finnish ports switched 
to a cleaner fuel grade, while younger vessels in regular traffic on the emission control area (especially roll on-roll off vessels) are most likely to use scrubbers. Their analysis also finds vessel size to not be a statistically significant determinant of compliance choice.

Some studies consider other marine fuel options under the context of GHG emission reduction, including alternative fuels that may not be widely available in the short term. Based on literature review and expert opinion, Andersson et al. list nine categories of criteria in marine fuel choice decisions: technical, economic, environmental, fuel distribution, safety and health, geopolitical stability, ethics, public acceptance, and policy (Andersson et al., 2020).

Studies of fuel choice in the global fleet tend to not consider differences by vessel flag. For example, the GHG4 work suggested two scenarios to describe world fleet responses (by penetration rates, $\%$ of ships applying a technology)-as if all ships acted similarly. ${ }^{26}$ In practice, characteristics of the shipping industry in each country can play a role in fuel choice decisions as is the case for the U.S.-flagged fleet.

The U.S. fleet recapitalizes at rates much lower than typical across the world fleet. What that means is that most U.S. ships are less quick to invest to modify the enabling factors in Table 9 in the near term. However, the U.S. fleet may be able to modernize at a higher pace when commitments to low-GHG fuels become mandatory. This is because the relative age of vessels may bring a set of co-benefits in terms of improved performance when the U.S. fleet begins investing in new ships.

\section{KEY FACTORS DRIVING MARINE FUEL PRICES}

\subsection{MARINE TRANSPORT ENERGY DEMAND}

Marine transport energy demand is driven by four factors that we discuss below:

- $\quad$ Trends in GDP and population (driving the demand for seaborne trade)

- $\quad$ Expanding trade agreements and free-trade zone agreements

- Changes in fleet size and composition

- Mandated and market-driven increases in energy efficiency

\subsubsection{Trends in GDP and population (driving the demand for seaborne trade)}

Gross domestic product (GDP), a commonly used measure of economic activity, drives seaborne trade, and seaborne trade can enhance economic activity. Studies indicate that the effects are indeed bidirectional. For example, Chang (2012) conducted statistical analysis of the relationship between marine energy consumption, marine emissions, and GDP from 1990 to 2006 for a subset of the countries that signed the Kyoto Protocol in 1997. The results indicated that GDP "Granger-caused" marine energy consumption in the short-run in Australia, marine energy consumption "Granger-caused" GDP in Finland, Italy, New Zealand and the United States, and Granger causality was bidirectional for Belgium, Canada, and the United Kingdom. ${ }^{27}$

As another indication of the close relationship between seaborne trade and global industrial economic activity, some macroeconomists use changes in seaborne trade as a proxy for fluctuations in global GDP.

\footnotetext{
${ }^{26}$ Table 75 of the IMO GHG4 study.

${ }^{27} \mathrm{X}$ "Granger-causes" $\mathrm{Y}$ if past values of $\mathrm{X}$ contain information that helps predict $\mathrm{Y}$ above and beyond the information contained in past values of $\mathrm{X}$.
} 
Kilian (2009) proposes a monthly index of dry cargo single voyage ocean freight rates (indicative of marine freight and marine energy volumes) as a measure of demand for industrial commodities in global markets, and thus a proxy for global economic activity.

The GHG4 study projects energy consumption and emissions based on projections of fleet activity which, in turn, are based on projections of transport work under a suite of long-term socioeconomic futures. Two methods are used: 1) logistic analysis, in which the relationship between transport work and its drivers is described by an empirically estimated logistic curve, 2) gravity model analysis, which models transport work as a function of per capita GDP and population of the trading countries and uses econometric techniques to estimate the elasticity of transport work with respect to its drivers based on panel data of bilateral trade flows.

\subsubsection{Expanding trade agreements and free-trade zone agreements}

New trade agreements increase global seaborne trade and, therefore, increase marine transport energy demand. The number of regional trade agreements grew rapidly in the past 25 years. The number of regional goods and/or services trade agreements in force went from 46 in 1995, the year in which the World Trade Organization was created, to 301 in $2019 .{ }^{28}$ Global seaborne trade more than doubled during that period, from less than 5 billion tons of goods loaded in 1995 to 11.1 billion tons in 2019 (UNCTAD 2020 Handbook of Statistics).

Empirical studies support the conclusion that free trade agreements (FTAs) expand trade and shipping. Using data on bilateral trade flows among 96 countries for the 1960-2000 period, Baier and Bergstrand (2005) find that an FTA increases two member countries' trade by an average $86 \%$ after 15 years. This study is one of the first in correcting for the endogeneity of FTAs in the gravity model equations used to estimate the impacts of trade policy on trade flows; the authors argue that most previous estimates of the effect of FTA on trade flows had been biased downward. In a meta-analysis of the determinants of bilateral trade flow volume using gravity equations, Head and Mayer (2013) find an average $80 \%$ increase in trade flow volume resulting from a trade agreement; this is similar in magnitude to the mean effects the same meta-analysis identifies for country contiguity and common language but lower than the effects of common currency, or the presence of a colonial link between importer and exporter. GDP and distance also have large effects on the trade volume between two countries.

\subsubsection{Changes in fleet size and composition}

The deployment of progressively larger fully cellular containerships, starting in the late 1960s, has resulted in economies of scale in cargo shipping that reduce the cost and fuel use per ton-mile shipped. The first generation of container ships (1970s) ranged in size between 1,000 and 2,500 TEUs while new containerships built today can have sizes greater than 20,000 TEUs. The growth of the containerized segment of the fleet is also associated with a change in the mix of goods being traded. In 1970, international seaborne trade was 55\% crude oil, petroleum products, and gas, $17 \%$ main bulks (iron ore, grain, and coal), and $28 \%$ other dry cargo. By 2017 , the cargo mix was dramatically different: only $29 \%$ oil and gas, 30\% main bulks, and 41\% other dry cargo (UNCTAD, 2018). ${ }^{29}$

Since 2014, the fleet segments experiencing the most growth are containers and gas carriers. On the other hand, growth in oil tankers and bulk carriers has slowed down. In 2018, world fleet tonnage growth

\footnotetext{
${ }^{28}$ http://rtais.wto.org/UI/charts.aspx\#

${ }^{29}$ The UNCTAD database differs from the MARAD database presented in Chapter 3 in several aspects. Apart from being global rather than referring only to U.S.-flagged vessels, the UNCTAD database includes vessels > $100 \mathrm{GT}$ rather than 1,000 GT and some of the vessel types it covers (e.g., fishing vessels) are not part of the MARAD dataset.
} 
(2.61\%) was the lowest of the previous ten years (UNCTAD, 2019). In 2019, the average age of the world merchant fleet was 21 years but there were significant differences in age across vessel categories. The youngest segments of the fleet are bulk carriers (average age of 10 years) and containerships (average age of 12 years). The oldest are general cargo vessels with an average age of 26 years (UNCTAD, 2019).

\subsubsection{Mandated and market-driven increases in energy efficiency, or reductions in emissions}

Marine diesel engines are the most fuel-efficient engines across the entire transportation sector. Except for those commodities that can be transported via pipeline, it is not possible to reduce fuel and emissions per ton-mile of cargo by switching from marine shipping to a different mode of transportation (McCollum et al., 2009). However, the energy efficiency of marine transport varies with ship size, design, speed, operational patterns (particularly load factor), and engine technology. Despite improvements in the energy efficiency of the global fleet over time, partly tied to the increase in average ship size, total fuel use and $\mathrm{CO}_{2}$ emissions from the shipping sector continue to increase because the expansion in ton-miles shipped more than offsets the increases in energy efficiency.

To identify options for reducing fuel use and emissions in the marine sector, the GHG4 study presents a marginal abatement cost (MAC) curve that ranks 44 measures to reduce GHG emissions, including (1) energy-saving technology adoption (e.g., optimization of water flow hull openings, hull maintenance, reduced auxiliary power usage, main engine improvements), (2) shifts to renewable energy (hybrid auxiliary power, wind, or solar, or alternative carbon-neutral or low-carbon fuels), and (3) operational changes (speed reduction is the only option considered in GHG4, but there are others). All cost-effective measures are energy-saving technologies. The estimated MAC of alternative fuels is $\$ 416 /$ ton $\mathrm{CO}_{2}$ for zero-carbon fuels and $\$ 258 /$ ton $\mathrm{CO}_{2}$ for fuels that still emit some $\mathrm{CO}_{2}$. The MAC of speed reduction is $\$ 17 /$ ton $\mathrm{CO}_{2}$. A few of the measures have a negative MAC meaning that these technologies are profitable to install, at least from a social perspective. However, the amount of $\mathrm{CO}_{2}$ reduction by these negative MAC measures is relatively small-less than 10\% reductions from the baseline in 2030 and $18 \%$ reduction by 2050. In 2050, the IMO GHG4 study concludes that about $64 \%$ of the total amount of $\mathrm{CO}_{2}$ reduction should result from the use of alternative fuels. This result confirms that it is difficult to achieve the IMO's mid-term target for $\mathrm{CO}_{2}$ emission reductions by energy-saving technologies and speed reduction in ships only.

The GHG4 study shows that main engine fuel consumption varies significantly within ship categories. This variability suggests that there is potential for reductions in fuel use that do not require engine technology changes. The Clean Cargo Working Group is an example of a benchmarking initiative that compiles data on container ship fuel use and emissions to help vessel owners assess their performance and shippers choose vessels with better environmental performance indicators. ${ }^{30}$

\subsection{OIL PRICE}

As shown in Table 1, petroleum-based fuels accounted for more than $95 \%$ of global marine fuel consumption in 2018. Marine fuel prices are strongly correlated with crude oil prices. From January 2000 to December 2020, the correlation between the benchmark West Texas Intermediate (WTI) crude oil spot price and HSFO at the U.S. Gulf Coast was very high, $94.7 \% .{ }^{31}$ Similarly, the correlation between the WTI price and heating oil price (a good proxy for the price of marine gasoil) was $97.5 \%$. The correlations are even higher if Brent crude oil price is considered instead $(99.3 \%$ for heating oil and $98.6 \%$ for fuel oil).

\footnotetext{
${ }^{30} \mathrm{https}: / /$ www.clean-cargo.org/data-methods

${ }^{31}$ Brent is another useful benchmark crude for global marine fuels and may avoid issues associated with the recent divergence of WTI and Brent following the sharp expansion of U.S. inland oil production.
} 
Clearly, the price of oil matters for the competitiveness of alternative fuels with conventional petroleum fuels. Figure 11 displays the range of crude oil price projections presented in EIA's AEO 2021. Oil price is one of the key inputs to AEO scenarios where a market equilibrium model solves for the supply, demand, and prices for the entire U.S. energy sector. The AEO contains additional scenarios that vary the assumptions about macroeconomic growth, domestic oil and gas recoverable resource volumes, and technological progress in renewables. The resulting oil prices from all those other scenarios lie within the range shown in Figure 11.

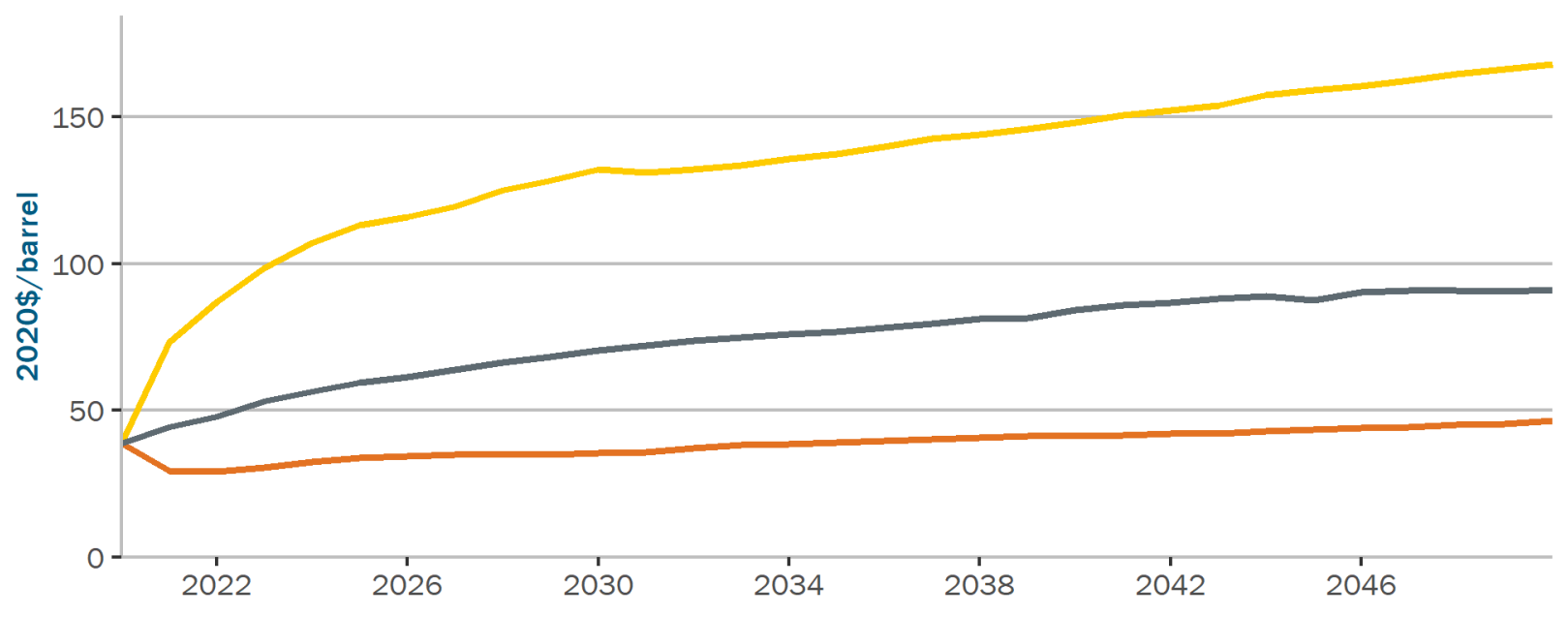

Scenario — Reference — Low_Oil_Price — High_Oil_Price

Figure 11. Crude oil (WTI) price projections

Source: EIA Annual Energy Outlook 2021

In the Reference case, global oil supply and demand are assumed to grow steadily and at similar rates resulting in a smooth price trajectory with average annual growth rate of $2.3 \%$. Within the United States, total light-duty vehicle sales start decreasing in 2020. Although the share of electric and hybrid vehicles increases, gasoline continues to be the dominant fuel for new vehicles in the Reference case with a share of $79 \%$ of sales by 2050 . The driving assumptions for the Low Oil Price case are lower demand and higher supply outside the United States than in the Reference case. The opposite forces (higher demand and lower supply than in the Reference case) would drive the High Oil Price case. The average annual growth rates for oil price in the Low Oil Price and High Oil price cases are $0.6 \%$ and $3.1 \%$, respectively. The marine fuel price trajectories used in Chapter 6 correspond to the Reference, High Oil Price, and Low Oil Price cases.

One important feature of EIA's AEO scenarios is they only model laws and regulations that are already enacted/approved. None of these scenarios model the effect of potential decarbonization targets in the electricity or transportation sectors. The impact of decarbonization policies has been considered in other global energy market outlooks (e.g., BP Energy Outlook, IEA Net Zero Roadmap, OPEC World Oil Outlook), but these typically generate projections for oil demand rather than price. Overall, these outlooks indicate that strong commitments by governments toward decarbonization are a stronger lever than GDP growth rate or oil prices for the evolution of oil demand. With the policies already in place as of 2020, oil demand stays around $100 \mathrm{MMbbl} /$ day or higher by mid-century. Ambitious decarbonization scenarios 
lead to large decreases of oil demand. For instance, global oil demand is $71 \mathrm{MMbbl} /$ day in 2045 in the Mitigation A scenario from the OPEC World Oil Outlook 2020, $24 \mathrm{MMbbl} /$ day in the Net Zero scenario from BP Energy Outlook 2020 by 2050 and 21 MMbbl/day in IEA's Net Zero Roadmap by 2050. The IEA Net Zero Roadmap also includes a crude oil price projection. Crude oil price does not recover from 2020 levels; instead, it progressively declines to $\$ 24 /$ bbl by 2050 ; that is approximately half the value projected in EIA's Low Oil Price scenario by mid-century.

\subsection{REFINERY ECONOMICS AND THE DEMAND FOR OTHER PETROLEUM PRODUCTS}

Petroleum Product mix supplied and demanded in all sectors: Although the level of all petroleumbased fuel prices will reflect trends in global crude oil demand and price, the relative prices of the various petroleum-based fuels can shift markedly with the mix supplied and demanded. For the United States, Figure 12 shows the evolution of the refined product mix in the past decade. Notably, the share of residual fuel oil (the most relevant product for marine fuel during this period) declined steadily from $3.7 \%$ in 2010 to $2 \%$ in 2019. This decline in share results from a combination of lower residual fuel oil production volumes and increase in total refinery output. The reduction in residual fuel oil production is partly due to the change in crude slates at U.S. refineries toward lighter crude oils. In the USGC, where more than 50\% of U.S. refinery capacity is located, the share of crudes with the largest residual fuel oil yields (medium sour and heavy sour) decreased from $40 \%$ to $20 \%$ in the last decade. ${ }^{32}$ Refinery product mix depends on refinery economics and configuration and will be an important driver for the relative prices of the petroleum-based fuels that vessel owners can use to comply with the IMO 2020 rule.
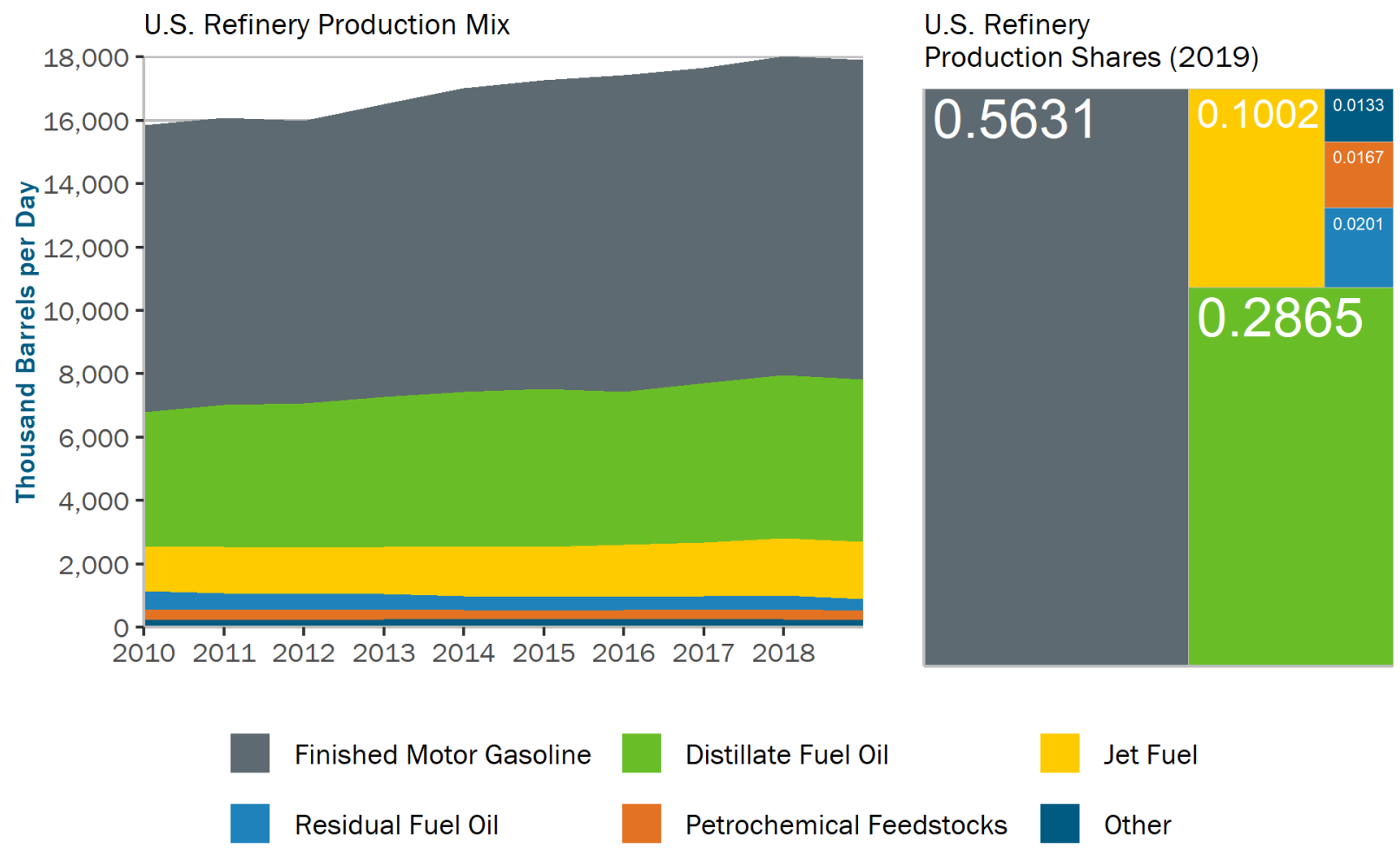

Distillate Fuel Oil

Jet Fuel

Petrochemical Feedstocks

Other

Figure 12 U.S. refinery product mix

Source: EIA

${ }^{32}$ https://rbnenergy.com/comin-to-america-part-4-gulf-coast-refineries-slashing-their-need-for-imported-crude-oil 
Figure 13 presents a longer history of residual fuel oil production and sales in the United States breaking out the portion of sales that is consumed by marine vessels (for either domestic or international shipping). The three series in Figure 13 trend downwards, but sales for vessel bunkering have remained much more stable over the past 35 years than U.S. residual fuel oil production or total sales. Despite the pronounced decline in residual fuel oil production by U.S. refineries, the domestic demand for it (mostly in uses other than marine fuel such as electricity generation) declined faster. In 2009, the United States transitioned from net importer to net exporter of residual fuel oil. The fraction of residual fuel used in the bunkering sector increased steadily from $22 \%$ in 1984 to $98 \%$ in 2014. However, from 2015 to 2018, it decreased rapidly to $55 \%$ in 2018 due to a combination of increased total sales and decreased use by marine vessels.

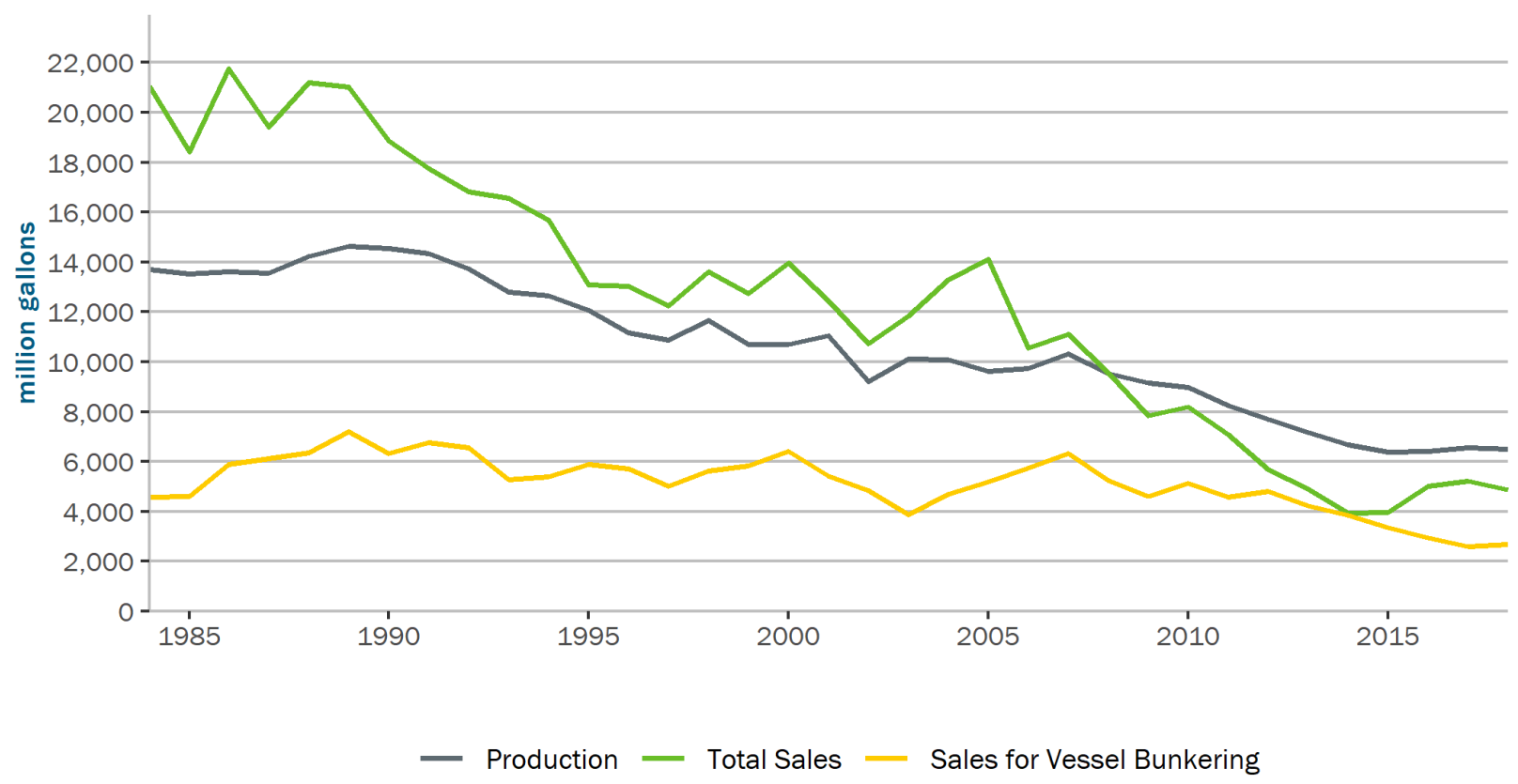

Figure 13. U.S. production and sales of residual fuel oil

Source: EIA 


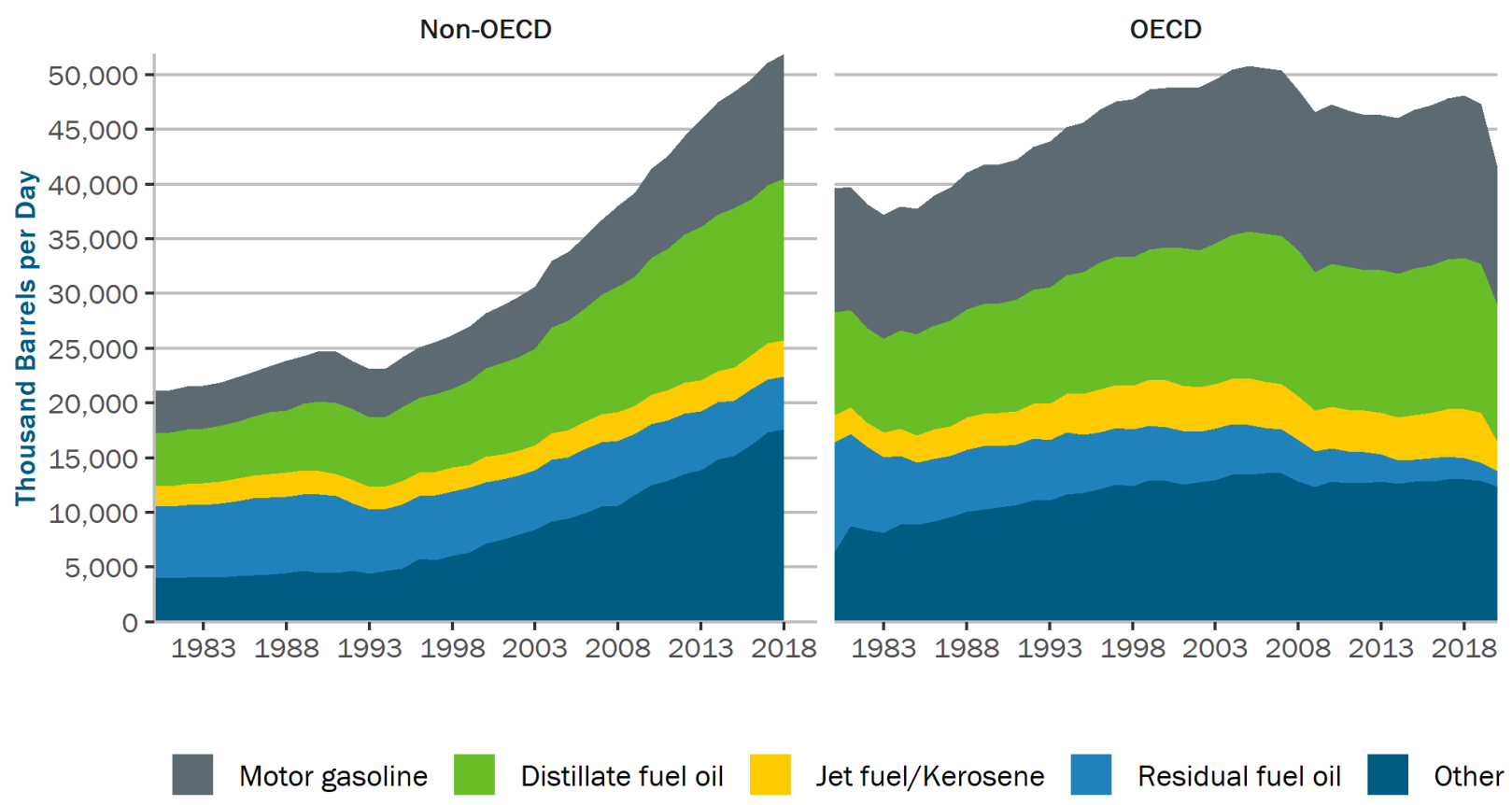

Figure 14. Global consumption of refinery products by region (1986-2018)

Source: EIA

Figure 14 shows the progressive substitution of distillate fuel oil for residual fuel oil in the global mix of refined products consumed. The decline in the share of residual fuel oil is more pronounced in OECD countries where residual fuel oil has steadily declined from $25 \%$ of the volume of refined products consumed in 1980 to $3 \%$ in 2020 . In non-OECD, residual fuel oil declined from a share of $31 \%$ in 1980 to 9\% in 2018 and the consumption shares of distillate fuel oil and "other" products increased.

The relative prices of VLSFO, MGO, and HSFO will be influenced by refinery economics. The relative demand for key products (i.e., gasoline versus diesel, which varies by world region and season), refinery configuration (e.g., desulfurization capacity availability), and refinery process flexibility are three important drivers of refinery production mix and prices.

Refinery operations and process flexibility: The flexibility of refinery operations is important for the stability of product supply and price. For shippers, the level and volatility of VLSFO price (the marine fuel with the largest market share post IMO 2020) is important for fuel risk management purposes.

VLSFO is a blend of multiple streams and can be produced in different ways.

1. Processing very-low sulfur (i.e., sweet) crudes

- If a refinery were to purchase oil to maximize VLSFO production, the ideal crude oil type would have medium to high density (because these crude types have higher residue yields) and low sulfur content (sweet crude). ${ }^{33}$

2. Removing sulfur from sour crude residue in an atmospheric residue desulfurization unit or vacuum residue desulfurization unit

- $\quad$ OPEC (2020) projects substantial need for additional desulfurization capacity out to 2045 driven by two trends: a) near-universal adoption of low-sulfur gasoline and diesel, b)

\footnotetext{
${ }^{33} \mathrm{https}: / / \mathrm{www} . \operatorname{argusmedia.com/en/blog/2019/august/28/imo-2020-vlsfo-blends~}$
} 
expected increase in the average sulfur content of the global crude oil pool. As of 2020, North America is the world region with the highest fraction of desulfurization capacity $(\sim 85 \%)$ relative to crude oil distillation capacity. ${ }^{34}$

3. Diverting hydrotreated VGO to the bunker fuel pool

4. Blending low-sulfur distillates (e.g., jet fuel, gasoil) with residual fuel oil ${ }^{35}$

The VLSFO coming out of each refinery will depend on the type of crude it processes (sweet or sour, light or heavy), refinery configuration, and target product slate. While the exact composition of VLSFO may be unknown to the shipper that buys it, VLSFO fuel sample properties provide information to infer it. For instance, VLSFO blends with VGO have higher pour points while VLSFO blends containing distillates have lower densities.

Variability in VLSFO composition makes it difficult to identify the key price relationships to track for fuel purchase and price risk hedging decisions. On the other hand, the flexibility of VLSFO production pathways potentially gives this fuel greater resilience to shifting patterns of demand and supply across the petroleum product complex. Figure 15 and Figure 16 show how price differentials between VLSFO and various refinery products experienced pronounced shifts in 2020.
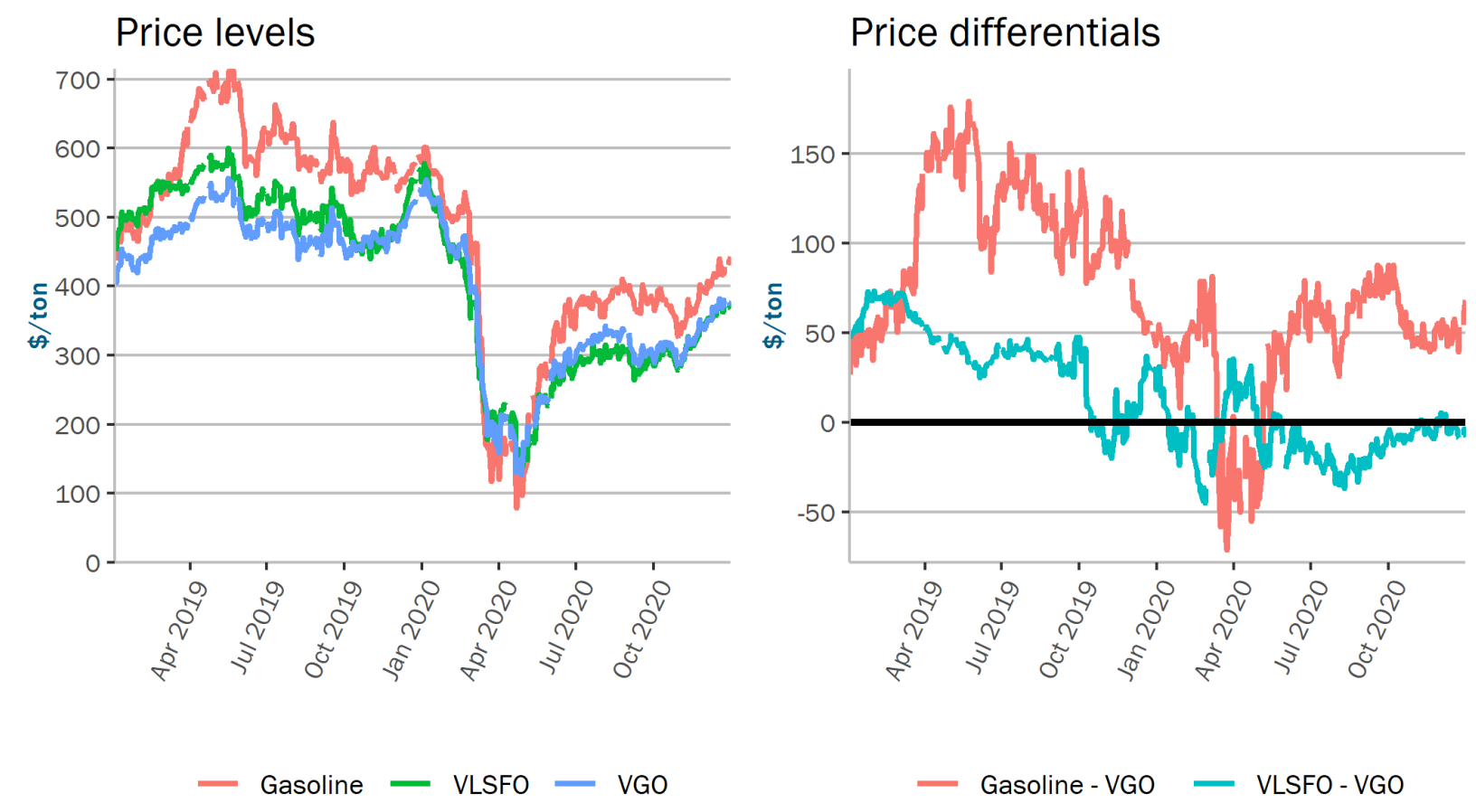

Figure 15. Prices of gasoline, VGO, and VLSFO in Northwest Europe (2019-2020)

Source: Argus

In 2019, VGO had the lowest price among the three products in Figure 15. VGO is typically priced lower than gasoline as it is an input to gasoline production in fluid catalytic crackers. However, from March to May 2020, the price of gasoline dropped below that of VLSFO and VGO due to the very large reduction in gasoline consumption brought about by COVID lockdowns in Europe. Marine fuel demand also

\footnotetext{
34 The capacity of the distillation process unit is often used interchangeably with refinery capacity.

${ }^{35}$ https://www.argusmedia.com/en/news/2147975-distillate-blending-in-vlsfo-raises-concerns
} 
decreased less severely during those months making the bunker fuel pool a higher value use of VGO than gasoline. During the summer months, gasoline started selling again at a premium relative to VGO.

VLSFO sold lower than VGO during the summer suggesting that it contained a blend of VGO and other cheaper components. Finally, towards the end of 2020, VGO and VLSFO were selling at approximately the same price.

The price relationship between gasoline, VGO, and VLSFO is one to keep tracking beyond 2020 to assess its stability as COVID-related decreases in light-duty vehicle and aviation fuel use are reversed.
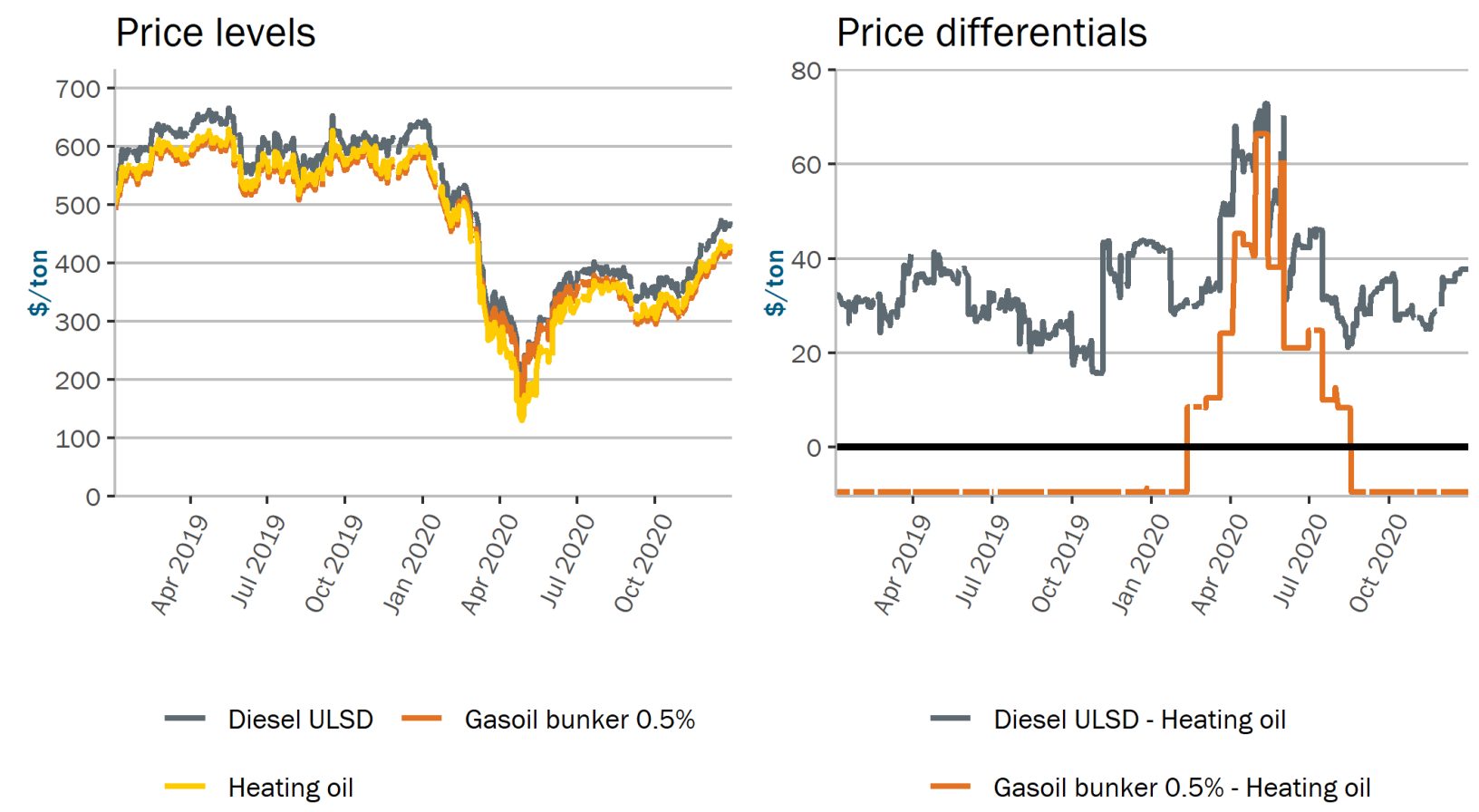

Figure 16. Distillate product prices in New York Harbor (2019-2020)

Source: Argus

Price relationships among distillate fuels: Using New York Harbor as an example, Figure 16 shows that prices move close together within the category of distillate products which includes diesel, heating oil, and gasoil bunker (MGO). The correlations among the price levels of distillates in New York are all above $99 \%$ in 2019-2020. MGO is close in composition to heating oil so that they compete for similar refinery product streams.

From January 2019 to December 2020, the average price at New York Harbor was \$499/ton for ultra-low sulfur diesel (ULSD), used for road transportation, and $\$ 465 /$ ton for heating oil and gasoil bunker with $0.5 \%$ sulfur. In 2019, gasoil bunker was the bottom price among these three series and ULSD was the ceiling. ULSD remained the highest price in 2020 but, from March to September, the gasoil bunker price rose above the heating oil price. This seems to indicate that there was more demand for marine distillates than heating oil during that period. Heating oil has a markedly seasonal demand but, in 2019, there was no sustained reversal in the spread outside of the heating season.

In 2020, shippers chose VLSFO over MGO because it was cheaper and the initial availability and quality concerns regarding VLSFO did, in general, not materialize. Post-2020, VLSFO price could increase in the 
short run if quick recovery of gasoline and jet fuel demand post-COVID uses up the VGO streams that went into the bunker fuel pool in 2020. However, a scenario where MGO is chosen instead of VSLFO for IMO 2020 compliance purposes is unlikely. Given the relative volumes of gasoline and diesel versus residual fuel oil, small percentage decreases in petroleum-based fuel consumption for road transportation as electrification progresses could influence the relative prices of VLSFO to marine gasoil going forward. A long-term decreasing trend in the price of gasoline would tend to keep the price of distillates like MGO higher than the price of VLSFO.

Price differentials between crude grades also matter for the VLSFO-HSFO spread. It was expected that, post IMO 2020, the spread between sweet and sour crudes would widen as sour, high-sulfur crudes become less attractive. However, in 2020, the spreads were narrow. On one hand, U.S. sanctions to Iran and Venezuela resulted in many countries avoiding purchases of oil from these countries which mostly produce sour crudes. This reduction in sour crude being processed made its price not fall as much as expected. On the other hand, low-sulfur sweet crudes maximize the yield of the refined products (gasoline, jet fuel) whose demand suffered the most due to COVID. Therefore, their price was lower than anticipated in 2020. In 2021 and beyond, the sweet-sour spread will likely widen. If it does widen, it would also be reflected in the spread between HSFO and VLSFO prices. This price spread was also narrower than expected in 2020 resulting in delays and cancellations of scrubber installations.

\subsection{ENVIRONMENTAL REGULATION AND INCENTIVES}

The IMO is the organization in charge of regulating the GHG emissions from international shipping; regulation of emissions from domestic shipping activities falls under the remit of national governments. In 2011, the IMO adopted the Energy Efficiency Design Index (EEDI) and the Ship Energy Efficiency Management Plan (SEEMP) which have the objective of reducing the carbon intensity of international shipping for new and existing ships, respectively. The EEDI mandates new ships within specific type and size categories to have technical carbon intensity ( $\mathrm{gCO}_{2} /$ ton-mile) below a maximum value. The SEEMP is a ship-specific plan to improve operational energy efficiency through adequate maintenance, installation of waste heat recovery methods, weather routing, optimized cargo handling, or energy management systems on ship, among other measures. Having an approved SEEMP on board will become mandatory for vessels over 400 gross tons in 2023.

Additionally, in 2018, the IMO adopted its initial GHG strategy with the aspirational goals of:

- Reduction in average carbon intensity of international shipping by at least $40 \%$ by 2030 and $70 \%$ by 2050 relative to 2008 levels

- Reduction in the absolute level of GHG emissions by at least $50 \%$ with respect to 2008 levels by 2050 .

It is widely agreed that achievement of these goals would require substantial levels of adoption of lowcarbon fuels.

Additional policy proposals aiming to reduce $\mathrm{CO}_{2}$ emissions in the shipping sector are arising at the regional level. In July 2021, the European Commission released a proposal to expand its carbon trading market, the European Union (EU) Emissions Trading System (ETS), to include shipping emissions starting in 2023. The qualifying shipping emissions would be phased-in between 2023 and 2026. The requirement to surrender allowances in the EU ETS would apply to $100 \%$ of $\mathrm{CO}_{2}$ emissions in intra-EU voyages, $50 \%$ in voyages that start (end) at one of the EU Member states and end (start) outside the EU, and $100 \%$ of $\mathrm{CO}_{2}$ emissions at berth in any EU port. Therefore, if implemented, this policy would apply to voyages by the U.S.-flagged fleet involving an origin or destination in the EU. The average price of EU 
ETS allowances was 25 euros/ton of $\mathrm{CO}_{2}$ equivalent ( $\$ 28 /$ ton of $\mathrm{CO}_{2}$ equivalent) in 2019 ; this is the highest annual average price since the EU ETS allowance trading started in 2005 (Nissen et al., 2020).

Reduction of $\mathrm{CO}_{2}$ emissions is not the only type of environmental regulation in the horizon for marine shippers. For instance, the IMO GHG4 study shows that the fastest increase in GHG emissions from marine shipping in recent years came from methane rather than $\mathrm{CO}_{2}$. LNG use in international shipping increased by $\sim 30 \%$ from 2012 to 2018 and methane emissions in the marine sector increased by $150 \%$ during that period. The difference in growth rates has to do with the change in the types of ships using LNG. Up to 2012, most LNG was consumed by LNG carriers in steam boilers. Since then, other types of ships including container ships and cruise ships have also started using LNG as fuel, but they use internal combustion engines that emit more unburned methane than the steam turbines. Methane is not yet regulated by the IMO, but it could be in the future as concerns regarding "methane slip" intensify.

\section{SCENARIOS: FUEL PRICE, POLICY, AND TECHNOLOGY}

\subsection{GENERAL DESCRIPTION OF THE SCENARIO ANALYSIS}

We built a cost model to compare different alternatives for a U.S. vessel (containership or tanker) to comply with the IMO 2020 rule. The model does not describe the full shipping cost; it focuses on the two components - capital cost (retrofit cost or new ship cost) and fuel cost- that vary the most across the different compliance approaches. Other ship operating costs (crew cost, maintenance, insurance etc.) are not expected to vary substantially with compliance approaches. The cost model equations are presented in Appendix B.

We apply the model for a "typical" U.S. vessel in terms of size and age. We consider the two types of vessels (containerships and tankers) that make up $70 \%$ of the U.S. fleet of ocean-going vessels as shown in Figure 7. The average U.S. containership has a capacity of 44,425 gross tons and is 19 years old. The average U.S. tanker has a capacity of 39,228 gross tons and is 14 years old. Capacity is kept fixed at the average values in all the scenarios, but age is treated as a sensitivity in the analysis.

There are four general alternatives for a (U.S.) vessel to comply with the IMO 2020 rule:

- use low sulfur fuel oil (VLSFO) on existing vessel

- retrofit the vessel to install a scrubber and keep using HSFO

- retrofit the vessel/engine to use an alternative fuel (e.g., $L N G$ )

- build a new ship to use conventional low sulfur oil (VLSFO) or an alternative fuel (LNG; ammonia, methanol, ethanol).

Table 10 further details the eight compliance approaches explored in the cost model for each vessel type. Each compliance approach is defined by a combination of capital equipment investment (if needed), fuel used, and associated engine type which determines the engine efficiency parameter. Alternatives involving the switch to alternative lower carbon or zero-carbon fuels not only comply with IMO 2020 but are also valuable for advancing decarbonization goals. 
Table 10. Primary Fuel and Technology Compliance Path Options Evaluated

\begin{tabular}{llll}
\hline Compliance Approach & Capital Equipment & Fuel & Engine Efficiency Type \\
\hline VLSFO_existingship & none & VLSFO & Otto \\
\hline HSFO_scrubber & scrubber_retrofit & HSFO & Otto \\
\hline LNG_retrofitengine & LNG_retrofit & LNG & Diesel \\
\hline VLSFO_newship & newship & VLSFO & Diesel \\
\hline LNG_newship & newship & LNG & Diesel \\
\hline Ethanol_newship & newship & Ethanol & Diesel \\
\hline Methanol_newship & newship & Methanol & Diesel \\
\hline Ammonia_newship & newship & Ammonia & Diesel \\
\hline
\end{tabular}

Uncertainty is treated through sensitivity analysis. This highlights the range of outcomes and lets us illustrate the risk associated with the choices (e.g., risk from investing in a technology/fuel alternative that turns out to be higher cost or less aligned with emerging regulatory initiatives and environmental goals). Some compliance strategies may be more able to do well over a range of uncertain cases.

Costs for each compliance approach are calculated under a variety of scenarios:

- fuel prices

- $\quad$ Three scenarios (Reference, Low Oil Price, and High Oil Price) from the U.S. EIA's Annual Energy Outlook (AEO) 2021 projections

- One scenario using recent average prices for conventional petroleum fuels and the future fuel prices stated in the IMO GHG4 study for alternative fuels

- decarbonization/regulatory cases are addressed through the implied cost of $\mathrm{CO}_{2}$ reductions for the different IMO compliance approaches

- We do not make explicit assumptions about GHG prices, markets, or the choice between buying credits versus investing in lower GHG technology.

- vessel age (remaining service years)

- interest/discount rate sensitivity: low, medium, high (see Table 11)

- scrubber efficiency sensitivity: low, medium, high (see Table B-2)

\subsection{MODEL INPUT PARAMETERS AND DATA}

\subsubsection{Vessel, fuel, engine, and cost parameters}

The data needed for the analysis include some parameters that are specific to each vessel type and compliance approach as well as the parameters on cost and economic data listed in Table 11 which are shared by all scenarios.

Table 11. Cost Parameters Shared by All Cases

\begin{tabular}{lrrr}
\hline Parameter & Low & Base & High \\
\hline interest_rate & 0.03 & 0.04 & 0.1 \\
\hline base_vessel_lifespan & 15.0 & 20.0 & 35.0 \\
\hline current_year & 2021 & 2021 & 2021 \\
\hline LNG_newship_cost_premium & 0.2 & 0.2 & 0.2 \\
\hline Altfuel_newship_cost_premium & 0.5 & 0.5 & 0.5 \\
\hline newship_cost_multiple_USvsforeign & 3.0 & 3.0 & 3.0 \\
\hline
\end{tabular}




\subsubsection{Average projected marine fuel prices}

Average fuel prices are constructed from the cases in EIA's AEO 2021. The prices for HSFO and ethanol are directly taken from the AEO. For the rest, we used historical data to estimate linear equations that describe the relationship between the target fuel series (VLSFO, MGO, LNG, methanol, ammonia) and a fuel that is part of the AEO projections (HSFO, diesel for industrial use, Brent crude oil, natural gas). The estimated equations are then applied to the relevant AEO series to obtain projections of the price of the target fuel. The estimated coefficients for these equations are presented in Table B- 5 .

All fuel prices are converted to dollars per ton of fuel oil equivalent to account for the different energy content of the various fuels considered. The prices for ammonia and methanol are for "grey" versions of the fuel that use natural gas as the feedstock. The projected average prices for 2020-2050 of conventional and alternative marine fuels, based on EIA's AEO 2021 cases, are summarized in Figure 17. It shows that some of the alternative fuels (ethanol, ammonia, methanol) are less sensitive to variations in crude oil price than the petroleum-based marine fuels and so are comparatively more (or less) competitive in high (or low) oil price scenarios.

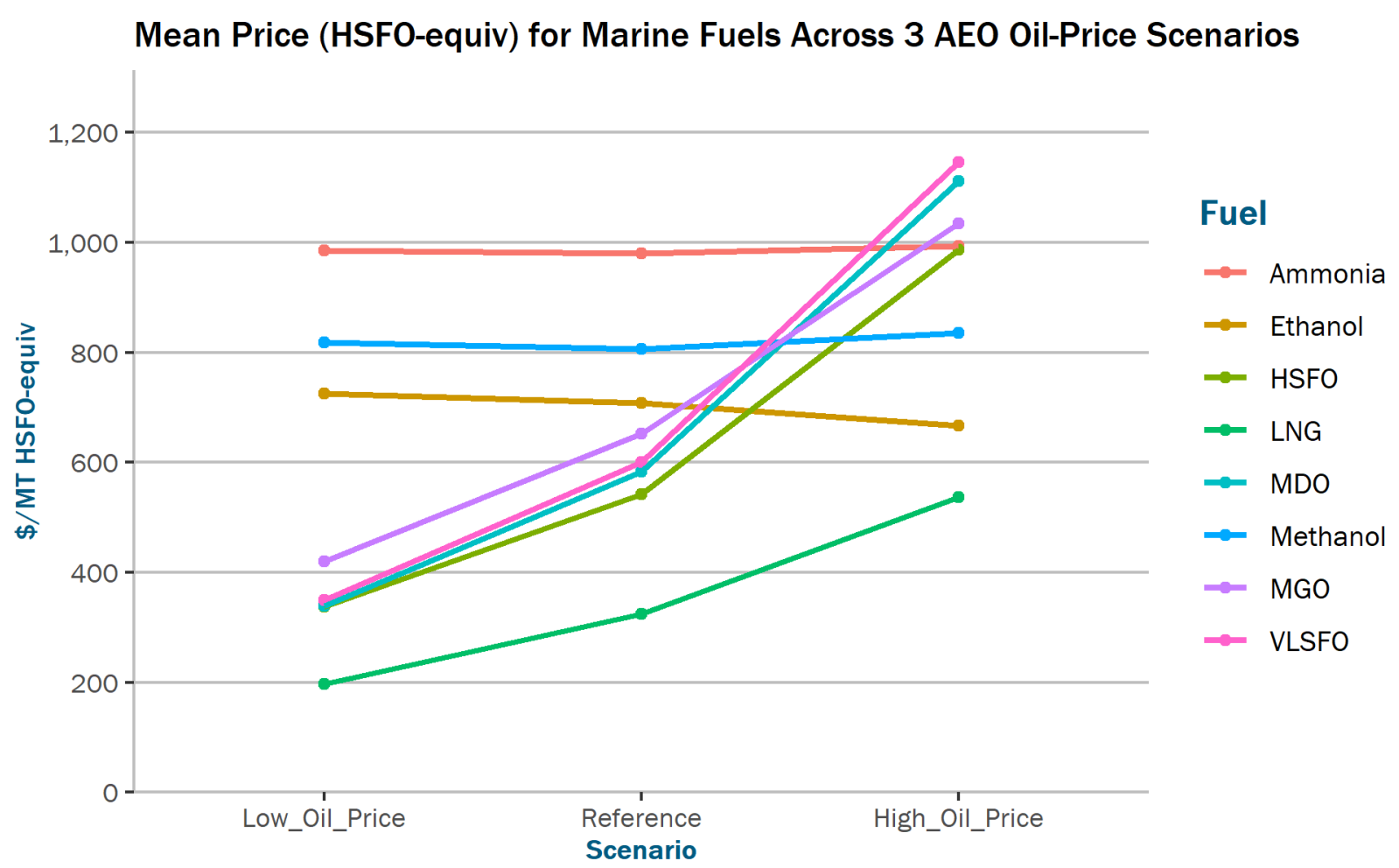

Figure 17. Mean price for marine fuels across three AEO oil price scenarios.

For each price scenario, cost calculations are based on the AEO mean price projection for 2020-2050. A fourth price scenario uses the average 2019 observed prices from Argus for petroleum-based fuels and the future prices (2050) listed in the IMO GHG4 study for the ammonia, ethanol, LNG, and methanol. Table 12 compares mean prices (in dollars per ton) across the four cases. Results in the rest of the chapter are based on prices in dollar per ton of HSFO equivalent. 
Table 12. Mean prices from AEO (and IMO GHG4 study/Argus)

\begin{tabular}{lrrrr}
\hline Fuel & Low_Oil_Price & Reference & High_Oil_Price & IMO_GHG4/Argus \\
\hline Ammonia & 554 & 551 & 559 & 660 \\
\hline Ethanol & 490 & 478 & 450 & 670 \\
\hline HSFO & 338 & 543 & 986 & 400 \\
\hline LNG & 236 & 389 & 644 & 590 \\
\hline MDO & 364 & 627 & 1,195 & 501 \\
\hline Methanol & 464 & 457 & 474 & 400 \\
\hline MGO & 452 & 702 & 1,112 & 561 \\
\hline VLSFO & 364 & 627 & 1,195 & 501 \\
\hline
\end{tabular}

\subsection{ESTIMATED COSTS FOR BASE CASES OF EACH COMPLIANCE APPROACH}

Given the framework for fuel and capital cost accounting described above, we compute the costs of alternative compliance approaches (in U.S. dollars per year) and $\mathrm{CO}_{2}$ emissions.

$$
\text { Cost }=\text { annual capital charge }+ \text { annual fuel consumption } * \text { fuel price }
$$

The fuel consumption reflects any fuel-efficiency effects of the engine/ship choice and the fuel efficiency penalty of a scrubber, if chosen. The annualized capital cost is determined by total capital cost of scrubber, engine retrofit, or new ship capital costs, vessel's loan period (20 years) and interest rate ( $4 \%$ in the base case). New ship efficiency gain of $45 \%$ is assumed.

A bar chart of the results for the Base Case Set, with Reference mean AEO fuel prices shows that the compliance approaches using new ships are, not surprisingly, far more expensive than approaches that utilize existing ships and either low-sulfur fuel oil or retrofits for scrubbers or LNG. These results are for ships of average age in the U.S. fleet: 19 years for containership and 14 years for tanker. 


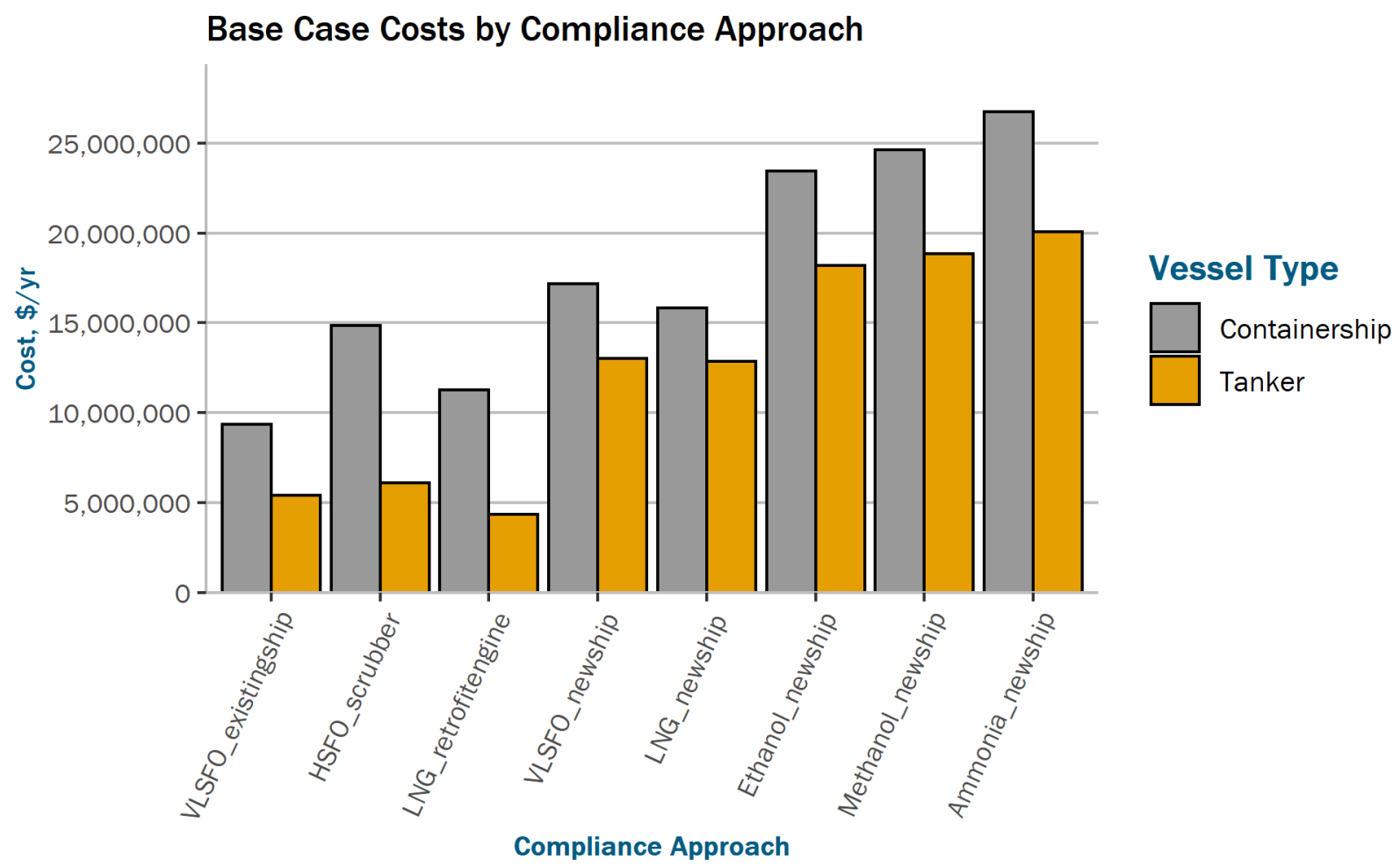

Figure 18. Base case costs by compliance approach and vessel type

The pattern of relative costs of compliant approaches is similar for containerships and tankers. One exception is that the estimated incremental cost of retrofitting for the use of LNG is lower for tankers than containerships. This is due to differences in vessel configuration and the more limited space on container vessels for LNG storage and fuel management equipment. The assumed incremental capital cost of LNG retrofitting is disproportionately lower for tankers ( $1 \%$ of new ship cost) than for containerships ( $3 \%$ of new ship cost). Furthermore, incremental annual capital charge for LNG retrofit is also lower on a typical tanker because tankers are on average younger than containerships and have more years of service remaining over which to amortize the retrofit cost.

\subsection{ESTIMATED COSTS AND CO $\mathrm{CO}_{2}$ EMISSIONS FOR SENSITIVITY CASES}

We consider sensitivity cases for variations of the following parameters:

- Fuel prices

- Vessel age

- Interest rate

- Scrubber efficiency penalty

\subsubsection{Sensitivity to vessel age}

We consider a range of vessel ages for an exploration of the sensitivity of compliance approach cost to vessel age. Figure 19 displays the total capital plus fuel cost of the eight compliance approaches for each of the two ship types, for vessel ages from zero years (new) to 20 years. 


\section{Cost by Fuel/Tech Compliance Approach, Sensitivity to Age}

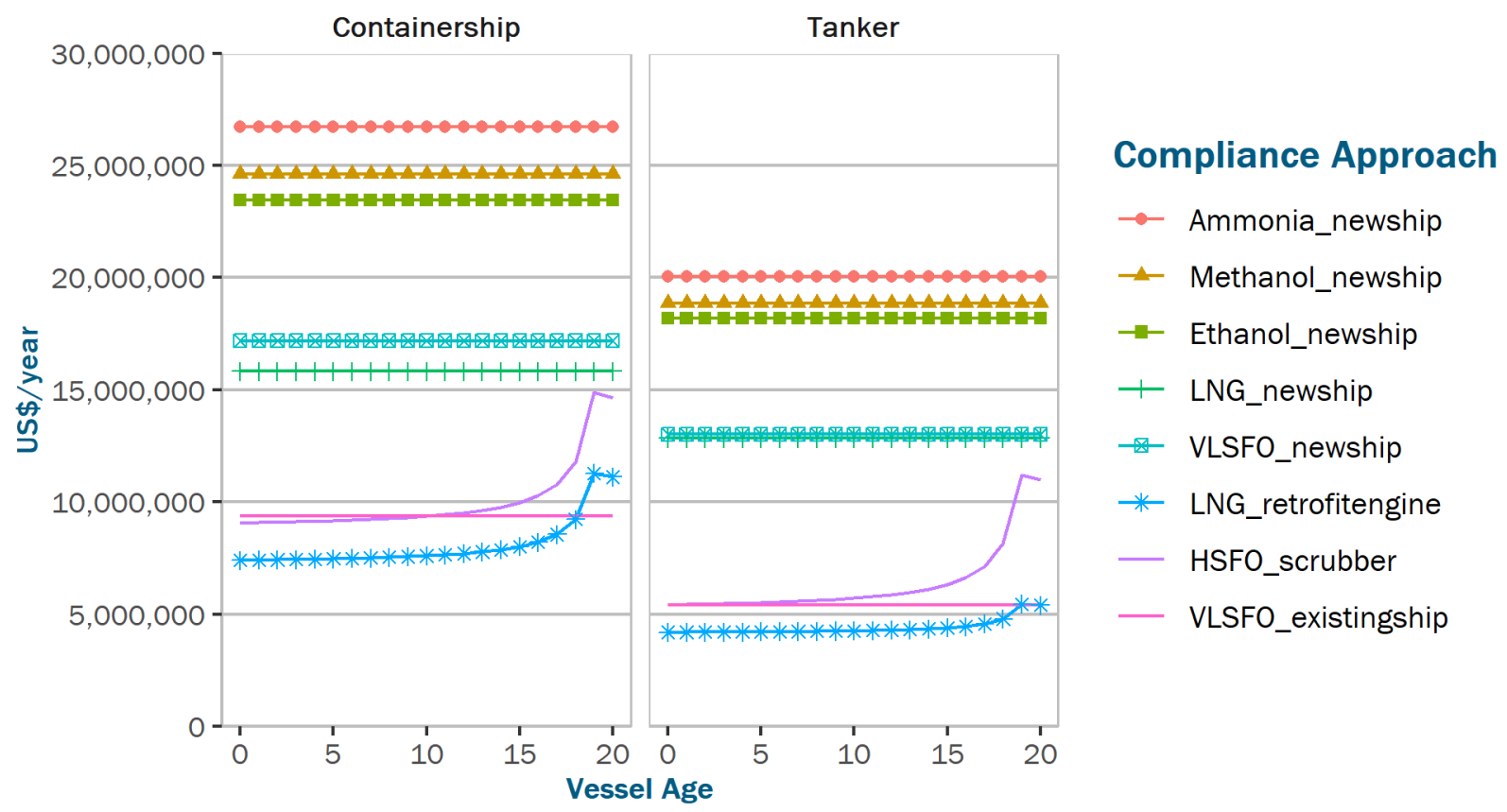

Figure 19. Cost by fuel/technology compliance approach, sensitivity to vessel age

Figure 19 shows there are three clearly distinct regimes or groupings of compliance approaches in terms of costs (particularly for tankers): 1) low-sulfur petroleum fuels or LNG retrofit are all part of the lowest cost regime 2) VLSFO new ship/LNG new ship are intermediate in cost, and 3) new ships with alternative fuels are highest cost.

The principal age-sensitivity arises for older vessels, here ages $\sim 14-19$ years, when the annualized capital cost of the retrofit options (scrubber, LNG-retrofit) rises quickly because of the limited remaining vessel life over which to amortize it.

Our approach to costing out the capital cost of any option involving a new ship makes the annual cost result invariant with the age of the existing ship. A critical assumption is that the scrappage cost, and the used-vessel value, is taken as approximately zero in the U.S. market of older Jones Act vessels. A second important assumption is that new vessel construction costs for a U.S. Jones Act-eligible vessel are substantially higher than constructions costs in the global market. ${ }^{36}$ As a result, for a vessel of any age from 0 to 19 years, it is more cost-effective to continue to operate used vessels as long as practical than to buy a new vessel of any kind. This is despite the assumed $45 \%$ higher efficiency of new ships (with new engines and hull designs).

As shown earlier, under the current and projected Reference oil market outlook, the lowest cost compliance approach in many instances is VLSFO. Except perhaps for LNG, VLSFO dominates all other compliance approaches over all ages, for both ship types. With the substantially lower LNG prices available in the U.S. market (relative to other world regions), retrofitting existing vessels with LNG can

\footnotetext{
${ }^{36}$ Subsides for U.S. shipbuilding are no longer provided. Such subsidies "were passed as part of the Merchant Marine Act of 1936 and later expanded by the Merchant Marine Act of 1970 before being scrapped by the Reagan administration in 1981." (Grabow, 2021).
} 
be the lowest cost IMO-compliant approach in the Reference AEO price scenario. The next best option, purely in terms of fuel and capital cost, is HSFO-scrubber. HSFO with scrubber retrofit has about the same cost as VLSFO for all ages up to $\sim 12-15$ years old. After that, it becomes much more expensive.

\subsubsection{Sensitivity to fuel price}

A key uncertainty is the cost of petroleum and alternative fuels. Considering the range of average future fuel prices in the 4 price cases developed with EIA and IMO/Argus assumptions, shows a substantial dispersion of total costs of IMO compliance approaches. Figure 20 shows the cost of 8 compliance approaches for containerships and tankers, with dots showing the annual costs for the Reference price case and for 3 alternative price cases derived from the EIA AEO 2021 Low and High Oil Price outlooks, and from the IMO $4^{\text {th }}$ GHG Study/Argus. Colored lines connect the outcomes for the same price scenario across compliance approaches.

\section{Compliance Approach Costs, various price cases}

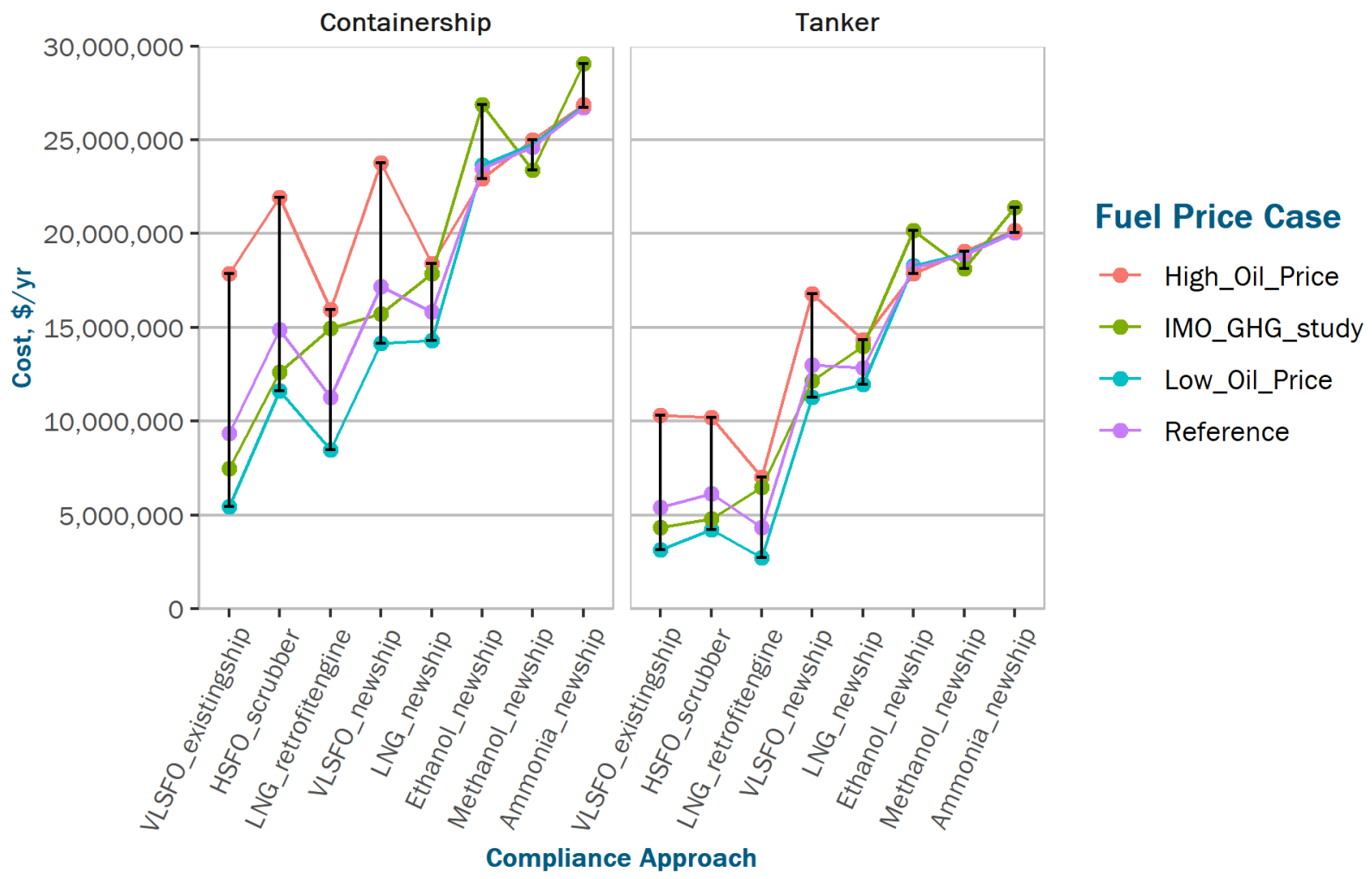

Figure 20. Compliance approach costs by fuel price case and vessel type

The previous message of 3 distinct cost regimes for compliance approaches is robust to the price sensitivity cases considered, particularly for tankers. For containerships it is not as clear cut, but there are still 2 distinct groupings: one for petroleum-based fuels and LNG, another for new alternative fuel ships with potentially lower $\mathrm{CO}_{2}$ emissions. The prices of non-fossil fuels (ethanol, methanol and ammonia, even if produced with fossil feedstock) move differently under different oil prices than the petroleum and LNG fuels. Thus, we see that the costs of new alternative fuel options are in a narrower range, far less 
dependent on the prices of oil. New ship options are also less sensitive to fuel prices due to their assumed greater efficiency than existing ships.

VLSFO use by existing ships is a highly competitive alternative for IMO compliance both under current prices and the projected AEO Reference and Low oil price cases (on average through 2050). The prospect of sustained lower petroleum prices as many regions move to electrify road transport could also create strong competition for non-petroleum marine fuels that might be used to both reduce marine sulfur and $\mathrm{CO}_{2}$ emissions. However, a return to a High Oil Price world would make the more efficient new options a lower cost option.

\subsubsection{Compliance approach costs vs strategy for sensitivity case set results}

Figure 21 and Figure 22 show compliance cost and $\mathrm{CO}_{2}$ emissions for each compliance approach combining results from all the sensitivity cases (fuel price, vessel age, interest rate, and scrubber efficiency). Each individual dot in the left panels corresponds to a combination of values for those four sensitivities. Colored lines connect the mean outcomes for each price scenario across compliance approaches.

The right panel shows the estimated tank-to-wake emissions of $\mathrm{CO}_{2}$ for each fuel, using a single carbon intensity for each fuel. Uncertainty about scrubber efficiency and fuel penalty results in a small range of $\mathrm{CO}_{2}$ emissions in the HSFO-with-scrubber compliance approach. While these are essentially tank-towake emissions, they could also be lifecycle emissions, if cost-competitive net-zero GHG versions of ethanol and ammonia can be produced. It is important to note that we only look at $\mathrm{CO}_{2}$ emissions (rather than $\mathrm{CO}_{2}$-equivalent); possible methane slip is not accounted for.

In broad terms, the costs generally rise across the options from left to right, while the estimated $\mathrm{CO}_{2}$ emissions generally fall. Again, the prices of non-fossil fuels behave differently under different oil prices, and new ship alternative fuel options are less dependent on the prices of oil. Furthermore, the cost of new alternative fuel and other new ship options, both alternative and conventionally fueled, are less dependent on ship age, since the old ship is assumed scrapped. But new ships are a more capital-intensive approach and do show sensitivity to the cost of capital (the interest rate). 


\section{Containership Cost and CO2 Emissions, with Sensitivity Cases \\ Costs CO2 Emissions}
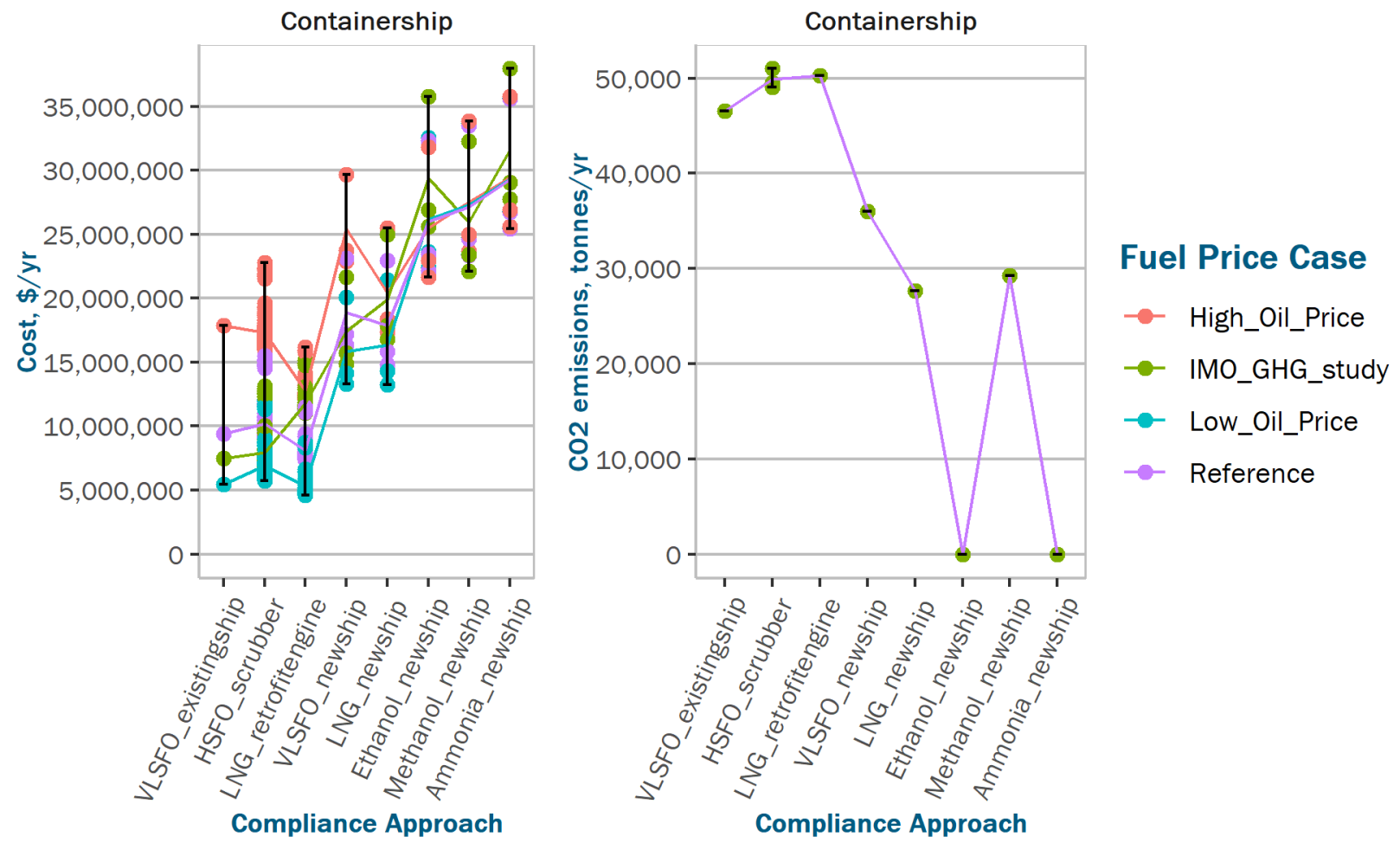

Figure 21. Compliance approach cost and $\mathrm{CO}_{2}$ emissions for containership, with sensitivity cases 
Tanker Cost and CO2 Emissions, with Sensitivity Cases

Costs

CO2 Emissions
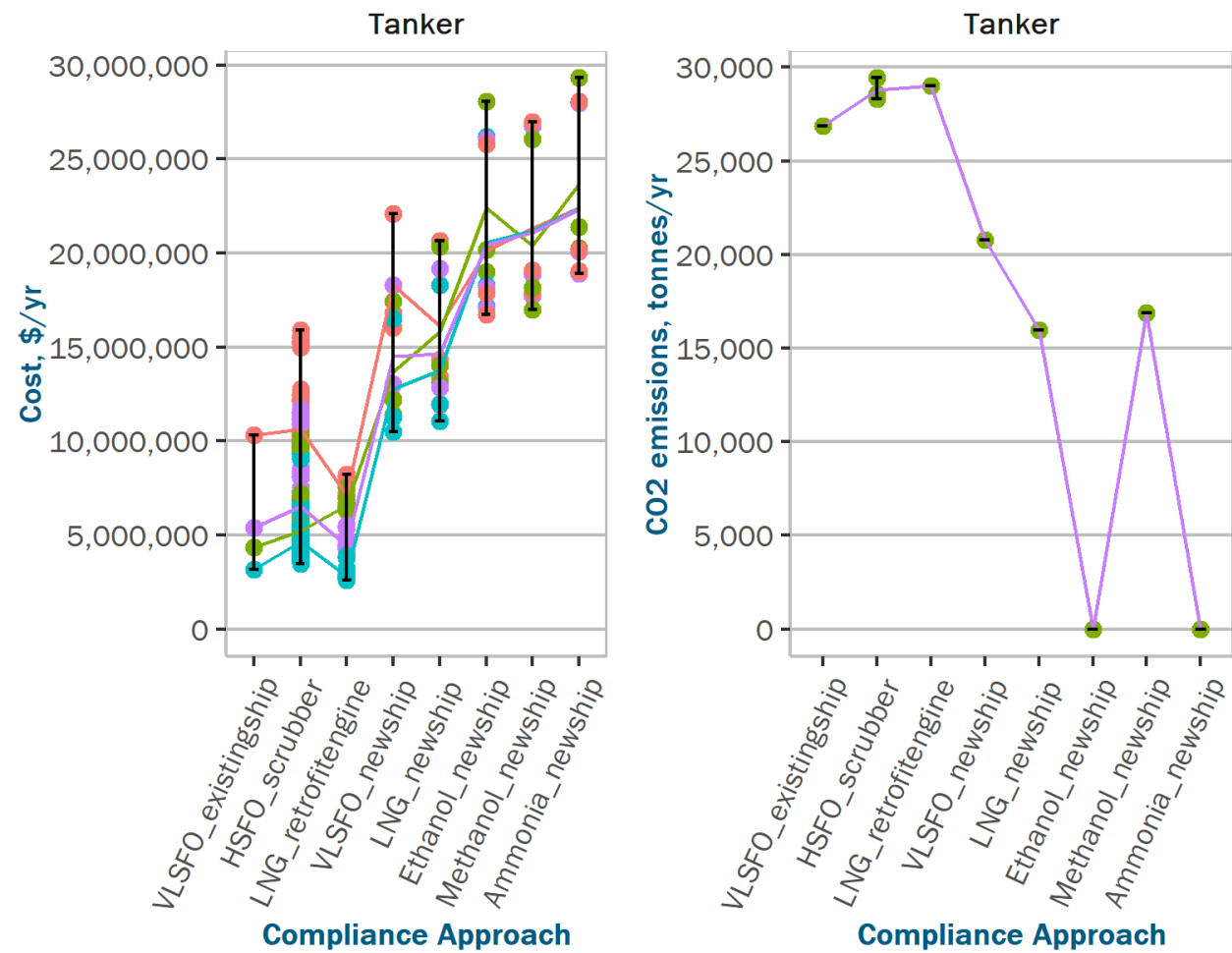

Fuel Price Case

- High_Oil_Price

$\rightarrow$ IMO_GHG_study

- Low_Oil_Price

$\rightarrow$ Reference

Figure 22. Compliance approach cost and $\mathrm{CO}_{2}$ emissions for tanker, with sensitivity cases 


\subsubsection{Implications of a carbon-constrained world}

C02 Switchover Cost, Various Sensitivity Cases

(Fuel Price, Age, Interest Rate, Scrubber Efficiency)

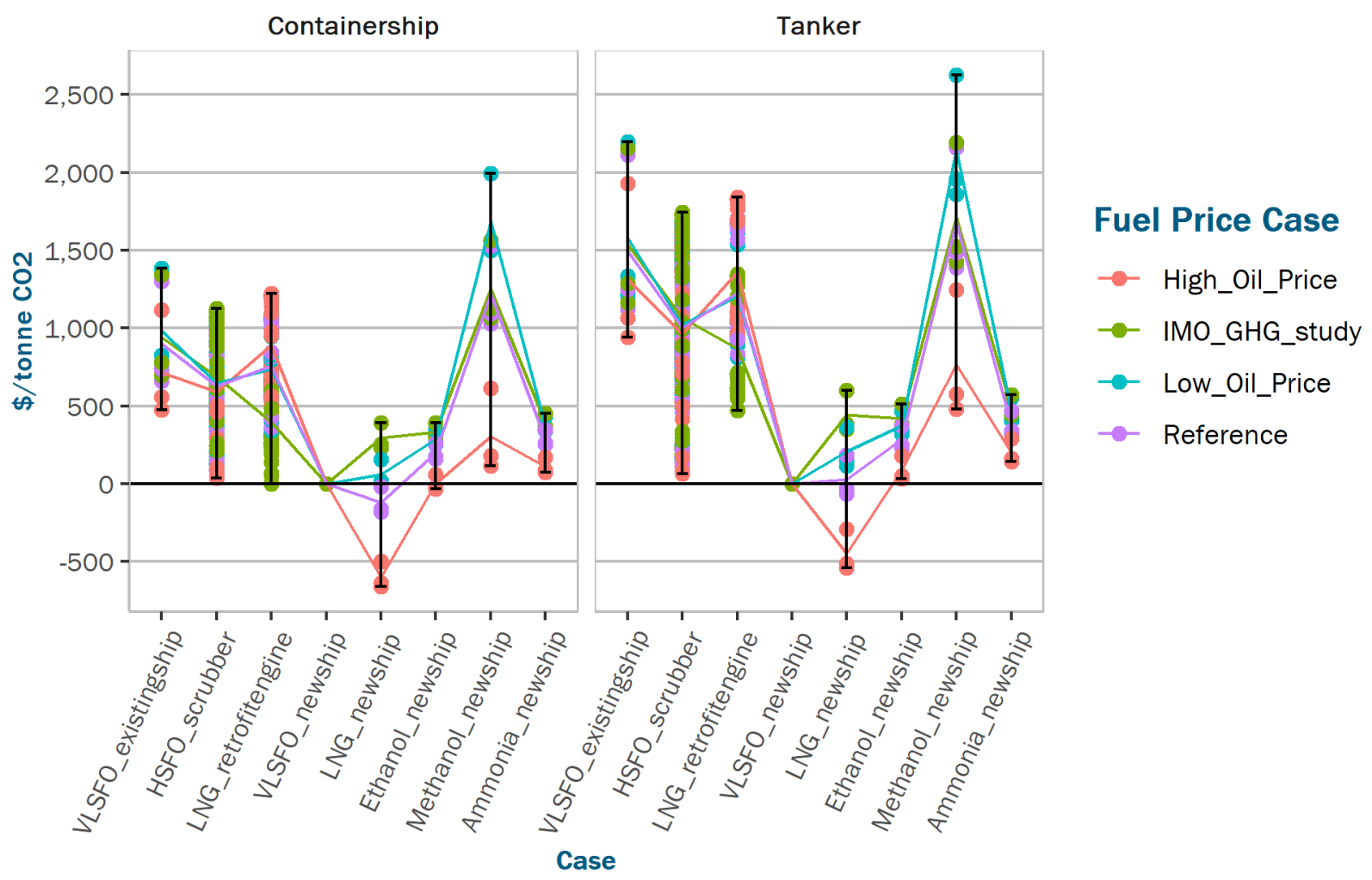

Figure 23. $\mathrm{CO}_{2}$ switchover cost by compliance approach and vessel type (across all sensitivity cases)

Figure 23 reports the $\mathrm{CO}_{2}$ switchover cost for the eight compliance approaches using a new ship fueled by VLSFO as the reference point. Some basis of comparison is necessary, and VLSFO new ship was chosen as the reference because it was an intermediate approach both in terms of cost and $\mathrm{CO}_{2}$ emissions. As the reference option, the switchover cost for VLSFO new ship is reported as zero across all the sensitivities.

Given a non-zero carbon cost, approaches to the right of VLSFO new ship, which have higher cost but lower $\mathrm{CO}_{2}$ emissions, become relatively more advantageous due to the carbon price. In contrast, points to the left (lower cost, higher emissions) would get penalized by a carbon price. Note that a carbon price tilts the costs around the new VLSFO ship (raising cost of existing petroleum ships, lowering relative cost of new-non-petroleum ships). Absent a $\mathrm{CO}_{2}$ cost, VLSFO new ship is in the middle in terms of cost and $\mathrm{CO}_{2}$ emissions given its more efficient use of petroleum than an existing typical U.S. ship.

Figure 23 shows that a positive $\mathrm{CO}_{2}$ cost could make cost-effective switching from an existing ship using petroleum or LNG to a new, more efficient ship using VLSFO. A (typically large) positive $\mathrm{CO}_{2}$ cost could also make switching from VLSFO new ship to a new alternative fuel (ethanol, methanol or ammonia) ship cost-effective, provided those fuels achieve lower $\mathrm{CO}_{2}$ emissions. This figure shows that in many cases, particularly those involving a new alternative fuel ship, the $\mathrm{CO}_{2}$ cost would have to be rather high for average U.S.-flagged containerships and tankers before such an investment would be justified based on net economics alone. However, this switchover cost is lower for scenarios with higher oil prices, and lower if capital costs or alternative fuel costs can be reduced. 


\section{CONCLUSIONS}

- Marine transport energy demand is driven by four identified factors: trends in GDP and population (driving the demand for seaborne trade); expanding trade agreements and free-trade zone agreements that have been shown to increase trade activity; changes in fleet size and composition, with containerization and larger ships increasing trade and fuel use; and mandated and marketdriven increases in energy efficiency or emissions reductions. These factors combine to indicate continued strong growth in marine transport demand and fuel demand; a shifting mix of fuel and engine technologies will be needed to avoid the growth in marine fuel demand to be accompanied by increases in $\mathrm{CO}_{2}$ emissions.

- $\quad$ Prior to 2020, IMO 2020 analyses anticipated significant fuel mix shift toward marine gasoil, with some challenges to fuel availability, and potentially substantial increases, at least in the short run, for the cost of marine fuels ( $40 \%$ or more). Some studies also anticipated observable spillover effects on the prices of diesel and gasoline fuel.

- $\quad$ Contrary to some initial concerns, compliance with low-sulfur, petroleum-based fuels neither has turned out to be, nor is expected to be (based on AEO 2021 price forecasts), very expensive.

- Concerns about low sulfur fuel availability turned out to be overstated. For example, the number of reports of VLSFO non-availability in the IMO GISIS system from January 1st, 2020 to July 1st, 2020 is much lower than what was expected.

- A comparison of the cost of eight IMO 2020 compliance approaches shows that there are three clearly distinct regimes or groupings of compliance approaches in terms of costs: 1) low-sulfur petroleum fuels or LNG retrofit are all part of the lowest cost regime 2) VLSFO new ship/LNG new ship are intermediate in cost, and 3) new ships with alternative fuels are the highest cost regime.

- There are some differences in the relative cost ranking of compliance approaches across vessel types; for instance, the HSFO plus scrubber option and the LNG retrofit option are relatively more attractive for tankers than containerships.

- $\quad$ LNG retrofit is cheaper than use of VLSFO or HSFO plus scrubbers in some of the price scenarios; although choosing LNG can make sense from a commercial/cost optimization standpoint and for reduction of local air pollutants, it offers limited improvement in $\mathrm{CO}_{2}$ emissions which makes it a risky fuel in the context of potential more ambitious targets by IMO.

- If the existing U.S. fleet has low resale value in other markets, and if new ships must be constructed in the U.S. at substantially higher cost than in some global markets, then there are significant barriers to IMO compliance via new ships and new fuels. Similarly, capital cost for retrofits of existing ships is less economic for those ships which are older, i.e. much of the U.S. fleet.

- $\quad$ Based on past price histories and sensitivity cases constructed from AEO projections, fuel price risk/uncertainty is higher for petroleum-based fuels than the rest, such as LNG or biofuel.

- $\quad$ Petroleum-based marine fuels (HSFO, VLSFO, MGO) show price differences, but the prices generally move together across regions and fuels, linked to developments in the global crude oil markets.

- $\quad$ To date, both ethanol and LNG prices are less correlated with petroleum prices and have been generally more stable. Both methanol and ammonia are mostly used in industrial applications currently and display relatively low correlations with the HSFO price. 
- $\quad$ Relative to the existing fleet, fueled almost entirely with petroleum-based fuels, a more diversified fuel mix likely results in lower overall price risk.

- This result is driven by the fact that the correlation between petroleum fuels and alternative fuels is lower than the correlation across petroleum fuels (e.g., residual fuels and distillate fuels). Reductions in price risk due to portfolio diversification are possible at the fleet level and at the vessel level (with dual-fuel engines).

- There are concerns within the shipping industry, and more widely, about the long-term sustainability of some of the compliance approaches undertaken so far in response to IMO 2020.

- Medium- and long-term strategy measures will rely on fuel substitution with lower-carbon alternative fuels. These potential GHG reduction measures may impact fuel selections.

- While $\mathrm{CO}_{2} / \mathrm{GHG}$ emissions are not directly a consideration for IMO 2020 compliance, there is a prospect of a more carbon-constrained global energy market. IMO has already begun establishing $\mathrm{CO}_{2}$ and GHG reduction guidelines. The fuel and vessel options for IMO 2020 compliance vary significantly in their carbon intensity, particularly on a tank-to-propeller basis. The potential need for ships to reduce their carbon intensity can be a supplementary consideration for U.S. shippers evaluating the longer-term implications of their IMO compliance approaches and investments.

- However, the comparatively high cost of new ship investment, based on U.S. construction costs, implies that in many cases a high effective cost for $\mathrm{CO}_{2}$ would be needed to motivate the switchover from existing ships to new, more efficient ships, or new alternative fuel ships, based on net economics alone.

- There remains substantial uncertainty about this switchover cost of $\mathrm{CO}_{2}$ in part because the costs of producing low- or zero-lifecycle $\mathrm{CO}_{2}$ fuels in volume for marine use (such as green ammonia or biofuel) are not yet established.

- This switchover cost is lower for scenarios with higher oil prices, and lower if capital costs or alternative fuel costs can be reduced.

- Absent a $\mathrm{CO}_{2}$ cost, a new VLSFO ship is in the middle of the IMO 2020 compliance options considered, in terms of cost and $\mathrm{CO}_{2}$ emissions, given its more efficient use of petroleum than existing ships. The continued used of low-sulfur petroleum fuels, or for ships with many years of service remaining retrofit with HSFO scrubber or LNG, are the lower cost approaches for IMO 2020.

New ships using low-carbon alternative fuels are the highest cost compliance approaches absent a $\mathrm{CO}_{2}$ cost. Note that a $\mathrm{CO}_{2}$ cost or carbon price tilts the cost curve around the middle New VLSFO Ship approach for compliance, raising the cost of existing petroleumusing ships which are less energy-efficient, and lowering the relative cost of new lowcarbon fuel ships. Given a non-zero carbon cost, approaches to the right of VLSFO new ship, which have higher cost but lower $\mathrm{CO}_{2}$ emissions, become relatively more advantageous due to the carbon price. In contrast, points to the left (lower cost, higher emissions) would get penalized by a carbon price.

- $\quad$ The prospect of sustained lower petroleum prices as many regions move to electrify road transport could also create strong competition for non-petroleum marine fuels that might be used to both reduce marine sulfur and $\mathrm{CO}_{2}$ emissions. 


\section{REFERENCES}

AGERTON, M. 2017. Global LNG Pricing Terms and Revisions: An Empirical Analysis. The Energy Journal, 38:1, 133-165.

ANDERSSON, K., BRYNOLF, S., HANSSON, J. \& GRAHN, M. 2020. Criteria and Decision Support for A Sustainable Choice of Alternative Marine Fuels. Sustainability, 12, 3623.

ATABANI, A. E., SILITONGA, A. S., BADRUDDIN, I. A., MAHLIA, T. M. I., MASJUKI, H. H. \& MEKHILEF, S. 2012. A comprehensive review on biodiesel as an alternative energy resource and its characteristics. Renewable and Sustainable Energy Reviews, 16, 2070-2093.

BAIER, S.L., AND BERGSTRAND, J.H. 2005. Do free trade agreements actually increase members' international trade? Working Paper, No. 2005-3, Federal Reserve Bank of Atlanta. Atlanta, GA.

BRITISH PETROLEUM. 2020. Energy Outlook 2020 edition. September 2020. Available at https://www.bp.com/content/dam/bp/business-sites/en/global/corporate/pdfs/energyeconomics/energy-outlook/bp-energy-outlook-2020.pdf

CE DELFT. 2021. Comparison of $\mathrm{CO}_{2}$ emissions of MARPOL Annex VI compliance options in 2020.

CE DELFT, STRATAS ADVISORS, UMAS, NMRI, PETROMARKET RESEARCH GROUP \& SHINICHI HANAYAMA. 2016. Assessment of fuel oil availability-final report prepared for the IMO.

CHANG, C. 2012. Marine energy consumption, national economic activity, and greenhouse gas emissions from international shipping. Energy Policy 41:843-848.

CHONG, K. \& BRIDGWATER, A. 2017. Fast pyrolysis oil fuel blend for marine vessels. Environmental Progress \& Sustainable Energy, 36, 677-684.

CORBETT, J.J. \& WINEBRAKE, J.J. 2018. Life Cycle Analysis of the Use of Methanol for Marine Transportation. Available at https://www.maritime.dot.gov/sites/marad.dot.gov/files/docs/innovation/meta/11056/marinemethanol-report-20180810final-002.pdf

CUONG, N. M. \& HUNG, P. V. 2020. An analysis of available solutions for commercial vessels to comply with IMO strategy on low sulphur. Journal of International Maritime Safety, Environmental Affairs, and Shipping, 4, 40-47.

DIERICKX, J., BEYEN, J., BLOCK, R., HAMROUNI, M., HUYSKENS, P., MEICHELBÖCK, C. \& VERHELST, S. 2018. Strategies for introducing methanol as an alternative fuel for shipping. 7th Transport Research Arena, 2018. Ghent University, 1-10.

DIMITRIADIS, A., NATSIOS, I., DIMARATOS, A., KATSAOUNIS, D., SAMARAS, Z., BEZERGIANNI, S. \& LEHTO, K. 2018. Evaluation of a Hydrotreated Vegetable Oil (HVO) and Effects on Emissions of a Passenger Car Diesel Engine. Frontiers in Mechanical Engineering, 4.

DIMITRIOU, I., GOLDINGAY, H. \& BRIDGWATER, A. V. 2018. Techno-economic and uncertainty analysis of Biomass to Liquid (BTL) systems for transport fuel production. Renewable and Sustainable Energy Reviews, 88, 160-175.

DNV. 2019. Maritime Forecast to 2050. Energy transition outlook 2018. Available at https://eto.dnv.com/2018/maritime

DNV. 2014. Liquefied Natural Gas (LNG) Bunkering Study. Available at https:/www.maritime.dot.gov/sites/marad.dot.gov/files/docs/innovation/meta/9806/dnvlngbunker ingstudy3sep14.pdf

DOUVARTZIDES, S. L., CHARISIOU, N. D., PAPAGERIDIS, K. N. \& GOULA, M. A. 2019. Green diesel: Biomass feedstocks, production technologies, catalytic research, fuel properties and performance in compression ignition internal combustion engines. Energies, 12, 809.

EIA 2019a. The effects of changes to marine fuel sulfur limits in 2020 on energy markets. Available at https://www.eia.gov/outlooks/studies/imo/ 
ENGMAN, A., HARTIKKA, T., HONKANEN, M., KIISKI, U., KURONEN, L., LEHTO, K., MIKKONEN, S., NORTIO, J., NUOTTIMÄKI, J. \& SAIKKONEN, P. 2016. Neste renewable diesel handbook. Neste Proprietary Publication, Espoo.

FUELS INSTITUTE 2019. Literature review summary: IMO 2020 sulfur reduction rule.

GIRDHAR, S. 2018. Basic LNG Training. Available at https://www.slideshare.net/SaurabhGirdhar2/liquefied-natural-gas-lng-88300233.

GRABOW, C. 2021. Are Shipyard Subsidies a Good Idea? Cato at Liberty. May 25, 2021. Available at https://www.cato.org/blog/are-shipyard-subsidies-good-idea

HANSSON, J., MANSSON, S., BRYNOLF, S., \& GRAHN, M. 2019. "Alternative marine fuels:

Prospects based on multi-criteria decision analysis involving Swedish stakeholders." Biomass and

Bioenergy 126: 159-173.

HEAD, K., MAYER, T. 2014. Gravity Equations: Workhorse, Toolkit, and Cookbook. 2013. Discusssion Paper hal-00973067. Available at https://hal-sciencespo.archivesouvertes.fr/file/index/docid/973067/filename/dp2013-02headmayer.pdf

HOEKMAN, S. K., BROCH, A., ROBBINS, C., CENICEROS, E. \& NATARAJAN, M. 2012. Review of biodiesel composition, properties, and specifications. Renewable and Sustainable Energy Reviews, 16, 143-169.

HSIEH, C. \& FELBY, C. 2017. Biofuels for the Marine Shipping Sector, An Overview and Analysis of Sector Infrastructure, Fuel Technologies and Regulations. International Energy Agency Bioenergy, Task 39.

ICCT. 2011. Reducing Greenhouse Gas Emissions from Ships. Cost Effectiveness of Available Options. White Paper Number 11. Available at https://theicct.org/sites/default/files/publications/ICCT_GHGfromships_jun2011.pdf

IEA 2021. Net Zero by 2050, a roadmap for the global energy sector. Available at https://www.iea.org/reports/net-zero-by-2050.

IEA. 2018. The Future of Petrochemicals. Available at https://www.iea.org/reports/the-future-ofpetrochemicals

INTERNATIONAL TRANSPORT FORUM 2016. Reducing sulphur emissions from ships: the impact of international regulation. Corporate Partnership Board Report, OECD.

KESIEME, U., PAZOUKI, K., MURPHY, A. \& CHRYSANTHOU, A. 2019. Biofuel as an alternative shipping fuel: technological, environmental and economic assessment. Sustainable Energy \& Fuels, 3, 899-909.

KILIAN, L. 2009. Not All Price Shocks are Alike: Disentangling Demand and Supply Shocks in the Crude Oil Market. American Economic Review 2009, 99:3, 1053-1069.

KIM, H., KOO, K. Y. \& JOUNG, T.-H. 2020. A study on the necessity of integrated evaluation of alternative marine fuels. Journal of International Maritime Safety, Environmental Affairs, and Shipping, 4, 26-31.

KNOTHE, G. 2010. Biodiesel and renewable diesel: A comparison. Progress in Energy and Combustion Science, 36, 364-373.

LE FEVRE, C.N. 2018. A review of demand prospects for LNG as a marine transport fuel. Oxford Institute for Energy Studies. OIES NG-133. June 2018.

LI, K., WU, M., GU, X., YUEN, K. F. \& XIAO, Y. 2020. Determinants of ship operators' options for compliance with IMO 2020. Transportation Research Part D: Transport and Environment, 86, 102459.

LI, X., \& YIP, T.L. 2019. Dynamic Interdependence and Spillovers of Market Volatility over Distance: Evidence from Bunker Fuel Markets. Proceedings of the International Forum on Shipping, Ports and Airports (IFSPA) 2019.

LINDFORS, L. P. 2010. High quality transportation fuels from renewable feedstock. Neste Corporation. XXIst World Energy Congress Montreal, Canada September 12-16, 2010. 
LIVANOS, G. A., THEOTOKATOS, G. \& PAGONIS, D.-N. 2014. Techno-economic investigation of alternative propulsion plants for Ferries and RoRo ships. Energy Conversion and Management, 79, 640-651.

LUNDGREN, A. \& WACHSMANN, A. 2014. The potential of methanol as a competitive marine fuel. Report no. Si-14/122.

MCCOLLUM, D.L., GOULD, G., \& GREENE, D.L. 2009. Greenhouse Gas Emissions from Aviation and Marine Transportation: Mitigation Potential and Policies. Available at https://escholarship.org/content/qt5nz642qb/qt5nz642qb.pdf

MING, L., \& CHEN, L. 2021. Methanol as a Marine Fuel: Availability and Sea Trial Considerations. Available at https://www.methanol.org/wp-content/uploads/2020/04/SG-NTU-methanol-marinereport-Jan-2021-1.pdf

MOHD NOOR, C. W., NOOR, M. M. \& MAMAT, R. 2018. Biodiesel as alternative fuel for marine diesel engine applications: A review. Renewable and Sustainable Energy Reviews, 94, 127-142.

NIELSEN, J.B., JENSEN, A., MADSEN, L.R., LARSEN, F.H., FELBY, C. \& JENSEN, A.D. 2017. Noncatalytic Direct Liquefaction of Biorefinery Lignin by Ethanol. Energy and Fuels 31, 72237233.

NISSEN, C., CLUDIUS, J., GRAICHEN, V., GRAICHEN, J. \& GORES, S. 2020. Trends and Projections in the EU ETS. EIONET report - ETC/CME 3/2020. November 2020.

OPEC. 2020. World Oil Outlook 2045. October 2020. Available at https://www.opec.org/opec web/en/publications/340.htm.

PERČIĆ, M., VLADIMIR, N. \& FAN, A. 2020. Life-cycle cost assessment of alternative marine fuels to reduce the carbon footprint in short-sea shipping: A case study of Croatia. Applied Energy, 279, 115848 .

RANTANEN, L., LINNAILA, R., AAKKO, P. \& HARJU, T. 2005. NExBTL-Biodiesel fuel of the second generation. SAE Technical Paper 2005-013771.

RODRIGUE, JEAN-PAUL. 2020. The Geography of Transport Systems. Routledge. ISBN 978-0-36736463-2.

SHARAFIAN, A., BLOMERUS, P. \& MÉRIDA, W. 2019. Natural gas as a ship fuel: Assessment of greenhouse gas and air pollutant reduction potential. Energy Policy, 131, 332-346.

SOLAKIVI, T., LAARI, S., KIISKI, T., TÖYLI, J. \& OJALA, L. 2019. How shipowners have adapted to sulphur regulations - Evidence from Finnish seaborne trade. Case Studies on Transport Policy, 7, 338-345.

STOPFORD, M. 2009. Maritime Economics, $3^{\text {rd }}$ edition. Routledge. ISBN 0-203-89174-0.

TESFA, B., MISHRA, R., GU, F. \& POWLES, N. 2010. Prediction models for density and viscosity of biodiesel and their effects on fuel supply system in CI engines. Renewable Energy, 35, 2752 2760 .

THOMSON, H., CORBETT, J. J. \& WINEBRAKE, J. J. 2015. Natural gas as a marine fuel. Energy Policy, 87, 153-167.

TYROVOLA, T., DODOS, G., KALLIGEROS, S. \& ZANNIKOS, F. 2017. The introduction of biofuels in marine sector. Journal of Environmental Science and Engineering A, 6, 415-421.

UNCTAD. 2019. Review of Maritime Transport 2019. Available at https://unctad.org/system/files/official-document/rmt2019 en.pdf

UNCTAD. 2018. 50 Years of Review of Maritime Transport, 1968-2018: Reflecting on the past, exploring the future. Available at https://unctad.org/system/files/officialdocument/dt12018d1 en.pdf

VAN BIERT, L., GODJEVAC, M., VISSER, K. \& ARAVIND, P. 2016. A review of fuel cell systems for maritime applications. Journal of Power Sources, 327, 345-364.

WANG, Z., SILBERMAN, J.A. \& CORBETT, J.J. 2021. Container vessels diversion pattern to transArctic shipping routes and GHG emission abatement potential. Maritime Policy \& Management $48: 4,543-562$. 
YAO, C., PAN, W. \& YAO, A. 2017. Methanol fumigation in compression-ignition engines: A critical review of recent academic and technological developments. Fuel, 209, 713-732.

ZHOU, Y., PAVLENKO, N., RUTHERFORD, D., OSIPOVA, L. \& COMER, B. 2020. The potential of liquid biofuels in reducing ship emissions. Working Paper. Available at https://heicct.org/sites/default/files/publications/Marine-biofuels-sept2020.pdf 
APPENDIX A. FUEL PROPERTIES 
Table A-1. Correspondence between petroleum-based fuels discussed in the report and ISO 8217-2017 fuel standards

\begin{tabular}{|c|c|c|}
\hline Fuel category & ISO 8217 Grade & Source \\
\hline MGO & DMA & $\frac{\text { https://www.livebunkers.com/singapore }}{\text { (ISO 8217:2005 or 2010) }}$ \\
\hline MDO & DMB & $\begin{array}{l}\text { S\&P Global Platts (ISO 8217:2010): } \\
\text { https://dieselnet.com/standards/us/fuel.php } \\
\text { https://www.marquard- } \\
\text { bahls.com/en/news- } \\
\text { info/glossary/detail/term/marine-fuels- } \\
\text { bunker-fuels.html }\end{array}$ \\
\hline $\begin{array}{l}\text { Fuel oil } 180 \\
(3.5 \% \mathrm{~m} / \mathrm{m} \mathrm{S})\end{array}$ & RME & S\&P Global Platts \\
\hline $\begin{array}{c}\text { Fuel oil } 380 \\
(3.5 \% \mathrm{~m} / \mathrm{m} \mathrm{S})\end{array}$ & $\begin{array}{l}\text { RMG } 380 \\
\text { RMK } 380\end{array}$ & $\begin{array}{l}\text { https://www.livebunkers.com/singapore } \\
\text { S\&P Global Platts: } \\
\text { https://www.marquard- } \\
\text { bahls.com/en/news- } \\
\text { info/glossary/detail/term/marine-fuels- } \\
\text { bunker-fuels.html }\end{array}$ \\
\hline $\begin{array}{l}\text { Fuel oil } 500 \\
(3.5 \% \mathrm{~m} / \mathrm{m} \mathrm{S})\end{array}$ & RMK 500 & \multirow{3}{*}{ S\&P Global Platts } \\
\hline $\begin{array}{l}\text { Fuel oil }(0.5 \% \\
\mathrm{m} / \mathrm{m} \mathrm{S})\end{array}$ & RMG & \\
\hline $\begin{array}{l}\text { Fuel oil }(0.1 \% \\
\mathrm{m} / \mathrm{m} \mathrm{S})\end{array}$ & RMD 80 & \\
\hline
\end{tabular}

Table A- 2. Properties of HSFO

\begin{tabular}{|c|c|c|c|}
\hline Characteristic & HSFO 180cst (RME 180) & $\begin{array}{c}\text { HSFO 380cst (RMG } 380 \text { or } \\
\text { RMK 380) }\end{array}$ & $\begin{array}{c}\text { HSFO 500est (RMK } \\
\text { 500) }\end{array}$ \\
\hline $\begin{array}{l}\text { Kinematic viscosity at } \\
40^{\circ} \mathrm{C}, \mathrm{mm}^{2} / \mathrm{s}^{\text {a }} \text { (cst) }\end{array}$ & 180.0 & 380.0 & 500.0 \\
\hline $\begin{array}{c}\text { Density at } 15 \\
\mathbf{k g} / \mathbf{m}^{3}\end{array}$ & $<991$ & $<991$ or 1010 & $<1010$ \\
\hline $\begin{array}{l}\text { Calculated Carbon } \\
\text { Aromaticity Index }\end{array}$ & $<860$ & $<870$ & $<870$ \\
\hline Flash point, ${ }^{\circ} \mathbf{C}$ & $>60$ & $>60$ & $>60$ \\
\hline $\begin{array}{c}\text { Hydrogen sulfide, } \\
\text { mg/kg }\end{array}$ & $<2.00$ & $<2.00$ & $<2.00$ \\
\hline $\begin{array}{c}\text { Acid number, mg } \\
\mathrm{KOH} / \mathrm{g}\end{array}$ & $<2.5$ & $<2.5$ & $<2.5$ \\
\hline $\begin{array}{c}\text { Total sediment-aged, } \\
\text { mass \% }\end{array}$ & $<0.1$ & $<0.1$ & $<0.1$ \\
\hline $\begin{array}{c}\text { Carbon residue - } \\
\text { Micro method on the } \\
10 \% \text { volume } \\
\text { distillation residue, } \\
\text { mass \% }\end{array}$ & $<15$ & $<18$ or 20 & $<20$ \\
\hline $\begin{array}{c}\text { Pour point (upper), } \\
{ }^{\circ} \mathrm{C}\end{array}$ & $<30$ Winter and Summer & $<30$ Winter and Summer & $\begin{array}{l}<30 \text { Winter and } \\
\text { Summer }\end{array}$ \\
\hline Water, volume \% & $<0.5$ & $<0.5$ & $<0.5$ \\
\hline Ash, mass \% & $<0.07$ & $<0.1$ or $<0.15$ & $<0.15$ \\
\hline
\end{tabular}




\begin{tabular}{cccc}
\hline Vanadium, mg/kg & $<150$ & $<350$ or 450 & $<450$ \\
\hline Sodium, mg/kg & $<50$ & $<100$ & $<100$ \\
\hline Aluminum plus & $<50$ & $<60$ & $<60$ \\
Silicon, mg/kg & & & \\
\hline
\end{tabular}

Table A- 3 Properties of Marine Gasoil (MGO)

\section{Characteristic}

Kinematic viscosity at $40^{\circ} \mathrm{C}, \mathrm{mm}^{2} / \mathrm{s}$ a (cst)

Density at $15^{\circ} \mathrm{C}, \mathrm{kg} / \mathrm{m}^{3}$

Cetane index

Sulfur, mass \%

Flash point, ${ }^{\circ} \mathrm{C}$

Hydrogen sulfide, $\mathrm{mg} / \mathrm{kg}$

Acid number, mg KOH/g

Oxidation stability $\mathbf{g} / \mathrm{m}^{3}$

Carbon residue - Micro method on the $10 \%$ volume

distillation residue, mass $\%$

Pour point (upper), ${ }^{\circ} \mathrm{C}$

Ash, mass \%

Lubricity, corrected wear scar diameter

(WSD) at $60^{\circ} \mathrm{C}, \mu \mathrm{m}$
MGO (Category ISO-F-DMA)

$$
2.000-6.000
$$

$<890$

$>40$

$<1.00$

$>60$

$<2.00$

$<0.5$

$<25$

$<0.3$

$<-6$ Winter

$<0$ Summer

$<0.01$

$<520$

Table A- 4 Properties of Marine Diesel Oil (MDO)

Characteristic

Kinematic viscosity at $40{ }^{\circ} \mathrm{C}, \mathrm{mm}^{2} / \mathrm{s}^{\text {a }}$ (cst)

Density at $15^{\circ} \mathrm{C}, \mathrm{kg} / \mathrm{m}^{3}$

Cetane index

Sulfur, mass $\%$

Flash point, ${ }^{\circ} \mathrm{C}$

Hydrogen sulfide, $\mathrm{mg} / \mathrm{kg}$

Acid number, mg KOH/g

Oxidation stability $\mathbf{g} / \mathrm{m}^{3}$

Carbon residue - Micro method on the $10 \%$ volume

distillation residue, mass \%

Pour point (upper), ${ }^{\circ} \mathrm{C}$

Ash, mass \%

Lubricity, corrected wear scar diameter

(WSD) at $60^{\circ} \mathrm{C}, \mu \mathrm{m}$

\section{MDO (Category ISO-F-DMB)}

$2.000-11.000$

$<900$

$>40$

$<1.5$

$>60$

$<2.00$

$<0.5$

$<25$

No data in the ISO report

\begin{tabular}{cc}
\hline Pour point (upper), ${ }^{\circ} \mathbf{C}$ & $<0$ Winter \\
& $<6$ Summer \\
\hline Ash, mass \% & $<0.01$ \\
\hline Lubricity, corrected wear scar diameter & $<520$ \\
(WSD) at $60^{\circ} \mathbf{C}, \boldsymbol{\mu m}$ & \\
\hline
\end{tabular}


Table A- 5.Properties of Selected Biofuels

\begin{tabular}{|c|c|c|c|c|c|}
\hline Property & SVO & $\begin{array}{l}\text { Biodiesel- } \\
\text { (FAME) }\end{array}$ & BTL-diesel & $\begin{array}{l}\text { Renewable } \\
\text { diesel (HVO) }\end{array}$ & $\begin{array}{l}\text { Fast pyrolysis } \\
\text { oil (bio-oil) }\end{array}$ \\
\hline $\operatorname{Density}\left(15^{\circ} \mathrm{C}\right), \mathrm{kg} / \mathrm{m}^{3}$ & $900-930$ & $860-900$ & $770-785$ & 778.7 & $1100-1250$ \\
\hline $\begin{array}{l}\text { Kinematic viscosity } \\
\left(40^{\circ} \mathrm{C}\right) \text {, cst }\end{array}$ & 39.6 & $3.5-5.0$ & $3.2-4.5$ & $3-4$ & 40-100 \\
\hline Cetane number & $36-42$ & 51 & $73-81$ & $70-90$ & \\
\hline Flash point, ${ }^{\circ} \mathrm{C}$ & $590-600$ & $>120$ & 71 & 83 & \\
\hline Ash content, $\%$ & & $<0.01$ & & $<0.001$ & \\
\hline $\begin{array}{l}\text { Acid number, mg } \\
\text { KOH/g }\end{array}$ & & $<0.5$ & & & \\
\hline $\begin{array}{l}\text { Calorific value, } \\
\mathrm{MJ} / \mathrm{kg}\end{array}$ & $36-40$ & 37.5 & $36-43$ & 44 & $14-18$ \\
\hline Pour point, ${ }^{\circ} \mathrm{C}$ & -33 to -3 & -7 to 16 & & & -12 to -33 \\
\hline Water content, ppm & & $<500$ & & 20 & $15-30$ \\
\hline
\end{tabular}

Sources: SVO from (Kesieme et al., 2019) BTL-diesel from (Rantanen et al., 2005, Douvartzides et al., 2019) Renewable diesel from (Hoekman et al., 2012, Dimitriadis et al., 2018); FP oil from (Kesieme et al., 2019, Chong and Bridgwater, 2017); standard specifications of ASTM D6751 and EN 14214, ASTM D975, and EN 590 are shown at https://dieselnet.com/tech/fuel_biodiesel_std.php. 
APPENDIX B. COST MODEL DETAILS

A-5 


\section{Cost model equations}

The following are the basic equations of the cost model (accurate, but pseudocode):

Capital_Investment $=$ full_capital_cost $($ Capital_Equipment $) *(1+$ fuel_newship_costprem(fuel $))$

Amortization_Years $=$ ship_lifespan if CapitalEquipment $==$ "newship"

$=$ ship_remaining_life otherwise

Increased_capital_cost_dpy $=-$ pmt(interest_rate, Amortization_Years, Capital_Investment)

Relative_Engine_Efficiency = engine_efficiency(enginetype)/engine_efficiency("Otto")

Relative_New_Vessel_Efficiency $=(1.0$ - newship_efficiencygain $)$ if (Capital_Equipment $==$ "newship")

$=1.0$ otherwise

Relative_Fuel_Energy $=$ ref_fuel_energy_content/fuel_energy_content(fuel)

Fuel_consumption_tpy $=$ ave_fuel_cons_ktpy $* 1000 *$ Relative_Engine_Efficiency $*$

Relative_New_Vessel_Efficiency* Relative_Fuel_Energy

scrubber_efficiencypenalty_value $=($ scrubber_efficiencypenalty) if (Capital_Equipment

$==$ "scrubber_retrofit"),

0 otherwise

Fuel_cost_dpy $=$ Fuel_consumption_tpy $*(1+$ scrubber_efficiencypenalty_value $) *$ fuel_price

Fuel_penalty_dpy $=$ Fuel_consumption_tpy $*$ scrubber_efficiencypenalty_value $*$ fuel_price

(For info only to track extra fuel costs in Fuel_cost_dpy, 0 if no scrubber)

Compliance_cost_dpy = Increased_capital_cost_dpy + Fuel_cost_dpy

CO2_emission_tpy $=$ fuel_emissions_tCO2_per_tFuel $*$ Fuel_consumption_tpy $*(1+$ scrubber_efficiencypenalty_value)

\section{Capital cost calculation}

Capital cost charge is based on standard accounting cashflow in the shipping industry (Stopford, 2009). Annual vessel capital cost (\$/year/vessel) is based on the amortization of total capital costs required for the needed scenario. That is, the annual cost is loan (finance) payment that would be made on a loan principal equal to the capital cost, at the assumed interest rate $i$ (base value 4\%) and for the remaining vessel lifetime $n$ (base value 20 years).

The annual capital charge, or annuity $A$ with net present value equal to the principal (vessel capital cost) $P$ satisfies: 


$$
P=N P V(i, n, A)=A \sum_{t=1}^{n} \frac{1}{(1+i)^{t}}
$$

- $\quad P$ is ship price, or retrofit capital investment cost,

- $\quad n$ is investment/financing maturity (taken as vessel useful life for a new ship, or remaining useful life for a used vessel), and

- $\quad i$ is yearly interest rate.

This can be calculated with an financial function, e.g. FinCal::pmt(), or by directly calculating with the closed form expression

$$
C_{c a p} / y r \equiv A=P /\left(\sum_{t=1}^{n} \frac{1}{(1+i)^{t}}\right)=P \cdot \frac{i(i+1)^{n}}{\left[(i+1)^{n}-1\right]}
$$

We can define annual capital charge per dollar initial (up-front) capital cost, which depends only on the interest rate $i$ and amortization length $n$ :

$$
c c_{\text {cap }}(i, n) \equiv C_{\text {cap }} / y r / P=\frac{i}{\left[1-(1+i)^{-n}\right]}
$$

In the case of capital investment in a new vessel, the base vessel newbuild cost $P_{n e w, s, b a s e}$ is established for each vessel type $s$, (container, tanker, etc.) and then a capital cost premium $\pi_{K, f}$ adjustment is applied depending on the fuel/engine type $f$.

$$
C_{\text {cap }, \text { new }, s, f} / y r=c c_{c a p}(i, n) P_{\text {new }, \text { s, base }} \cdot\left(1+\pi_{K, f}\right)
$$

In the case of retrofit investments (e.g. conversion to LNG, or HSFO scrubber) the base retrofit price/cost $P_{\text {retro,s,base }}$ is established for retrofit type retro and each vessel type $s$, (container, tanker, etc.) Fuel specific premia are not applied to retrofit costs, but some retrofits are only applicable for certain fuels.

$$
C_{\text {cap }, \text { retro }, s, f} / y r=c c_{c a p}(i, n) P_{\text {retro,s,base }}
$$

\section{Data, units, and sources}

Table B-1. Cost Parameters Shared by All Cases

\begin{tabular}{lrrr}
\hline Parameter & Low & Base & High \\
\hline interest_rate & 0.03 & 0.04 & 0.1 \\
\hline base_vessel_lifespan & 15.00 & 20.00 & 35.0 \\
\hline current_year & 2021 & 2021 & 2021 \\
\hline LNG_newship_cost_premium & 0.20 & 0.20 & 0.2 \\
\hline Altfuel_newship_cost_premium & 0.50 & 0.50 & 0.5 \\
\hline newship_cost_multiple_USvsforeign & 3.0 & 3.0 & 3.0 \\
\hline
\end{tabular}


Table B- 2. Engine Parameters

\begin{tabular}{lrrrr}
\hline Case & $\begin{array}{r}\text { Scrubber efficiency } \\
\text { penalty }\end{array}$ & Otto efficiency & Diesel efficiency & $\begin{array}{r}\text { Newship } \\
\text { efficiency gain }\end{array}$ \\
\hline Low & 0.01 & 0.32 & 0.45 & 0.45 \\
\hline Base & 0.02 & 0.32 & 0.45 & 0.45 \\
\hline High & 0.05 & 0.32 & 0.45 & 0.45 \\
\hline
\end{tabular}

Table B- 3 Fuel Parameters (IMOGHG4/Argus price case)

\begin{tabular}{lrrrr}
\hline Fuel & energy content & price & $\mathbf{C O}_{2}$ emissions tpt & newship costprem \\
\hline HSFO & 40.0 & 400 & 3.114 & 0.0 \\
\hline VLSFO & 41.7 & 501 & 3.114 & 0.0 \\
\hline MDO & 43.0 & 501 & 3.206 & 0.0 \\
\hline MGO & 43.0 & 561 & 3.206 & 0.0 \\
\hline LNG & 48.0 & 590 & 2.750 & 0.2 \\
\hline Ammonia & 22.5 & 660 & 0.000 & 0.5 \\
\hline Methanol & 22.7 & 400 & 1.375 & 0.5 \\
\hline Ethanol & 27.0 & 670 & 0.000 & 0.5 \\
\hline
\end{tabular}

Note: $\mathrm{CO}_{2}$ emissions correspond to the tank-to-propeller stage only.

Table B-4. Vessel Parameters (Base case)

\begin{tabular}{lrr}
\hline Parameter & Containership & Tanker \\
\hline Lifespan (years) & 20 & 20 \\
\hline build_year(Average) & 2002 & 2007 \\
\hline Age (average) & 19 & 14 \\
\hline IMO_GHG4_size_category & $\mathrm{NA}$ & $\mathrm{NA}$ \\
\hline gross_tons & 44,425 & 39,228 \\
\hline DWT_tonnes & 49,091 & 64,964 \\
\hline TEU & 3,507 & $\mathrm{NA}$ \\
\hline ave_ME_power_kW & 29,038 & 10,205 \\
\hline ave_design_speed_kts & 22 & 15 \\
\hline ave_ME_fuel_ktpy & 13 & 5 \\
\hline ave_AE_fuel_ktpy & 2 & 1 \\
\hline ave_boiler_fuel_ktpy & 1 & 3 \\
\hline newship_cost & $135,000,000$ & $120,000,000$ \\
\hline LNG_retrofit_cost & $4,000,000$ & $1,300,000$ \\
\hline scrubber_retrofit_cost & $6,000,000$ & $6,000,000$ \\
\hline
\end{tabular}




\section{Notes on Units}

- fuel energy_content: kJ_per_gram

- fuel price: USD_per_tonne

- fuel $\mathrm{CO}_{2}$ emissions: ton_CO $\mathrm{CO}_{2}$ per_ton_fuel (not $\mathrm{CO}_{2} \mathrm{e}$ )

- fuel_consumption: tonne_per_yr (if

- newship_costprem: unitless; fractional increase in capital cost associated with a newship of that fuel type

\section{Constructed Marine Fuel Price Projections}

We construct marine fuel price projections (Reference and Alternative cases) from AEO2021 data on petroleum prices. The prices of marine fuels are computed from EIA projected energy commodity prices in the AEO2021, using coefficients estimated from historical price data. The coefficients are reported in Table B- 5.

Table B- 5. Marine Fuel Prices (\$MT) Based on Relationships to Other Prices

\begin{tabular}{llrr}
\hline $\begin{array}{l}\text { depvar_fuel } \\
\text { (Fuels of interest } \\
\text { for cost model) }\end{array}$ & $\begin{array}{l}\text { indvar_series } \\
\text { (Related fuels for which AEO 2021 includes projections) }\end{array}$ & intercept & slope \\
\hline Ammonia & Natural Gas Industrial (2020USDperMcf) & 380.474 & \\
\hline Ethanol & Ethanol Transportation (2020USDpergal) & 0.000 & 39.194 \\
\hline HSFO & Residual Fuel Oil Transportation (2020USDperbbl) & 0.000 & 6.740 \\
\hline LNG_Japan & Brent Spot (2020USDperbbl) & 54.281 & 6.107 \\
\hline LNG_US & Brent Spot (2020USDperbbl) & 71.446 & 4.131 \\
\hline Methanol & Natural Gas Industrial (2020USDperMcf) & 95.442 & 83.116 \\
\hline MGO & Distillate Fuel Oil Industrial (2020USDpergal) & -81.850 & 275.416 \\
\hline VLSFO_MDO & Residual Fuel Oil Transportation (2020USDperbbl) & -68.201 & 8.579 \\
\hline
\end{tabular}

\section{Other Assumptions:}

- Fuel Price:

- $\quad$ Price of LNG, ammonia, methanol, ethanol: Table 76 of 4th IMO GHG study (projected future cost for year 2030)

- $\quad$ Price of HSFO, VLSFO, MGO: annual_avg_US_prices_wavg dataframe produced in price_analysis.Rmd (volume-weighted average observed prices 2019 with weights based on bunker sales at the various U.S. regions for which we have Argus price data)

- $\quad$ Price of MDO: no Argus prices; MDO is a blend of HSFO and distillates, Using the VLSFO price as proxy.

- $\quad$ Scrubber fuel penalty: $0.02 \%$ of fuel use/cost (1\% to $5 \%$ sensitivity range)

- U.S. shipbuilding cost premium (as multiple of international shipbuilding costs): $3 \mathrm{X}$

\section{Sources}

- $\quad$ LNG retrofit premium: REMPEC/WG.45/INF.9

- $\quad$ Scrubber cost source: California Air Resources Board (2018) "Technology Assessment: Oceangoing Vessels".

- $\quad$ Energy content: Bengtsson et al 2011. Bengtsson, S., Andersson, K., and Fridell, E., (2011) A comparative lifecycle assessment of marine fuels: Liquefied natural gas and three other fossil fuels, In: Proceedings of the institution of mechanical engineers, Vol 224, Part M: Journal of Engineering for the Marine environment, p. 97-110. 


(n)

